\title{
Stress reactivity in borderline personality disorder
}

Citation for published version (APA):

Glaser, J-P. (2009). Stress reactivity in borderline personality disorder. [Doctoral Thesis, Maastricht University]. Datawyse / Universitaire Pers Maastricht. https://doi.org/10.26481/dis.20091029jg

Document status and date:

Published: 01/01/2009

DOI:

10.26481/dis.20091029jg

Document Version:

Publisher's PDF, also known as Version of record

\section{Please check the document version of this publication:}

- A submitted manuscript is the version of the article upon submission and before peer-review. There can be important differences between the submitted version and the official published version of record.

People interested in the research are advised to contact the author for the final version of the publication, or visit the DOI to the publisher's website.

- The final author version and the galley proof are versions of the publication after peer review.

- The final published version features the final layout of the paper including the volume, issue and page numbers.

Link to publication

\footnotetext{
General rights rights.

- You may freely distribute the URL identifying the publication in the public portal. please follow below link for the End User Agreement:

www.umlib.nl/taverne-license

Take down policy

If you believe that this document breaches copyright please contact us at:

repository@maastrichtuniversity.nl

providing details and we will investigate your claim.
}

Copyright and moral rights for the publications made accessible in the public portal are retained by the authors and/or other copyright owners and it is a condition of accessing publications that users recognise and abide by the legal requirements associated with these

- Users may download and print one copy of any publication from the public portal for the purpose of private study or research.

- You may not further distribute the material or use it for any profit-making activity or commercial gain

If the publication is distributed under the terms of Article $25 \mathrm{fa}$ of the Dutch Copyright Act, indicated by the "Taverne" license above, 


\section{Stress reactivity in borderline personality disorder}


I'm good at love I'm good at hate

It's in between I freeze. . .

Leonard Cohen, 'Thousand Kisses Deep'

Book of Longing, 2006

(C) Jean-Paul Glaser, Maastricht 2009

ISBN 9789052788678

Universitaire Pers Maastricht

Layout en druk: Datawyse bv, Maastricht

Cover design: Datawyse bv, Maastricht

All rights are reserved. No part of this thesis may be reproduced, stored or transmitted in any form or by any means, without written permission from the author, or when appropriate, the publisher of the article. 


\title{
Stress reactivity in borderline personality disorder
}

\author{
P R O E F S C H R I F T
}

ter verkrijging van de graad van doctor aan de Universiteit Maastricht, op gezag van de Rector Magnificus, Prof. mr. G.P.M.F. Mols, volgens het besluit van het College van Decanen, in het openbaar te verdedigen op donderdag 29 oktober 2009 om 12.00 uur.

door

\section{Jean-Paul Glaser}

Geboren op 25 februari 1969 te Heerlen

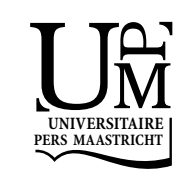


Promotor

Prof. dr. J. van Os

Copromotor

Dr. I. Myin-Germeys

Beoordelingscommissie

Prof. dr. M. deVries (voorzitter)

Dr. J.M.L.G. à Campo

Prof. dr. U.W. Ebner-Priemer (Universiteit van Karlsruhe, Duitsland)

Em. Prof. dr. H.M. van Praag

Prof. dr. W.A. Verhoeven (Erasmus Universiteit, Rotterdam)

South Limburg Mental Health Research and Teaching Network, PhD Series

The research presented in this thesis was conducted at Maastricht University in the School for Mental Health and Neuroscience (MHeNS), Mental Health division; the Riagg Midden-Limburg, and Mondriaan: Heerlen and Maastricht (Vijverdal) locations. 
Aan de patiënten

Paranimfen

Anita Boreas

Paola Geijselaers 



\section{CONTENTS}

\section{CHAPTER 1}

Introduction

\section{CHAPTER 2}

A momentary assessment study of the reputed emotional phenotype associated with borderline personality disorder

\section{CHAPTER 3}

Psychotic reactivity in borderline personality disorder

\section{CHAPTER 4}

Childhood trauma and emotional reactivity to daily life stress in adult frequent attenders of general practitioners

\section{CHAPTER 5}

Discussion

Summary

Samenvatting

Dankwoord

Curriculum vitae

List of publications 

CHAPTER 1

Introduction 



\section{INTRODUCTION}

Borderline personality disorder (BPD) is a chronic psychiatric condition that affects close to 1 percent of the general population (Samuels et al., 2002; Torgersen, Kringlen, \& Cramer, 2001). Genetic and environmental factors have been shown to be involved in the development of the disorder (Lieb, Zanarini, Schmahl, Linehan, \& Bohus, 2004). BPD causes most problems in early adulthood, a period in which - in western society - most people are busy laying the foundation for their future lives (Erikson, 1982). About $8 \%$ of the patients die by committing suicide (Pompili, Girardi, Ruberto, \& Tatarelli, 2005). BPD has a substantial impact on mental health care facilities and societal costs (Hyman, 2002; van Asselt, Dirksen, Arntz, \& Severens, 2007). Psychotherapy is the mainstay of treatment, although psychiatric medication may also be indicated (Paris, 2005; Practice guideline for the treatment of patients with borderline personality disorder. American Psychiatric Association," 2001). Recently, it has been shown that the disorder becomes less symptomatic over the years (Gunderson et al., 2004; Paris \& Zweig-Frank, 2001; Zanarini, Frankenburg, Hennen, \& Silk, 2003). A 27 year follow-up study by Paris et al. (Paris \& Zweig-Frank, 2001) revealed that by the age of forty years $75 \%$ of the patients regained close to normal functioning, while by the age of fifty $90 \%$ recovered (Paris, 2005).

DSM-IV borderline personality disorder classification (American Psychiatric Association, 2000) refers to BPD as a pervasive pattern of instability of interpersonal relationships, self-image and affects, and marked impulsivity beginning by early adulthood and present in a variety of contexts, as indicated by 5 or more of the following symptoms:

\section{Affective symptoms}

- Affective instability due to a marked reactivity of mood (e.g. intense episodic dysphoria, irritability or anxiety usually lasting a few hours and only rarely more than a few days).

- Inappropriate, intense anger or difficulty controlling anger (e.g. frequent displays of temper, constant anger, recurrent physical fights).

- Chronic feelings of emptiness. 


\section{Impulsive symptoms}

- Recurrent suicidal behavior, gestures or threats, or self-mutilating behavior.

- Impulsivity in at least 2 areas that are potentially self-damaging (e.g. spending, sex, substance abuse, reckless driving, binge eating).

- A pattern of unstable and intense interpersonal relationships characterized by alternating between extremes of idealization and devaluation.

\section{Interpersonal symptoms}

- Frantic efforts to avoid real or imagined abandonment.

- Identity disturbance: markedly and persistently unstable self-image or sense of self.

\section{Cognitive symptoms}

- Transient, stress-related paranoid ideation or severe dissociative symptoms.

\section{Categorical versus dimensional diagnosis}

According to DSM-IV borderline personality diagnosis can only be made when a person fulfils at least 5 of nine borderline criteria. This 'all or nothing' principle may be useful for clinical communication and decision making, it is, however, unlikely to reflect the real prevalence of BPD vulnerability in nature (Hyman, 2002; Siever, Torgersen, Gunderson, Livesley, \& Kendler, 2002; Skodol, Gunderson et al., 2002; Skodol, Siever et al., 2002). For personality disorders in particular there is evidence for a continuous representation (normal distribution) of personality traits (dimensions) assigning a certain personality trait level to each member of the population (Chabrol, Chouicha, Montovany, \& Callahan, 2001; Widiger, 2007). Factor analysis revealed the following symptom dimensions underlying the nine DSM-IV borderline personality disorder criteria: 1) affective symptoms; 2) impulsivity; 3) identity disturbance and 4) cognitive-perceptual disturbances (Paris, 2005; Skodol, Gunderson et al., 2002). A symptom dimensional approach is an important addition to categorical diagnoses (van Praag, van Os, \& de Kloet, 2004). It enhances research possibilities as it can attribute symptoms more specifically to environmental, genetic and neurobiological risk factors (van Praag et al., 2004). 


\section{THE PHENOMENOLOGY OF BORDERLINE PERSONALITY DISORDER}

DSM-IV defines BPD by nine phenomenological criteria. The criteria affective instability due to a marked reactivity of mood and transient stress-related paranoid ideation may appear clear at first impression, however, the interpretation of these criteria is far from univocal. With regard to the criterion affective instability due to a marked reactivity of mood it is unclear what exactly is meant by affective instability. Does affective instability refer to the frequency, the duration, or the intensity of affect switches? Does affective instability refer to all affect types or does it pertain to certain affects that are more prone to switches than others (e.g. switching from elation to anxiety)? What exactly is meant by reactivity of mood? If reactivity refers to stress, then which stimuli will impact most strongly on affective instability and on the intensity of psychotic symptoms? Will interpersonal stressors - known to impact strongly on functioning in BPD - impact more specifically on affective instability and psychotic symptoms than common stresses that continually happen in the flow of everyday life? Is paranoid ideation the only psychotic symptom - as suggested by DSM-IV - prone to evolve from stressful situations in subjects with BPD?

After describing a research tool specifically designed to investigate the above mentioned questions the current state of the evidence on affective instability and psychotic stress reactivity will be outlined.

\section{Experience Sampling Method (ESM)}

To adequately investigate affective instability, mood reactivity or psychotic reactivity to stress a research instrument is needed that has: i) the capacity to assess changes in symptom intensity over time and ii) the capacity to assess symptom intensity in direct relation to contextual factors such as stressors. Research designs that meet these standards are called daily process designs, momentary assessment studies or experience sampling studies (Delespaul, 1995; Tolpin, Gunthert, Cohen, \& O'Neill, 2004). The Experience Sampling Method (ESM) is pre-eminently appropriate to study affective instability and psychotic reactivity in BPD since it assesses - in the natural environment of daily life (e.g. not in the doctor's office) - mood, thoughts and perceptions in direct relation to contextual factors. It assesses experiences in a momentary fashion (e.g. subjects are asked about what they experience at the moment) by means of self-report questionnaires yielding the least risk of recall bias. ESM data collection offers multiple assessments over time enhancing statistical 
power. Previous applications of ESM have demonstrated the feasibility, validity and reliability of the method in general population samples and in samples of psychiatric patients (Ebner-Priemer, Kuo et al., 2007; Glaser, van Os, Portegijs, \& Myin-Germeys, 2006; Myin-Germeys et al., 2003; Myin-Germeys \& van Os, 2007; Peeters, Nicolson, Berkhof, Delespaul, \& deVries, 2003; Stein, 1996; M. van Eck, Berkhof, Nicolson, \& Sulon, 1996; M. M. van Eck, Nicolson, Berkhof, \& Sulon, 1996)

\section{Affective instability}

Several experience sampling and daily process studies have been conducted to investigate the phenomenology of affective instability in BPD. Cowdry et al. (Cowdry, Gardner, O'Leary, Leibenluft, \& Rubinow, 1991) assessed mood diurnally by means of self-report over 14 consecutive days and found that borderline patients showed a high degree of mood variability in a way that differed from subjects with major depression, premenstrual syndrome, and healthy controls. Stein et al. (Stein, 1996) assessing affect 50 times over a 10-day period reported higher levels of unpleasant affect in BPD and greater intra-individual variability in unpleasant affects relative to asymptomatic controls (Stein, 1996). Ebner-Priemer et al. (Ebner-Priemer, Welch et al., 2007) assessed affective instability every 10-20 minutes during a 24-h period and found borderline patients to express a higher frequency and intensity of self-reported emotions, more complex emotions and greater problems in identifying specific emotions when compared to healthy controls. BPD reported more negative emotions, fewer positive emotions, and a greater intensity of negative emotions. BPD moreover expressed a heightened affective instability for emotional valence when compared to healthy control subjects (Ebner-Priemer, Kuo et al., 2007). A borderline specific pattern of instability was characterized by sudden large decreases from positive mood states. About 50 percent of declines went from very positive mood states into a negative mood states, which was only the case in 9 percent of the healthy control subjects (Ebner-Priemer, Kuo et al., 2007). In 2002 Koenigsberg et al. (Koenigsberg et al., 2002) used a retrospective selfreport measure and reported that borderline patients - relative to other personality disorders - are more liable in terms of anger and anxiety and oscillation between depression and anxiety, but not in terms of oscillation between depression and elation. Remarkably they found increases in subjective affective intensity not to be more prominent in BPD than in other personality disorders. Russel et al. (Russell, Moskowitz, Zuroff, Sookman, \& Paris, 2007) conducting a 20-day event-contingent mood assessment found borderline patients to experi- 
ence more unpleasant valenced affect than non-clinical controls. On a behavioral level borderline patients were less dominant, more submissive, more quarrelsome and more extreme in overall levels of behavior. Though this study assessed affect as well as behavior it did not analyze the interaction between affect (dependent variable) and behavior (independent variable) in terms of an environmental effect (e.g. stress).

\section{Mood reactivity}

The previous studies investigated affect instability in BPD in terms of changes during and between days, changes in intensity of affect, changes in types of affects and oscillations between different emotions. None of these studies, however, investigated emotional instability in relation to stress (e.g. emotional reactivity). Gunderson and Phillips (Gunderson \& Phillips, 1991) reported that BPD shares enhanced global levels of negative affect with depressive disorder, but differs from depression through its expression of frequent, rapid and extreme changes in mood that are highly responsive to environmental factors. Most studies that have been conducted on stress in BPD investigated life events and interpersonal stressors and concluded that these stressors have a huge negative impact on functioning in BPD (Jovev \& Jackson, 2006; Tolpin et al., 2004). However, the class of common small daily events, rather than lowprevalent life events, likely represent more important predictors of psychopathology in general (Kanner, Coyne, Schaefer, \& Lazarus, 1981; Monroe, 1983), and of borderline personality disorder in particular (Jovev \& Jackson, 2006). No study until this thesis, however, has investigated by momentary assessment the effects of common daily stresses on affect in daily life of subjects with BPD.

\section{Psychotic stress reactivity}

With the transition from DSM-III-R to DSM-IV transient stress-related paranoid ideation has been added as the ninth criterion in BPD classification (American Psychiatric Association, 2000). Although this suggests sufficient and conclusive evidence of psychosis in BPD, research appears to be hampered by methodological flaws such as retrospective designs, low participant numbers, confounding and unclarity about the definitions of psychosis (broadly defined, narrowly defined, quasi-psychotic symptoms). Interpretation and comparability of studies furthermore is hampered by different and lack of control groups. The issue of confounding due to affective disorder, in particular, has rarely been addressed in a methodologically systematic fashion (Pope, Jonas, Hudson, Cohen, \& Tohen, 1985). 
Given these limitations, most but not all studies on psychosis in BPD conclude that narrowly defined psychotic symptoms such as delusions and hallucinations according to DSM-IV (Pope et al., 1985) are rare in borderline personality disorder and when present are likely due to axis I comorbidity such as affective disorder and substance abuse (Chopra \& Beatson, 1986; Jonas \& Pope, 1984; Links, Steiner, \& Mitton, 1989; Pope et al., 1985; Zanarini, Gunderson, \& Frankenburg, 1990). One study, however, reported narrowly defined psychotic symptoms to be independent of concurrent affective and substance abuse disorder (Miller, Abrams, Dulit, \& Fyer, 1993).

Broadly defined psychotic symptoms such as derealisation, depersonalisation and disturbances in reality testing not at DSM psychosis level (Pope et al., 1985) are generally reported to be common in BPD (Links et al., 1989; Nishizono-Maher et al., 1993; Pope et al., 1985), but there is inconsistency about whether these symptoms are more prevalent in BPD than in control groups of healthy subjects (Jonas \& Pope; Pope et al., 1985), subjects with schizophrenia and subjects with other personality disorders (Jonas \& Pope, 1984; Pope et al., 1985; Zanarini, Gunderson, \& Frankenburg, 1990; Zanarini, Gunderson, Frankenburg, \& Chauncey, 1990).

Quasi-psychotic symptoms defined as delusions and hallucinations lasting less than 2 days, or affecting only one or two areas of the patient's life, or possibly reality-based or totally phantasic in content have been reported to be characteristic of borderline personality disorder (Zanarini, Gunderson, \& Frankenburg, 1990).

Research on psychosis in BPD thus seems to have focused primarily on the prevalence - and not reactivity - of psychotic symptoms assigning major significance to the narrowly, broadly and quasi-psychotic symptom distinction. Though the categorical distinction between narrowly, broadly and quasipsychotic symptoms suggest the existence of different and separate psychotic syndromes, there is growing evidence that the narrowly-broadly-'quasipsychotic' distinction merely reflects a psychosis continuum in which symptom aspects such as duration, level of reality testing, severity and impact on functioning determine the position on the continuum (Krabbendam et al., 2004; Stefanis et al., 2002; van Os, Linscott, Myin-Germeys, Delespaul, \& Krabbendam, 2009; Widiger, 2005).

The general conclusion that has been drawn from - thus far - categorical psychosis research in BPD (e.g. "Borderline patients do not experience true psychotic symptoms") holds the risk of diminishing further scientific interest in psychosis in BPD and may result in an inadequate clinical attitude towards 
borderline patients with psychotic symptoms. Investigating psychotic symptoms using a psychosis continuum approach - on the other hand - will fuel interest in psychosis research in BPD and offers excellent opportunities to study aetiological and pathogenetic mechanisms at the lower end of the psychosis continuum (e.g. broadly and quasi-psychotic symptoms). The current thesis will investigate psychotic reactivity to stress in BPD using a continuum approach of psychotic symptoms.

\section{AETIOLOGY OF BORDERLINE PERSONALITY DISORDER}

BPD is a complex disease which is likely to be caused by genetic and environmental factors interacting during the first two decades of human development (American Psychiatric Association, 2000; Lieb et al., 2004; Paris, 2005). Evidence shows that the variance of personality traits such as affective instability and impulsivity is for about 50 percent genetically determined (Lieb et al., 2004; Paris, 2005). Twin studies reveal a similar genetic influence for BPD (Torgersen et al., 2000). Low social-economic status, family dysfunction, female sex, difficulties in attaining stable attachments, and childhood neglect, separation, losses and sexual and physical abuse all have been postulated to be risk factors for the disorder (Lieb et al., 2004; Paris, 2005). Although childhood sexual abuse has been receiving much attention as a possible cause of BPD, and some researchers even questioned whether BPD is not merely a variant of post traumatic stress disorder (Driessen et al., 2002), a meta-analysis on childhood sexual abuse in BPD revealed a moderate pooled effect size estimate $r$ of 0.28 . Community studies on childhood trauma (CT) moreover show extensive resilience for childhood trauma and less severe adversities in particular (Paris, 2005). The most valid studies that have been conducted have shown that a quarter of the subjects with BPD report sexual abuse by a caretaker and about a third report severe forms of abuse (Paris, 2005). Although childhood abuse is clearly a risk factor for BPD, it is neither a sufficient nor a necessary cause.

\section{Childhood trauma and emotional reactivity to stress}

Although association studies using BPD samples are important tools in the search for the causes for the disorder, they don't elucidate the underlying mechanism leading from childhood trauma to BPD. Investigating childhood trauma in relation to symptom dimensions, instead of categorical diagnosis, may offer a more nuanced understanding of the relationship between childhood 
trauma and BPD. Since symptom reactivity (to stress) is a prominent feature of $\mathrm{BPD}$, it is attractive to hypothesize that childhood trauma may cause borderline symptoms such as psychosis and affective instability by generating enhanced sensitivity to stress. Several studies, already, have reported enhanced emotional reactivity to daily life stress to be a vulnerability factor for affective and psychotic disorders (Myin-Germeys et al., 2003). Recent research, moreover, has outlined evidence for sensitization processes (Collip, Myin-Germeys, \& Van Os, 2008; Wichers et al., 2008), showing that childhood trauma interacting with (epi) genetic and adverse social factors may cause enhanced emotional reactivity to (eventually) common stresses that continually happen in the flow of everyday life. Experimental studies with rodents strongly support a sensitization hypothesis showing that early traumatic experiences such as maternal separation shortly after birth may have enduring effects on hypothalamic-pituitaryadrenal (HPA) axis functioning, a prominent neurobiological stress system (van Praag et al., 2004). Hyper-responsiveness of the HPA axis has also been reported in borderline patients with a history of sustained childhood abuse (Rinne et al., 2002). The current thesis contributes to the evidence of stress sensitization processes by investigating the relationship between childhood trauma and emotional reactivity to daily life stress in a non-clinical population of frequent attenders of the general practitioner, thus minimizing the confounding effects of severity variables such as comorbidity, hospitalization and multiple psychiatric medications.

\section{Aims of THE THESIS}

In this thesis we investigated the phenomenology and aetiology of BPD. This thesis consists of two sections, one corresponding to the phenomenology of $\mathrm{BPD}$ and the other section corresponding to the aetiology of BPD.

Our first aim was to validate the DSM-IV borderline criteria affective instability due to a marked reactivity of mood and stress-related paranoid ideation.

The second aim was investigate whether the 'reputed' association between childhood trauma and BPD would also apply to a non-clinical sample of frequent attenders of the general practitioner. 


\section{OUTLINE OF THE THESIS}

\section{Part 1}

This section concerns the phenomenology of BPD. In chapter 2 the borderline criterion affective instability due to a marked reactivity of mood is addressed by investigating emotional stress reactivity in daily life of subjects with BPD. The one study (Hochschild Tolpin et al, 2004) that investigated the effect of number of borderline criteria on emotional reactivity to stress with a daily process design used a student sample and focused primarily on interpersonal stress. The current theses therefore contains the first experience sampling study that investigated emotional reactivity to common stresses that continually happen in the flow of everyday life using a clinical sample of subjects with BPD. Besides healthy control subjects, patients with psychotic disorder - known for enhanced reactivity to daily life stress - were used as a comparison group.

In chapter 3 the borderline criterion 'stress-related paranoid ideation' is addressed by investigating psychotic reactivity to daily life stress in BPD.

Despite the many studies on psychosis in BPD and the incorporation of stressrelated paranoid ideation in DSM-IV, no study until this thesis has investigated the stress relatedness of psychotic symptoms in BPD in daily life. This thesis contains the first study that investigates the stress relatedness of psychotic symptoms in daily life of subjects with clinical BPD using comparison groups of subjects with active psychotic disorder, subjects with cluster $\mathrm{C}$ personality disorder and healthy controls.

\section{Part 2}

This section concerns the aetiology of BPD. It has been shown that emotional reactivity to daily life stress is a vulnerability factor underlying a broad range of psychopathology including BPD in particular (Glaser, Van Os, Mengelers, \& Myin-Germeys, 2008). It has also been shown that childhood trauma (CT) is a risk factor for BPD (Fossati, Madeddu, \& Maffei, 1999). In chapter 4 we investigated whether childhood trauma is a predictor of emotional reactivity to daily life stress in a non-clinical sample of frequent attenders of the general practitioner.

Non-clinical studies are important in elucidating the relationship between childhood trauma and symptom dimensions of BPD because they are not hampered by confounding and moderating influences related to clinical populations such as comorbidity, hospitalization, multiple psychiatric medications and severity of pathology. Moreover, non-clinical studies are in line with a continuum 
view of psychopathology since it has been shown that risk factors predicting severe psychopathology, likely also predict more subtle symptoms at the lower end of the continuum presenting in non-clinical populations (van Os et al., 2009). The current thesis contains the first experience sampling study to investigate the relationship between childhood trauma and emotional reactivity to daily life stress in a non-clinical sample of frequent attenders of the general practitioner. 


\section{REFERENCES}

American Psychiatric Association (2000). Diagnostic and Statistical Manual of Mental disorders, 4th edn, Text Revision (DSM-IV-TR). Washington, DC.

Chabrol, H., Chouicha, K., Montovany, A., \& Callahan, S. (2001). [Symptoms of DSM IV borderline personality disorder in a nonclinical population of adolescents: study of a series of 35 patients]. Encephale, 27(2), 120-127.

Chopra, H. D., \& Beatson, J. A. (1986). Psychotic symptoms in borderline personality disorder. Am J Psychiatry, 143(12), 1605-1607.

Collip, D., Myin-Germeys, I., \& Van Os, J. (2008). Does the Concept of "Sensitization" Provide a Plausible Mechanism for the Putative Link Between the Environment and Schizophrenia? Schizophr Bull.

Cowdry, R. W., Gardner, D. L., O’Leary, K. M., Leibenluft, E., \& Rubinow, D. R. (1991). Mood variability: a study of four groups. Am J Psychiatry, 148(11), 1505-1511.

Delespaul, P. A. E. G. (1995). Assessing Schizophrenia in Daily Life. Universitaire Pers Maastricht: Maastricht.

Driessen, M., Beblo, T., Reddemann, L., Rau, H., Lange, W., Silva, A., et al. (2002). [Is the borderline personality disorder a complex post-traumatic stress disorder? - The state of research]. Nervenarzt, 73(9), 820-829.

Ebner-Priemer, U. W., Kuo, J., Kleindienst, N., Welch, S. S., Reisch, T., Reinhard, I., et al. (2007). State affective instability in borderline personality disorder assessed by ambulatory monitoring. Psychol Med, 1-10.

Ebner-Priemer, U. W., Welch, S. S., Grossman, P., Reisch, T., Linehan, M. M., \& Bohus, M. (2007). Psychophysiological ambulatory assessment of affective dysregulation in borderline personality disorder. Psychiatry Res, 150(3), 265-275.

Erikson, E. H. (1982). The lifecycle completed: a review (First edition ed.). New York: Norton.

Fossati, A., Madeddu, F., \& Maffei, C. (1999). Borderline Personality Disorder and childhood sexual abuse: a meta-analytic study. J Personal Disord, 13(3), 268-280.

Glaser, J. P., Van Os, J., Mengelers, R., \& Myin-Germeys, I. (2008). A momentary assessment study of the reputed emotional phenotype associated with borderline personality disorder. Psychol Med, 38 (9), 1231-1239.

Glaser, J. P., van Os, J., Portegijs, P. J., \& Myin-Germeys, I. (2006). Childhood trauma and emotional reactivity to daily life stress in adult frequent attenders of general practitioners. $J$ Psychosom Res, 61(2), 229-236.

Gunderson, J. G., Morey, L. C., Stout, R. L., Skodol, A. E., Shea, M. T., McGlashan, T. H., et al. (2004). Major depressive disorder and borderline personality disorder revisited: longitudinal interactions. J Clin Psychiatry, 65(8), 1049-1056.

Gunderson, J. G., \& Phillips, K. A. (1991). A current view of the interface between borderline personality disorder and depression. Am J Psychiatry, 148(8), 967-975.

Hyman, S. E. (2002). A new beginning for research on borderline personality disorder. Biol Psychiatry, 51(12), 933-935.

Jonas, J. M., \& Pope, H. G. (1984). Psychosis in borderline personality disorder. Psychiatr Dev, 2(4), 295-308. 
Jovev, M., \& Jackson, H. J. (2006). The relationship of borderline personality disorder, life events and functioning in an Australian psychiatric sample. J Personal Disord, 20(3), 205217.

Kanner, A. D., Coyne, J. C., Schaefer, C., \& Lazarus, R. S. (1981). Comparison of two modes of stress measurement: daily hassles and uplifts versus major life events. J Behav Med, 4(1), 139.

Koenigsberg, H. W., Harvey, P. D., Mitropoulou, V., Schmeidler, J., New, A. S., Goodman, M., et al. (2002). Characterizing affective instability in borderline personality disorder. Am J Psychiatry, 159(5), 784-788.

Krabbendam, L., Myin-Germeys, I., De Graaf, R., Vollebergh, W., Nolen, W. A., Iedema, J., et al. (2004). Dimensions of depression, mania and psychosis in the general population. Psychol Med, 34(7), 1177-1186.

Lieb, K., Zanarini, M. C., Schmahl, C., Linehan, M. M., \& Bohus, M. (2004). Borderline personality disorder. Lancet, 364(9432), 453-461.

Links, P. S., Steiner, M., \& Mitton, J. (1989). Characteristics of psychosis in borderline personality disorder. Psychopathology, 22(4), 188-193.

Miller, F. T., Abrams, T., Dulit, R., \& Fyer, M. (1993). Psychotic symptoms in patients with borderline personality disorder and concurrent axis I disorder. Hosp Community Psychiatry, 44(1), 59-61.

Monroe, S. M. (1983). Major and minor life events as predictors of psychological distress: further issues and findings. J Behav Med, 6(2), 189-205.

Myin-Germeys, I., Peeters, F., Havermans, R., Nicolson, N. A., DeVries, M. W., Delespaul, P., et al. (2003). Emotional reactivity to daily life stress in psychosis and affective disorder: an experience sampling study. Acta Psychiatr Scand, 107(2), 124-131.

Myin-Germeys, I., \& van Os, J. (2007). Stress-reactivity in psychosis: evidence for an affective pathway to psychosis. Clin Psychol Rev, 27(4), 409-424.

Nishizono-Maher, A., Ikuta, N., Ogiso, Y., Moriya, N., Miyake, Y., \& Minakawa, K. (1993). Psychotic symptoms in depression and borderline personality disorder. J Affect Disord, 28(4), 279-285.

Paris, J. (2005). Borderline personality disorder. CMAJ, 172(12), 1579-1583.

Paris, J., \& Zweig-Frank, H. (2001). A 27-year follow-up of patients with borderline personality disorder. Compr Psychiatry, 42(6), 482-487.

Peeters, F., Nicolson, N. A., Berkhof, J., Delespaul, P., \& deVries, M. (2003). Effects of daily events on mood states in major depressive disorder. J Abnorm Psychol, 112(2), 203-211.

Pompili, M., Girardi, P., Ruberto, A., \& Tatarelli, R. (2005). Suicide in borderline personality disorder: a meta-analysis. Nord J Psychiatry, 59(5), 319-324.

Pope, H. G., Jr., Jonas, J. M., Hudson, J. I., Cohen, B. M., \& Tohen, M. (1985). An empirical study of psychosis in borderline personality disorder. Am J Psychiatry, 142(11), 1285-1290.

Practice guideline for the treatment of patients with borderline personality disorder. American Psychiatric Association. (2001). Am J Psychiatry, 158(10 Suppl), 1-52. 
Rinne, T., de Kloet, E. R., Wouters, L., Goekoop, J. G., DeRijk, R. H., \& van den Brink, W. (2002). Hyperresponsiveness of hypothalamic-pituitary-adrenal axis to combined dexamethasone/corticotropin-releasing hormone challenge in female borderline personality disorder subjects with a history of sustained childhood abuse. Biol Psychiatry, 52(11), 11021112 .

Russell, J. J., Moskowitz, D. S., Zuroff, D. C., Sookman, D., \& Paris, J. (2007). Stability and variability of affective experience and interpersonal behavior in borderline personality disorder. J Abnorm Psychol, 116(3), 578-588.

Samuels, J., Eaton, W. W., Bienvenu, O. J., 3rd, Brown, C. H., Costa, P. T., Jr., \& Nestadt, G. (2002). Prevalence and correlates of personality disorders in a community sample. Br J Psychiatry, 180, 536-542.

Siever, L. J., Torgersen, S., Gunderson, J. G., Livesley, W. J., \& Kendler, K. S. (2002). The borderline diagnosis III: identifying endophenotypes for genetic studies. Biol Psychiatry, 51(12), 964-968.

Skodol, A. E., Gunderson, J. G., Pfohl, B., Widiger, T. A., Livesley, W. J., \& Siever, L. J. (2002). The borderline diagnosis I: psychopathology, comorbidity, and personality structure. Biol Psychiatry, 51(12), 936-950.

Skodol, A. E., Siever, L. J., Livesley, W. J., Gunderson, J. G., Pfohl, B., \& Widiger, T. A. (2002). The borderline diagnosis II: biology, genetics, and clinical course. Biol Psychiatry, 51(12), 951-963.

Stefanis, N. C., Hanssen, M., Smirnis, N. K., Avramopoulos, D. A., Evdokimidis, I. K., Stefanis, C. N., et al. (2002). Evidence that three dimensions of psychosis have a distribution in the general population. Psychol Med, 32(2), 347-358.

Stein, K. F. (1996). Affect instability in adults with a borderline personality disorder. Arch Psychiatr Nurs, 10(1), 32-40.

Tolpin, L. H., Gunthert, K. C., Cohen, L. H., \& O’Neill, S. C. (2004). Borderline personality features and instability of daily negative affect and self-esteem. J Pers, 72(1), 111-137.

Torgersen, S., Kringlen, E., \& Cramer, V. (2001). The prevalence of personality disorders in a community sample. Arch Gen Psychiatry, 58(6), 590-596.

Torgersen, S., Lygren, S., Oien, P. A., Skre, I., Onstad, S., Edvardsen, J., et al. (2000). A twin study of personality disorders. Compr Psychiatry, 41(6), 416-425.

van Asselt, A. D., Dirksen, C. D., Arntz, A., \& Severens, J. L. (2007). The cost of borderline personality disorder: societal cost of illness in BPD-patients. Eur Psychiatry, 22(6), 354-361.

van Eck, M., Berkhof, H., Nicolson, N., \& Sulon, J. (1996). The effects of perceived stress, traits, mood states, and stressful daily events on salivary cortisol. Psychosom Med, 58(5), 447458.

van Eck, M. M., Nicolson, N. A., Berkhof, H., \& Sulon, J. (1996). Individual differences in cortisol responses to a laboratory speech task and their relationship to responses to stressful daily events. Biol Psychol, 43(1), 69-84.

van Os, J., Linscott, R. J., Myin-Germeys, I., Delespaul, P., \& Krabbendam, L. (2009). A systematic review and meta-analysis of the psychosis continuum: evidence for a psychosis proneness-persistence-impairment model of psychotic disorder. Psychol Med, 39(2), 179195. 
van Praag, H. M., van Os, J., \& de Kloet, E. R. (2004). Stress, the Brain and Depression: Cambridge University Press.

Wichers, M., Schrijvers, D., Geschwind, N., Jacobs, N., Myin-Germeys, I., Thiery, E., et al. (2008). Mechanisms of gene-environment interactions in depression: evidence that genes potentiate multiple sources of adversity. Psychol Med, 1-10.

Widiger, T. A. (2005). A dimensional model of psychopathology. Psychopathology, 38(4), 211 214.

Widiger, T. A. (2007). Dimensional models of personality disorder. World Psychiatry, 6(2), 7983.

Zanarini, M. C., Frankenburg, F. R., Hennen, J., \& Silk, K. R. (2003). The longitudinal course of borderline psychopathology: 6-year prospective follow-up of the phenomenology of borderline personality disorder. Am J Psychiatry, 160(2), 274-283.

Zanarini, M. C., Gunderson, J. G., \& Frankenburg, F. R. (1990). Cognitive features of borderline personality disorder. Am J Psychiatry, 147(1), 57-63.

Zanarini, M. C., Gunderson, J. G., Frankenburg, F. R., \& Chauncey, D. L. (1990). Discriminating borderline personality disorder from other axis II disorders. Am J Psychiatry, 147(2), 161-167. 


\section{Part 1}

Phe nom e n o logy 



\section{CHAPTER 2}

\section{A momentary assessment study of the reputed emotional phenotype associated with borderline personality disorder}

Jean-Paul Glaser ${ }^{1}$, Jim van Os ${ }^{1,2}$, Ron Mengelers ${ }^{1}$, Inez Myin-Germeys ${ }^{1,3,4}$

${ }^{1}$ Department of Psychiatry and Neuropsychology, South Limburg Mental Health Research and Teaching Network, EURON, Maastricht University, The Netherlands

${ }^{2}$ Division of Psychological Medicine, Institute of Psychiatry, London, UK

${ }^{3}$ Mondriaan Zorggroep, Section Social Cognition, Heerlen, the Netherlands

${ }^{4}$ School of Psychological Sciences, University of Manchester, UK

Psychological Medicine 2008; 38 (9): 1231-1239 


\section{Abstract}

Objective: Stress is postulated to play an essential role in the expression of core borderline symptoms. However, the phenomenology of stress reactivity in borderline personality disorder remains unclear. The current study investigated the phenomenology of stress sensitivity in borderline personality disorder in the flow of daily life and compared this with stress sensitivity in patients suffering from psychotic disorders, a group so far known to report the largest reactivity to stress.

Method: A total of 44 borderline patients, 42 patients with psychotic disorder and 49 healthy controls were studied with the Experience Sampling Method (a structured diary technique assessing current context and mood in daily life) to assess: (1) appraised subjective stress related to daily events and activities, and (2) emotional reactivity conceptualized as changes in positive and negative affect.

Results: Multilevel regression analysis revealed that subjects with borderline personality disorder experienced significantly more emotional reactivity to daily life stress compared with both patients with psychosis and healthy controls, as evidenced by a larger increase in negative affect and a larger decrease in positive affect following stress.

Conclusions: These results are the first to ecologically validate the incorporation of stress reactive symptoms in the diagnosis of borderline personality disorder. Borderline patients continually react stronger than patients with psychosis and healthy controls to small disturbances that continually happen in the natural flow of everyday life. Altered emotional stress reactivity may define borderline personality disorder.

Key words: affective reactivity; borderline personality disorder; momentary assessment; psychotic disorder; stress 


\section{INTRODUCTION}

Borderline personality disorder (BPD) is a chronic psychiatric condition characterised by affective instability, impulsive behaviour, interpersonal problems and cognitive disturbances (American Psychiatric Association, 2000; Paris, 2005). General population studies indicate a prevalence of close to 1 percent (Samuels et al., 2002; Torgersen, Kringlen, \& Cramer, 2001). Although the disorder may improve over time, it impacts on the life and development of young adults over periods of decades (Paris, 2005). About $10 \%$ of the patients die by suicide (Paris, 2005; Pompili, Girardi, Ruberto, \& Tatarelli, 2005).

Stress is postulated to play an essential role in the expression of core borderline symptoms. Borderline personality disorder, by definition, features criteria such as mood reactivity and transient stress-related paranoid ideation ("American Psychiatric Association, 2000). The explicit (and exceptional) incorporation of (stress) reactivity in these criteria, in the otherwise aetiologically neutral DSM IV (American Psychiatric Association, 2000), defines a prominent role for stress with regard to symptom expression.

However, the phenomenology of mood and stress reactivity in borderline personality disorder remains unclear. Some clinical studies focussed on emotional dysregulation, reporting stronger and specific patterns of emotional instability in borderline personality disorder as compared with controls (Cowdry, Gardner, O'Leary, Leibenluft, \& Rubinow, 1991; Ebner-Priemer et al., 2007; Koenigsberg et al., 2002; Stein, 1996; Stiglmayr et al., 2005). Other studies, including community and student samples, specifically investigated stress (appraisal) and found subjects with borderline syndrome to report more interpersonal stressors and higher stress appraisal compared with controls (Daley, Hammen, Davila, \& Burge, 1998; Jovev \& Jackson, 2006; Pagano et al., 2004; Sinha \& Watson, 1997; Stiglmayr et al., 2005; Trull, 1995).

A third series of studies investigated the effect of stress on mood in borderline personality disorder (Perry, Lavori, Pagano, Hoke, \& O’Conell, 1992; Tolpin, Gunthert, Cohen, \& O'Neill, 2004). One clinical study reported higher recurrence rates of depression following life events in borderline personality disorder (Perry et al., 1992). However, the class of common small daily events, rather than low-prevalent life events, probably represent more important predictors of psychopathology in general (Kanner, Coyne, Schaefer, \& Lazarus, 1981; Monroe, 1983), and of subjective distress in particular (Norman \& Malla, 1991). One study in students investigated whether borderline features were related to emotional reactivity to interpersonal stress on a day-to-day basis, using end-of- 
day questionnaires (Tolpin et al., 2004). This study found subjects with subclinical borderline syndrome to report more daily interpersonal stressors, but no greater negative affective reactivity to these stressors (Tolpin et al., 2004). The current study aimed to extend these findings to a clinical sample of patients with borderline personality disorder, using the only approach specifically designed to investigate emotional reactivity to minor stressors that continually happen in the flow of daily life: the Experience Sampling Method (ESM)(Delespaul, 1995).

Previous studies using ESM have shown that emotional reactivity to daily life stress is associated with a number of psychopathological disorders, such as major depression, bipolar disorder, and psychosis (Myin-Germeys et al., 2003). In order to investigate whether emotional reactivity to stress is a core feature of borderline personality disorder, rather than an expression of a general vulnerability to psychopathology, the current study not only compared a sample of patients with BPD with healthy controls, but also with a sample of patients with psychotic disorder. The rationale for the inclusion of this later comparison is that patients with psychotic disorder have been shown to display the largest reactivity to daily life stress, compared with major depressive and bipolar groups (Myin-Germeys et al., 2003).

The current study addressed the following questions: (1) does stress in the natural environment affect mood, and (2) does the emotional reaction to daily life stressors differ between patients diagnosed with psychotic disorder and with borderline personality disorder. A third group of healthy volunteers was included as reference category.

\section{METHOD}

\section{Subjects}

\section{Sample}

The sample consisted of 50 subjects with psychotic illness (PSY), 48 subjects diagnosed with a borderline personality disorder (BPD), and 50 healthy control subjects (CON). Written informed consent, conforming to the local ethics committee guidelines, was obtained from all subjects. All patients were receiving ambulatory treatment. All participants had to be between 18 and 55 years old with sufficient command of the Dutch language. Exclusion criteria were severe 
endocrine, cardiovascular or brain disease and severe alcohol or drug dependence.

PSY were recruited through the mental health facilities in the area of Southern Limburg in the Netherlands. PSY had to have a lifetime occurrence of psychotic symptoms (according to Research Diagnostic Criteria) for at least 2 weeks in clear consciousness. Extensive screening with diagnostic interviews such as the Brief Psychiatric Rating Scale (Ventura, Green, Shaner, \& Liberman, 1993) and the Positive and Negative Syndrome Scale (Kay, Fiszbein, \& Opler, 1987) was used to map axis I psychiatric symptomatology. Interview data and clinical record data were used to complete the Operational Criteria Checklist for Psychotic Illness, yielding DSM-III-R diagnoses through the OPCRIT computer program (McGuffin, Farmer, \& Harvey, 1991).

BPD had to fulfill the formal DSM-IV criteria for borderline personality disorder and were extensively screened with the complete versions of the structured clinical interview for

DSM-IV axis I and II disorders, the SCID I and the SCID II (First, Gibbon, Spitzer, Williams, \& Benjamin, 1997; First, Spitzer, Gibbon, \& Williams, 2002).

$\mathrm{CON}$ were recruited from the general population through a random mailing procedure in the area of Southern Limburg in the Netherlands. They were selected on the basis of absence of a family or personal history of psychosis, or current use of psychotropic medication including benzodiazepines. After obtaining informed consent subjects were interviewed to complete the Brief Psychiatric Rating Scale and the Operational Criteria Checklist for Psychotic Illness, yielding DSM-III-R diagnoses through the OPCRIT computer program (McGuffin et al., 1991).

\section{ESM}

ESM is a within-day momentary self-assessment technique. Previous applications of ESM have demonstrated the feasibility, validity and reliability of the method in general population samples and in samples of psychiatric patients (Jacobs et al., 2005; Myin-Germeys, Krabbendam, Jolles, Delespaul, \& van Os, 2002; Stein, 1996; van Eck, Nicolson, Berkhof, \& Sulon, 1996). Subjects were studied in their normal daily living environment. They received a digital wristwatch and a set of ESM self-assessment forms collated in a booklet for each day. Ten times a day on six consecutive days, the watch emitted a signal (beep) at unpredictable moments between 07:30 and 22:30 hours. After each 'beep', subjects were asked to stop their activity and fill out the ESM self-assessment 
forms previously handed out to them, collecting reports of thoughts, current context (activity, persons present, location), appraisals of the current situation, and mood. All self-assessment items were rated on seven-point Likert scales. The ESM procedure was explained to the subjects during an initial briefing session and a practice form was completed to confirm that subjects were able to understand the

seven-point Likert scale format. Subjects were asked to complete their reports immediately after the beep, thus minimizing memory distortions and to record the time at which they completed the form. During the sampling period subjects were repeatedly called by a research assistant to assess whether they were complying with the instructions. In order to know whether the subjects had completed the form within 15 minutes of the beep, the time at which subjects indicated they completed the report was compared to the actual time of the beep. All reports completed more than 15 minutes after the signal were excluded from the analysis. Previous work has shown that reports completed after this interval are less reliable and consequently less valid (Delespaul, 1995). For the same reason, subjects with less than 20 valid reports were also excluded from the analysis (Delespaul, 1995).

\section{Emotional stress reactivity assessment}

Previously, emotional stress reactivity was conceptualized as mood reactivity to daily events and minor disturbances in daily life (Myin-Germeys, van Os, Schwartz, Stone, \& Delespaul, 2001). Both the mood measures and the stress measures were derived from the experience sampling reports as described below.

\section{Mood assessments}

Mood states were assessed with 9 mood adjectives rated on seven-point Likert scales (1-7, indicating "not at all" to "very"). The mood adjectives "down," "guilty," "insecure," "lonely," and "anxious" formed the negative affect (NA) scale (Cronbach's $\alpha=0.94$ over the subject means). The mood adjectives "happy," "cheerful," "relaxed," and "satisfied" formed the positive affect (PA) scale (Cronbach's $\alpha=0.97$ over the subject means).

\section{Stress assessments}

Stress was conceptualized as the subjectively appraised stressfulness of distinctive events and minor disturbances that continually happen in the natural flow of daily life. Two different stress measures were computed. For event-related stress, subjects were asked to report the most important event that happened between 
the current and the previous reports. This event was subsequently rated on a seven-point bipolar scale $(-3=$ very unpleasant, $0=$ neutral, $3=$ very pleasant $)$. Responses were recoded to allow high scores to reflect stress $(-3=$ very pleasant, $0=$ neutral, 3 = very unpleasant). For activity-related stress, subjects judged their current activity on 3 self-report items (scored on seven-point Likert scales). The mean of the scales "I am not skilled to do this activity," "I would rather do something else," and "This activity requires effort," formed the activity-related stress scale (Crohnbach's $\alpha=.69$ over the subject means).

\section{Statistical analysis}

Initial pairwise group comparisons were performed on the number of valid beeps and the subjects' averages for the dependent variables NA and PA, and the independent variables event-related stress and activity-related stress, using one-way analysis of variance with the Tukey multiple comparison procedure. Correlations between the independent variables event-related stress and activityrelated stress and the dependent variables NA and PA were calculated per subject and subsequently analyzed as an individual-level variable. A one-sample, two-tailed $t$ test with $\alpha=0.05$ was conducted to test whether the mean of these individual-level correlation coefficients significantly deviated from zero. Distribution of demographic variables age and sex across the three groups were analyzed by pairwise group comparisons on the subjects' averages using one-way analysis of variance with the Tukey multiple-comparison procedure and by $\chi^{2}$ tests respectively.

In addition, multilevel linear random regression models were fitted. Multilevel or hierarchical linear modelling techniques are a variant of the more often used unilevel linear regression analyses and are ideally suited for the analysis of ESM data consisting of multiple observations in one person, i.e. at two levels (ESMbeep level and subject level)(Schwartz \& Stone, 1998). Since - in ESM - observations from the same subject are more similar than observations from different subjects, the residuals are not independent. Conventional regression techniques do not take into account the variance components at two different levels.

Data were analyzed with the multilevel XTREG module in STATA (Statacorp, 2004). The $\beta$ is the fixed regression coefficient of the predictor in the multilevel model and can be interpreted identically to the estimate in the conventional unilevel regression analysis.

In order to test the hypothesis that group modified the emotional reaction to daily life stress, multilevel linear regression analyses were conducted with stan- 
dardized NA and PA as the dependent variables (standardized NA=NA/S.D. of NA in the whole sample). According to Cohen, 0.8 S.D. can be considered a large effect size, and 0.2 S.D. a small effect size (Cohen, 1988). Group was a three-level categorical variable with value labels $0=\mathrm{CON}, 1=\mathrm{PSY}$, and $2=\mathrm{BPD}$. Group and the two stress measures were included in the model as covariates as well as their interactions: $\operatorname{mood}=\beta 0+\beta 1$ group $+\beta 2$ stress $+\beta 3$ group $x$ stress. Estimation of the effect sizes of stress on NA/PA for each group, were calculated from the model with the interactions by calculating appropriate linear combinations using the STATA LINCOM routine. Main effects and interactions were assessed by Wald test. Analyses were conducted separately for event-related stress and activity-related stress.

In order to control for possible differences between the three groups in level of depression, the mean scores per person on the ESM mood item "I feel down" (e.g. ESM depressed mood) were added to the analysis as a possible confounder along with the independent variables sex and age.

\section{RESULTS}

\section{Subjects}

Of the 50 control subjects who entered the study, one was excluded because of technical problems with the signalling device (see ESM section). Of the 50 patients with psychotic disorder, two did not return the diary booklets and six patients were unable to comply with the research protocol (they had fewer than 20 valid reports and were therefore excluded from the analysis, see ESM section). Four of the 48 patients with borderline personality disorder were excluded because they had fewer than 20 valid reports. The final sample thus consisted of 49 in the CON group, 42 in the PSY group and 44 in the BPD group (Table 1). Demographic and clinical characteristics of the research sample are summarized in Table 1 . The BPD group consisted of significantly more female subjects than the other two groups $\left[\chi^{2}(2)=13.10, p=0.001\right]$. The mean age of BPD was significantly higher than PSY $[\mathrm{F}(2,132)=3.26, \mathrm{p}<0.05$, Tukey honestly significant different test; BPD>PSY]. 
Table 1. Sociodemographic and Clinical Characteristics of the Research Sample

\begin{tabular}{|c|c|c|c|}
\hline & $\mathrm{BPD}(\mathrm{n}=44)$ & PSY $(n=42)$ & $\mathrm{CON}(\mathrm{n}=49)$ \\
\hline \multicolumn{4}{|l|}{ Sociodemographic variables } \\
\hline Mean age (S.D.), years [range] & $36.4(8.5)[19-55]$ & $31.9(7.7)[20-48]$ & $35.2(8.9)[21-50]$ \\
\hline Male-female ratio & $8: 36$ & $22: 20$ & $24: 25$ \\
\hline \multicolumn{4}{|l|}{ Education, \% } \\
\hline Elementary school & 2 & 24 & 8 \\
\hline Secondary school & 77 & 67 & 63 \\
\hline Higher education & 21 & 9 & 29 \\
\hline \multicolumn{4}{|l|}{ Marital status, \% } \\
\hline Married or living together & 32 & 21 & 82 \\
\hline Divorced & 21 & 5 & 2 \\
\hline Never married & 47 & 74 & 16 \\
\hline \multicolumn{4}{|l|}{ Work situation, \% } \\
\hline Working & 16 & 24 & 98 \\
\hline Unemployed & 7 & 0 & 2 \\
\hline Incapable of work & 66 & 66 & 0 \\
\hline Protected work & 2 & 10 & 0 \\
\hline School/education & 5 & & \\
\hline Household & 4 & & \\
\hline \multicolumn{4}{|l|}{ Clinical variables } \\
\hline \multirow{4}{*}{\multicolumn{4}{|c|}{$\begin{array}{l}\text { OPCRIT DSM III-R diagnosis } \\
\text { (lifetime) (subjects with psychotic } \\
\text { illness and controls) / DSM-IV } \\
\text { diagnosis (borderline patients) no. } \\
\text { of subjects }\end{array}$}} \\
\hline & & & \\
\hline & & & \\
\hline & & & \\
\hline Schizophrenia & 0 & 39 & 0 \\
\hline Schizoaffective disorder & 0 & 2 & 0 \\
\hline Atypical psychosis & 7 & 1 & 0 \\
\hline Depressive or anxiety disorder & 32 & 0 & 0 \\
\hline \multicolumn{4}{|l|}{ Medication, $\%$} \\
\hline Antipsychotics & 36 & 95 & 0 \\
\hline Antidepressants & 48 & 19 & 0 \\
\hline Benzodiazepines & 34 & 24 & 0 \\
\hline Mood stabilizer & 13 & 5 & 0 \\
\hline Anticholinergics & 5 & 14 & 0 \\
\hline No medication & 21 & 5 & 0 \\
\hline
\end{tabular}




\section{Stress and mood measures}

The number of valid reports and the mean scores of the independent and the dependent variables are shown in Table 2. The two mood variables, NA and PA, were significantly, but moderately, negatively correlated $(r=-0.44,95 \% \mathrm{CI}$ 0.49 to -0.39$)$.

Table 2. Means (S.D.) and F test statistics of the number of valid reports and the independent and dependent variables for patients with borderline personality disorder, patients with psychosis and control subjects.

\begin{tabular}{|c|c|c|c|c|c|c|c|}
\hline & $\begin{array}{l}\text { BPD } \\
(\mathrm{n}=44)\end{array}$ & $\begin{array}{l}\text { PSY } \\
(n=42)\end{array}$ & $\begin{array}{l}\text { CON } \\
(\mathrm{n}=49)\end{array}$ & $\begin{array}{l}\text { Total } \\
\mathrm{n}=135\end{array}$ & $\mathrm{~F}_{2,132}$ & p-value & $\begin{array}{l}\text { Turkey HSD } \\
\text { comparison }\end{array}$ \\
\hline Valid reports & $42(8)$ & $45(10)$ & $51(6)$ & $46(9)$ & 14.53 & $<0.001$ & $\mathrm{BPD}, \mathrm{PSY}<\mathrm{CON}$ \\
\hline \multicolumn{8}{|c|}{ Independent variables } \\
\hline $\begin{array}{l}\text { Event-related } \\
\text { stress }\end{array}$ & $-0.8(0.9)$ & ) $-1.2(0.9)$ & $-1.7(0.7)$ & $-1.2(0.9)$ & 12.74 & $<0.001$ & $\mathrm{BPD}, \mathrm{PSY}>\mathrm{CON}$ \\
\hline $\begin{array}{l}\text { Activity-related } \\
\text { stress }\end{array}$ & $3.2(0.9)$ & $2.5(0.7)$ & $2.3(0.6)$ & $2.7(0.9)$ & 17.17 & $<0.001$ & $\mathrm{BPD}>\mathrm{PSY}, \mathrm{CON}$ \\
\hline \multicolumn{8}{|c|}{ Dependent variables } \\
\hline NA & $2.9(1.3)$ & ) $1.8(0.7)$ & $1.2(0.4)$ & $1.9(1.1)$ & 44.26 & $<0.001$ & $\mathrm{BPD}>\mathrm{PSY}>\mathrm{CON}$ \\
\hline PA & $3.7(1.2)$ & $4.4(1.0)$ & $5.5(0.8)$ & $4.6(1.2)$ & 42.75 & $<0.001$ & $\mathrm{BPD}<\mathrm{PSY}<\mathrm{CON}$ \\
\hline
\end{tabular}

S.D. Standard deviation; BPD, borderline personality disorder; PSY, psychotic illness; CON, healthy controls; HSD, honestly significantly different.

Both BPD and PSY reported significantly more event-related stress compared to CON. BPD also reported significantly more activity-related stress than PSY and CON (Table 2). The two stress measures, event-related stress and activityrelated stress, were significantly correlated but the correlations were low $(r=0.17,95 \%$ CI 0.13 to 0.20$)$. BPD reported more NA and less PA compared to PSY, and both reported significantly more NA and less PA compared to CON.

\section{Predictors of mood states}

The multilevel random regression analysis showed that the two stress measures were significantly associated with NA [event-related stress: $\beta=0.06$ (S.E. $=0.00)$, $\mathrm{p}<0.001$ ); activity-related stress: $\beta=0.11$ (S.E. $=0.01$ ), $\mathrm{p}<0.001$ ) and PA (eventrelated stress: $\beta=-0.09$ (S.E. $=0.01$ ), $p<0.001$; activity related stress: $\beta=-0.17$ $(\mathrm{S} . \mathrm{E} .=0.01), \mathrm{p}<0.001)$. In addition, group was also significantly associated with 
NA and PA in the same fashion as reported in the unilevel analysis presented in Table 2.

Significant interaction effects between group and stress were found for both NA [activity-related stress: $B=0.05 \quad($ S.E. $=0.01), \quad \mathrm{p}<0.001$; event-related stress: $\beta=0.03$ (S.E. $=0.00$ ), $\quad p<0.001$ ), and PA (activity-related stress: $\beta=-0.05$ (S.E. $=0.01$ ), $p<0.001$; event-related stress: $\beta=-0.03$ (S.E. $=0.00$ ), $p<0.001$ ], indicating that group moderated the impact of small daily stress on mood. The interaction effects remained significant after controlling for the possible confounding effects of the variables age, sex and mean level per person of ESM depressed mood [NA: activity-related stress: $\beta=0.07$ (S.E. $=0.01$ ), $p<0.001$; event-related stress: $\beta=0.04$ (S.E. $=0.01$ ), $p<0.001$ ), PA: activity-related stress: $\beta=-0.05 \quad$ (S.E. $=0.01$ ), $\quad p<0.001$; event-related stress: $\beta=-0.04 \quad$ (S.E. $=0.01$ ), $\mathrm{p}<0.001]$.

Table 3. The effect of stress on Negative Affect (NA) by group

\begin{tabular}{lll}
\hline & NA & \\
\hline Group & Activity-related stress & Event-related stress \\
& $\beta^{\mathrm{a}}(95 \% \mathrm{CI} ; \mathrm{p})$ & $\beta^{\mathrm{a}}(95 \% \mathrm{CI} ; \mathrm{p})$ \\
CON & $\beta=0.03(0.01-0.05) ; \mathrm{p}=0.007$ & $\beta=0.01(-0.00-0.03) ; \mathrm{p}=0.10$ \\
PSY & $\beta=0.12(0.10-0.14) ; \mathrm{p}<0.001$ & $\beta=0.05(0.04-0.06) ; \mathrm{p}<0.001$ \\
BPD & $\beta=0.16(0.15-0.18) ; \mathrm{p}<0.001$ & $\beta=0.10(0.08-0.11) ; \mathrm{p}<0.001$ \\
$\mathrm{p}($ PSY v. CON) & $\chi^{2}(1) 39.70, \mathrm{p}<0.001$ & $\chi^{2}(1) 24.98, \mathrm{p}<0.001$ \\
$\mathrm{p}($ BPD v. CON) & $\chi^{2}(1) 112.04, \mathrm{p}<0.001$ & $\chi^{2}(1) 76.90, \mathrm{p}<0.001$ \\
$\mathrm{p}($ PSY v. BPD) & $\chi^{2}(1) 8.52, \mathrm{p}=0.004$ & $\chi^{2}(1) 10.41, \mathrm{p}=0.001$ \\
Interaction $^{\mathrm{b}}$ & $\chi^{2}(2)=113.28, \mathrm{p}<0.001$ & $\chi^{2}(2)=77.78, \mathrm{p}<0.001$ \\
Interaction $^{\mathrm{c}}$ & $\chi^{2}(2)=116.21, \mathrm{p}<0.001$ & $\chi^{2}(2)=76.97, \mathrm{p}<0.001$ \\
\hline
\end{tabular}

$\overline{{ }^{a}}$ regression coefficient indicates change in NA associated with activity-related stress adjusted for

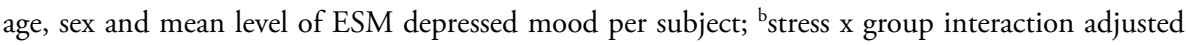
for age, sex and mean level of ESM depressed mood per subject; 'stress $x$ group interaction unadjusted for age, sex and mean level of ESM depressed mood per subject.

CI, Confidence interval; CON, healthy controls; PSY, psychotic illness; BPD, borderline personality disorder; ESM, Experience Sampling Method.

BPD reacted significantly stronger to daily life stress compared to PSY and CON, with larger decreases in PA and increases in NA. PSY reacted significantly stronger to daily life stress than CON (Table 3 and Table 4). Interaction effects differed significantly between BPD and PSY in adjusted and unadjusted conditions (Table 3 and Table 4) 
Table 4. The effect of stress on Positive Affect (PA) by group

\begin{tabular}{lll}
\hline & PA & \\
& Activity-related stress & Event-related stress \\
Group & $\beta^{\mathrm{a}}(95 \% \mathrm{CI} ; \mathrm{p})$ & $\beta^{\mathrm{a}}(95 \% \mathrm{CI} ; \mathrm{p})$ \\
\hline CON & $\beta=-0.10(-0.13--0.08) ; \mathrm{p}<0.001$ & $\beta=-0.05(-0.07--0.04) ; \mathrm{p}<0.001$ \\
PSY & $\beta=-0.18(-0.21--0.16) ; \mathrm{p}<0.001$ & $\beta=-0.09(-0.11--0.07) ; \mathrm{p}<0.001$ \\
BPD & $\beta=-0.21(-0.23--0.19) ; \mathrm{p}<0.001$ & $\beta=-0.13(-0.15--0.12) ; \mathrm{p}<0.001$ \\
$\mathrm{p} \mathrm{(PSY} \mathrm{v.} \mathrm{CON)}$ & $\chi^{2}(1) 20.14, \mathrm{p}<0.001$ & $\chi^{2}(1) 9.40, \mathrm{p}=0.002$ \\
$\mathrm{p}$ (BPD v. CON) & $\chi^{2}(1) 48.89, \mathrm{p}<0.001$ & $\chi^{2}(1) 42.77, \mathrm{p}<0.001$ \\
p (PSY v. BPD) & $\chi^{2}(1) 2.47, \mathrm{p}=0.12$ & $\chi^{2}(1) 11.40, \mathrm{p}<0.001$ \\
Interaction $^{\mathrm{b}}$ & $\chi^{2}(2)=50.15, \mathrm{p}<0.001$ & $\chi^{2}(2)=47.27, \mathrm{p}<0.001$ \\
Interaction $^{\mathrm{c}}$ & $\chi^{2}(2)=54.50, \mathrm{p}<0.001$ & $\chi^{2}(2)=49.32, \mathrm{p}<0.001$ \\
\hline
\end{tabular}

${ }^{a}$ regression coefficient indicates change in PA associated with activity-related stress adjusted for age, sex and mean level of ESM depressed mood per subject; ${ }^{b}$ stress x group interaction adjusted for age, sex and mean level of ESM depressed mood per subject; ' stress x group interaction unadjusted for age, sex and mean level of ESM depressed mood per subject.

CI, Confidence interval; CON, healthy controls; PSY, psychotic illness; BPD, borderline personality disorder; ESM, Experience Sampling Method.

\section{DISCUSSION}

This study is one of the first to ecologically validate the DSM-IV borderline criterion mood reactivity by investigating emotional reactivity to daily life stress in a clinical sample of borderline patients using a momentary design. The outcome of the current study suggests that enhanced emotional reactivity to daily life stress might be most specific for borderline personality disorder. Patients with borderline personality disorder not only reported significantly more emotional reactivity to daily life stress than healthy controls, but they also were emotionally more reactive than patients with psychotic disorder, a diagnostic group - until now - known to express the largest emotional reactivity to daily life stress (Myin-Germeys et al., 2003). The current study, therefore, generates scientific support for the incorporation of mood reactivity in DSM-IV borderline personality disorder classification and suggests that mood reactivity might be triggered by a broad range of small stressors in daily life. The effect sizes were small but not negligible, especially since we assessed frequently occurring exposures in daily life, the cumulative effects of which may be considerable.

Several studies have addressed stress, mood instability or aversive tension in borderline syndrome (Cowdry et al., 1991; Daley et al., 1998; Koenigsberg et 
al., 2002; Sinha \& Watson, 1997; Stein, 1996; Stiglmayr et al., 2005; Trull, 1995). However, only one previous study investigated the relationship between borderline features and emotional reactivity to daily life stress using a daily process design. This non-clinical study by Tolpin et al. (Tolpin et al., 2004) assessed emotional reactivity to interpersonal stress in daily life of college students with borderline features. They found that subjects with borderline features showed: (i) more interpersonal stress (in line with the results of the current study); (ii) more instability of mood; but (iii) - contrary to the authors' expectations and the results of the current study - no stronger emotional reactivity towards these stressors. The authors concluded that this last finding could be the consequence of methodological limitations such as using a non-clinical sample, collecting information once a the end of each day with the inherent risk of recall bias, or insufficient sensitivity of the measure of daily interpersonal stressors addressing only a specific range of daily events (questionnaire) without determining the frequency of a particular stressor during the day. Free from these limitations, the current clinical study - using a signal-contingent random sampling procedure with multiple assessments per day (Jacobs et al., 2005) indeed did find borderline personality disorder to express strongest emotional reactivity to daily life stress.

Many studies have focused on the importance of interpersonal stress in BPD (Gunderson \& Phillips, 1991; Tolpin et al., 2004). It could be argued that the current findings do not reflect over-reactivity to general stress but rather result from an over-representation of interpersonal stresses in the BPD group. However, similar results were found for both event- and activity-related stress. Whereas the first might include more interpersonal stresses, this is unlikely for the latter.

The current study also shows that borderline patients score worst on absolute mood (e.g. NA and PA) and stress measures (e.g. activity-related stress) (Table 2). Out-patient borderline patients, thus, not only react emotionally stronger to minor disturbances and daily hassles that continually happen in the flow of every day life, they also continually experience worse mood and more daily life stress than psychotic patients and healthy controls.

Previous experience sampling studies (Myin-Germeys, Krabbendam, Delespaul, \& van Os, 2004; Peeters, Nicolson, Berkhof, Delespaul, \& deVries, 2003) investigating depressive and psychotic disorder respectively, have shown that women express more emotional reactivity towards daily life stress than men. It has also been shown that borderline personality disorder improves with age (Paris, 2005). Although the BPD group in the current study consisted of sig- 
nificantly more female subjects than the other two groups (Table 1), and the mean age of BPD and CON was significantly higher than PSY (table 1), controlling for sex and age did not change the significant interaction between group and daily life stress in the current study.

In line with the literature, the borderline group showed large comorbidity of depressive and anxiety disorders (Zanarini et al., 1998; Zanarini, Frankenburg, Hennen, Reich, \& Silk, 2004). A total of 73\% (32 of 44 subjects) of the BPD subjects expressed a current anxiety or mood disorder. Controlling for the mean level of ESM depressive mood per person, a measure that can also be assessed in controls, however, revealed no substantial alteration in the relationship between group and emotional reactivity to daily life stress (see Results section).Controlling for SCID I depressive disorder - instead of mean level of ESM depressed mood per person - yielded the same results. This is in line with previous research suggesting that affective instability in BPD is not equivalent to depression given the high levels of environmental responsiveness (Gunderson \& Phillips, 1991). On the other hand, it might be argued that mood reactivity in BPD resembles the bipolarity in bipolar disorder. Studies investigating the interface between borderline personality disorder and depressive and bipolar disorder have concluded that they are independent disorders, with overlapping etiologies (Gunderson \& Phillips, 1991; Paris, Gunderson, \& Weinberg, 2007). The results of the current study and previous research of our group (MyinGermeys et al., 2003) are in line with this conclusion since it has been shown that enhanced stress reactivity is a mechanism underlying depressive disorder, bipolar disorder and borderline personality disorder, being most specific, however, for the latter group.

\section{Methodological issues}

The following methodological issues should be taken into account. First, the data are based on subjective reports. Although subjective reports are considered less reliable (e.g. do all subjects interpret or answer the questions identically?), they can be valid, whereas the validity of objective approaches cannot be taken for granted (Strauss, 1994). Second, the present study was a cross-sectional study, which makes it impossible to establish causal relationships. Therefore it is impossible to determine whether stress measures influenced mood, or mood influenced the subjective appraisal of stress. However either explanation has clinical relevance. Third, the current study used ESM, a daily life assessment technique in which subjects have to comply with a paper-and-pencil diary protocol without the researcher being present. Recently, some authors have put 
doubt on the reliability and subject compliance in paper-and-pencil ESM studies, favouring the use of electronic devices (Stone, Shiffman, Schwartz, Broderick, \& Hufford, 2002, 2003). However, in a comparative study, Green et al. concluded that both methods yielded similar results (Green, Rafaeli, Bolger, Shrout, \& Reis, 2006). In addition, a recent study of our group using a signalcontingent random time sampling procedure with multiple observations per day - such as the protocol used in the current study - also found evidence underscoring the validity of the paper-and-pencil random time self-report data in the current study (Jacobs et al., 2005).

It can be argued that stronger emotional reactivity to daily life stress in subjects with borderline personality disorder might result directly from the intrusiveness of the ESM. Indeed, borderline subjects reported significantly more distress from the ESM than subjects with psychotic disorder and healthy controls. Controlling for the ESM item "How much did this beep disturb you?", however, did not substantially change the results of the current study.

\section{Conclusion}

Since the introduction of DSM-IV in 1994 marked reactivity of mood is a core feature of DSM IV borderline personality disorder classification. The current study, however, is one of the first to validate this criterion by investigating emotional reactivity to daily life stress in (clinical) borderline personality disorder, using a momentary assessment design. Enhanced emotional reactivity to daily life stress may be most specific for borderline personality disorder since the current study showed that in this group it is even more pronounced than in psychotic disorder, a diagnostic category that thus far had been shown to be most emotionally reactive to the effects of daily life stress. 


\section{REFERENCES}

American Psychiatric Association (2000). Diagnostic and Statistical Manual of Mental disorders, 4th edn, Text Revision (DSM-IV-TR). Washington, DC.

Cohen, J. (1988). Statistical power analysis for the behavioral sciences (2nd edn. ed.). Hillsdale, NY: Lawrence Earlbaum Associates.

Cowdry, R. W., Gardner, D. L., O’Leary, K. M., Leibenluft, E., \& Rubinow, D. R. (1991). Mood variability: a study of four groups. Am J Psychiatry, 148(11), 1505-1511.

Daley, S. E., Hammen, C., Davila, J., \& Burge, D. (1998). Axis II symptomatology, depression, and life stress during the transition from adolescence to adulthood. J Consult Clin Psychol, 66(4), 595-603.

Delespaul, P. A. E. G. (1995). Assessing Schizophrenia in Daily Life. Universitaire Pers Maastricht: Maastricht.

Ebner-Priemer, U. W., Kuo, J., Kleindienst, N., Welch, S. S., Reisch, T., Reinhard, I., et al. (2007). State affective instability in borderline personality disorder assessed by ambulatory monitoring. Psychol Med, 1-10.

First, M. B., Gibbon, M., Spitzer, R. L., Williams, J. B. W., \& Benjamin, L. S. (1997). User's Guide for the Structured Clinical Interview for DSM-IV Axis II personality disorders (SCID-II). Washington, DC: American Psychiatric Press.

First, M. B., Spitzer, R. L., Gibbon, M., \& Williams, J. B. W. (2002). Structured Clinical Interview for DSM-IV Axis I Disorders-Patient Edition (SCID-I/P), 11-2002 revision. New York: Biometrics Research Department, New York State Psychiatric Institute.

Green, A. S., Rafaeli, E., Bolger, N., Shrout, P. E., \& Reis, H. T. (2006). Paper or plastic? Data equivalence in paper and electronic diaries. Psychol Methods, 11(1), 87-105.

Gunderson, J. G., \& Phillips, K. A. (1991). A current view of the interface between borderline personality disorder and depression. Am J Psychiatry, 148(8), 967-975.

Jacobs, N., Nicolson, N. A., Derom, C., Delespaul, P., van Os, J., \& Myin-Germeys, I. (2005). Electronic monitoring of salivary cortisol sampling compliance in daily life. Life Sci, 76(21), 2431-2443.

Jovev, M., \& Jackson, H. J. (2006). The relationship of borderline personality disorder, life events and functioning in an Australian psychiatric sample. J Personal Disord, 20(3), 205217.

Kanner, A. D., Coyne, J. C., Schaefer, C., \& Lazarus, R. S. (1981). Comparison of two modes of stress measurement: daily hassles and uplifts versus major life events. J Behav Med, 4(1), 139.

Kay, S. R., Fiszbein, A., \& Opler, L. A. (1987). The positive and negative syndrome scale (PANSS) for schizophrenia. Schizophr Bull, 13(2), 261-276.

Koenigsberg, H. W., Harvey, P. D., Mitropoulou, V., Schmeidler, J., New, A. S., Goodman, M., et al. (2002). Characterizing affective instability in borderline personality disorder. Am J Psychiatry, 159(5), 784-788.

McGuffin, P., Farmer, A., \& Harvey, I. (1991). A polydiagnostic application of operational criteria in studies of psychotic illness. Development and reliability of the OPCRIT system. Arch Gen Psychiatry, 48(8), 764-770. 
Monroe, S. M. (1983). Major and minor life events as predictors of psychological distress: further issues and findings. J Behav Med, 6(2), 189-205.

Myin-Germeys, I., Krabbendam, L., Delespaul, P. A., \& van Os, J. (2004). Sex differences in emotional reactivity to daily life stress in psychosis. J Clin Psychiatry, 65(6), 805-809.

Myin-Germeys, I., Krabbendam, L., Jolles, J., Delespaul, P. A., \& van Os, J. (2002). Are cognitive impairments associated with sensitivity to stress in schizophrenia? An experience sampling study. Am J Psychiatry, 159(3), 443-449.

Myin-Germeys, I., Peeters, F., Havermans, R., Nicolson, N. A., DeVries, M. W., Delespaul, P., et al. (2003). Emotional reactivity to daily life stress in psychosis and affective disorder: an experience sampling study. Acta Psychiatr Scand, 107(2), 124-131.

Myin-Germeys, I., van Os, J., Schwartz, J. E., Stone, A. A., \& Delespaul, P. A. (2001). Emotional reactivity to daily life stress in psychosis. Arch Gen Psychiatry, 58(12), 1137-1144.

Norman, R. M., \& Malla, A. K. (1991). Subjective stress in schizophrenic patients. Soc Psychiatry Psychiatr Epidemiol, 26(5), 212-216.

Pagano, M. E., Skodol, A. E., Stout, R. L., Shea, M. T., Yen, S., Grilo, C. M., et al. (2004). Stressful life events as predictors of functioning: findings from the collaborative longitudinal personality disorders study. Acta Psychiatr Scand, 110(6), 421-429.

Paris, J. (2005). Borderline personality disorder. Cmaj, 172(12), 1579-1583.

Paris, J., Gunderson, J., \& Weinberg, I. (2007). The interface between borderline personality disorder and bipolar spectrum disorders. Compr Psychiatry, 48(2), 145-154.

Peeters, F., Nicolson, N. A., Berkhof, J., Delespaul, P., \& deVries, M. (2003). Effects of daily events on mood states in major depressive disorder. J Abnorm Psychol, 112(2), 203-211.

Perry, J. C., Lavori, P. W., Pagano, C. J., Hoke, L., \& O’Conell, M. E. (1992). Life events and recurrent depression in borderline and antisocial personality disorders. Journal of Personality Disorders, 6, 394-407.

Pompili, M., Girardi, P., Ruberto, A., \& Tatarelli, R. (2005). Suicide in borderline personality disorder: a meta-analysis. Nord J Psychiatry, 59(5), 319-324.

Samuels, J., Eaton, W. W., Bienvenu, O. J., 3rd, Brown, C. H., Costa, P. T., Jr., \& Nestadt, G. (2002). Prevalence and correlates of personality disorders in a community sample. Br J Psychiatry, 180, 536-542.

Schwartz, J. E., \& Stone, A. A. (1998). Strategies for analyzing ecological momentary assessment data. Health Psychol, 17(1), 6-16.

Sinha, B. K., \& Watson, D. C. (1997). Psychosocial predictors of personality disorder traits in a non-clinical sample. Personality and Individual Differences, 22, 527-537.

Statacorp. (2004). Stata Statistical Software: Release 8.0. STATA: College Station; TX.

Stein, K. F. (1996). Affect instability in adults with a borderline personality disorder. Arch Psychiatr Nurs, 10(1), 32-40.

Stiglmayr, C. E., Grathwol, T., Linehan, M. M., Ihorst, G., Fahrenberg, J., \& Bohus, M. (2005). Aversive tension in patients with borderline personality disorder: a computer-based controlled field study. Acta Psychiatr Scand, 111(5), 372-379.

Stone, A. A., Shiffman, S., Schwartz, J. E., Broderick, J. E., \& Hufford, M. R. (2002). Patient non-compliance with paper diaries. BMJ, 324(7347), 1193-1194.

Stone, A. A., Shiffman, S., Schwartz, J. E., Broderick, J. E., \& Hufford, M. R. (2003). Patient compliance with paper and electronic diaries. Control Clin Trials, 24(2), 182-199. 
Strauss, J. S. (1994). The person with schizophrenia as a person. II: Approaches to the subjective and complex. Br J Psychiatry Suppl(23), 103-107.

Tolpin, L. H., Gunthert, K. C., Cohen, L. H., \& O’Neill, S. C. (2004). Borderline personality features and instability of daily negative affect and self-esteem. J Pers, 72(1), 111-137.

Torgersen, S., Kringlen, E., \& Cramer, V. (2001). The prevalence of personality disorders in a community sample. Arch Gen Psychiatry, 58(6), 590-596.

Trull, T. J. (1995). Borderline personality disorder features in nonclinical young adults: 1 . Identification and validation. Psychological Assessment, 7, 33-41.

van Eck, M. M., Nicolson, N. A., Berkhof, H., \& Sulon, J. (1996). Individual differences in cortisol responses to a laboratory speech task and their relationship to responses to stressful daily events. Biol Psychol, 43(1), 69-84.

Ventura, J., Green, M. F., Shaner, A., \& Liberman, R. P. (1993). Training and quality assurance with the Brief Psychiatric Rating Scale: 'The Drift Busters'. International Journal of Methods in Psychiatric Research, 3, 221-244.

Zanarini, M. C., Frankenburg, F. R., Dubo, E. D., Sickel, A. E., Trikha, A., Levin, A., et al. (1998). Axis I comorbidity of borderline personality disorder. Am J Psychiatry, 155(12), 1733-1739.

Zanarini, M. C., Frankenburg, F. R., Hennen, J., Reich, D. B., \& Silk, K. R. (2004). Axis I comorbidity in patients with borderline personality disorder: 6-year follow-up and prediction of time to remission. Am J Psychiatry, 161(11), 2108-2114. 


\section{CHAPTER 3}

\section{Psychotic reactivity in borderline personality disorder}

Jean-Paul Glaser ${ }^{1}$, Jim van Os $^{1,2}$, Viviane Thewissen ${ }^{1,3}$, Inez Myin-Germeys ${ }^{1,4}$

${ }^{1}$ Department of Psychiatry and Neuropsychology, South Limburg Mental Health Research and Teaching Network, EURON, Maastricht University Medical Center, The Netherlands

${ }^{2}$ Division of Psychological Medicine, Institute of Psychiatry, London, UK

${ }^{3}$ Faculty of Psychology, Open University of the Netherlands, Heerlen, The Netherlands

${ }^{4}$ School of Psychological Sciences, University of Manchester, UK

Acta Psychiatrica Scandinavica: Published online 25 June 2009 


\section{Abstract}

Objective: To investigate the stress relatedness and paranoia specificity of psychosis in borderline personality disorder (BPD).

Method: Fifty-six borderline patients, 38 patients with cluster C personality disorder, 81 patients with psychotic disorder and 49 healthy controls were studied with the Experience Sampling Method (a structured diary technique) to assess: (1) appraised subjective stress, and (2) intensity of psychotic experiences.

Results: All patient groups experienced significantly more increases in psychotic experiences in relation to daily life stress than healthy controls, borderline patients displaying the strongest reactivity. Borderline patients, moreover, reported significantly more hallucinatory reactivity than healthy controls and subjects with cluster $\mathrm{C}$ personality disorder. Paranoid reactivity to daily life stress did not differ between the patient groups.

Conclusions: These results are the first to ecologically validate stress-related psychosis in borderline personality disorder. However, psychotic reactivity was not limited to expression of paranoia but involved a broader range of psychotic experiences including hallucinations.

Keywords: borderline personality disorder; psychotic disorders; stress; personality disorders; paranoid disorders 


\section{INTRODUCTION}

Since the introduction of DSM-IV, transient stress-related paranoid ideation or severe dissociative symptoms has been considered a core feature of borderline personality disorder (BPD) and has been added as the ninth criterion in the DSM-IV borderline personality disorder classification ("American Psychiatric Association. Diagnostic and Statistical Manual of Mental disorders, 4th edn, Text Revision (DSM-IV-TR); Skodol et al., 2002). However, despite many studies examining expression of psychosis in BPD (Chopra \& Beatson, 1986; Frosch, 1964; Jonas \& Pope, 1984; Miller, Abrams, Dulit, \& Fyer, 1993; Pope, Jonas, Hudson, Cohen, \& Tohen, 1985; Silk, Westen, Lohr, Benjamin, \& Gold, 1990; Zanarini, Gunderson, \& Frankenburg, 1990), the crucial aspects of stress-relatedness and paranoid specificity of psychosis in BPD have not been validated.

Recent studies applying momentary assessment technology have shown that psychotic symptoms related to axis I psychotic disorders are constantly fluctuating over the day, even within hours, and that such fluctuations may be driven by momentary experiences of stress (Myin-Germeys, Delespaul, \& van Os, 2005; Myin-Germeys, Marcelis, Krabbendam, Delespaul, \& van Os, 2005). In particular, the small common hassles that happen in the flow of daily life were found to be associated with intensity levels of psychosis in patients diagnosed with psychotic disorders (Myin-Germeys, Delespaul et al., 2005; MyinGermeys, Marcelis et al., 2005; Myin-Germeys \& van Os, 2007). While in BPD the focus has been primarily on interpersonal stress and major stressful life events that impact negatively on functioning (Jovev \& Jackson, 2006; Pagano et al., 2004; Tolpin, Gunthert, Cohen, \& O’Neill, 2004), it is attractive to hypothesize that, similar to psychotic disorder, small daily events also represent a powerful predictor of subjective distress (Jacobs, Myin-Germeys, Derom, Vlietinck, \& van Os, 2005; Jovev \& Jackson, 2006; Norman \& Malla, 1991; Wichers et al., 2007) and subsequent psychotic experiences in BPD (Myin-Germeys, Delespaul et al., 2005; Myin-Germeys, Marcelis et al., 2005; Myin-Germeys \& van Os, 2007). If stress-related, fluctuating psychotic experiences are not specific to psychotic disorder but are also evident in BPD, the question arises as to what degree the two disorders display any quantitative difference in such psychotic reactivity and - given the dimensionality of personality disorder constructs (Markon \& Krueger, 2005; McCrae \& John, 1992) - whether psychotic reactivity is predicted solely by the ninth DSM-IV BPD criterion or using the total number of borderline personality disorder criteria met. In addition, BPD 
is highly comorbid with other personality disorders (Grilo, Miguel Anez, \& McGlashan, 2002; Zanarini et al., 1998b). Therefore, stress-related psychosis may also reflect a broader vulnerability underlying personality disorders in general.

Although DSM-IV specifically refers to stress-related paranoid ideation in BPD classification, several studies have also reported hallucinatory experiences in BPD (George \& Soloff, 1986; Miller et al., 1993; Yee, Korner, McSwiggan, Meares, \& Stevenson, 2005). The occurrence of hallucinatory experiences in BPD may be hypothesized a priori given the fact that: i) data indicate high rates of childhood trauma in BPD (Fossati, Madeddu, \& Maffei, 1999) and ii) studies sugges that childhood trauma increases the risk for hallucinatory experiences in psychotic disorder, bipolar disorder and non-clinical populations (Hammersley et al., 2003; Janssen et al., 2004; Offen, Waller, \& Thomas, 2003; Read, Agar, Argyle, \& Aderhold, 2003; Read, van Os, Morrison, \& Ross, 2005; Shevlin, Dorahy, \& Adamson, 2007; Whitfield, Dube, Felitti, \& Anda, 2005). Therefore, research is needed in order to determine whether BPD is associated with stress-related psychotic experience in general, including hallucinations, or whether BPD is characterized specifically by paranoid reactivity.

The current study used a momentary assessment approach to investigate psychotic reactivity.

\section{Aims of the study}

To investigate: i) whether psychotic reactivity to stress in daily life is specific for borderline personality disorder; ii) whether greater psychotic reactivity in BPD was predicted in a dose-response fashion by a greater number of BPD criteria (BPD dimensionality) met and iii) whether borderline personality disorder is specifically associated with paranoid rather than with hallucinatory reactivity to stress.

\section{MATERIAL AND METHODS}

\section{Subjects}

\section{Sample}

The sample consisted of: i) subjects diagnosed with a borderline personality disorder (BPD), (ii) subjects with Cluster C personality disorder (CPD), (iii) subjects with psychotic disorder in an active state of psychosis (PSY) and (iv) 
healthy control subjects (CON). In addition, 17 subjects with subthreshold BPD ( 3 or 4 borderline criteria) were included (see the Statistical analysis section).

The BPD, PSY and some CPD were recruited through the in- (only PSY) and out-patient mental health facilities in the area of Southern Limburg in the Netherlands. BPD were mainly recruited from out-patient social psychiatry units. Referral to these units is generally being indicated for borderline patients who are resistant to or unable to comply with specific psychotherapy regimens. The majority of the CPD were recruited through advertising in local newspapers. Control subjects were recruited from the general population in the same area through a random mailing procedure. The patients with psychosis were collected as part of the Maastricht Psychosis Study (see Myin-Germeys et al., Psychological Medicine 2005 for a full description of this sample) and as part of the ZAPP study, a study investigating psychological mechanisms underlying current psychotic symptoms (see Thewissen et al. 2008 for a full description of this sample) (Thewissen, Bentall, Lecomte, van Os, \& Myin-Germeys, 2008). Control subjects were collected as part of the Maastricht Psychosis Study.

Written informed consent, conforming to the local ethics committee guidelines, was obtained from all subjects. Participants had to be between 18 and 55 years old with sufficient command of the Dutch language. Exclusion criteria were severe endocrine, cardiovascular or brain disease and severe alcohol or drug dependence.

For PSY, extensive screening with diagnostic interviews such as the Brief Psychiatric Rating Scale (BPRS) (Ventura, Green, Shaner, \& Liberman, 1993) and the Positive and Negative Syndrome Scale (PANSS) (Kay, Fiszbein, \& Opler, 1987) was used to map axis I psychiatric symptomatology. Interview data and clinical record data were used to complete the Operational Criteria Checklist for Psychotic Illness, yielding DSM-III-R diagnoses through the OPCRIT computer program (McGuffin, Farmer, \& Harvey, 1991). PSY were not allowed to have a comorbid borderline personality disorder. For the current study, PSY was defined based on a PANSS score of $>3$ on at least one of the PANSS Positive Symptom Scale.

The patients with personality disorders had to fulfill the formal DSM-IV criteria for borderline or cluster $\mathrm{C}$ personality disorder and were extensively screened with the structured clinical interview for DSM-IV axis I and II disorders, the SCID I and the SCID II (First, Gibbon, Spitzer, Williams, \& Benjamin, 1997; First, Spitzer, Gibbon, \& Williams, 2002; Groenestijn, Akkerhuis, Kupka, Schneider, \& Nolen, 1999; Weertman, Arntz, \& Kerkhofs, 2000). Subjects 
with cluster $\mathrm{C}$ personality disorder were only included in the current study when reporting no more than two borderline criteria. Further exclusion criteria for the personality disorder groups were bipolar disorder, schizophrenia and schizoaffective disorder.

The control group was selected on the basis of absence of a family or personal history of psychosis, or current use of psychotropic medication including benzodiazepines. Subjects were interviewed to complete the Brief Psychiatric Rating Scale (Ventura et al., 1993) and the Operational Criteria Checklist for Psychotic Illness, yielding DSM-III-R diagnoses through the OPCRIT computer program (McGuffin et al., 1991).

\section{Experience Sampling Method (ESM)}

The Experience Sampling Method (ESM) is a within-day momentary selfassessment technique. Previous applications of ESM have demonstrated the feasibility, validity and reliability of the method in general population samples and in samples of psychiatric patients (Glaser, van Os, Portegijs, \& MyinGermeys, 2006; Lataster et al., 2009; Myin-Germeys et al., 2003; MyinGermeys \& van Os, 2007; Peeters, Nicolson, Berkhof, Delespaul, \& deVries, 2003; Stein, 1996; M. van Eck, Berkhof, Nicolson, \& Sulon, 1996; M. M. van Eck, Nicolson, Berkhof, \& Sulon, 1996). Subjects were studied in their normal daily living environment. They received a digital wristwatch and a set of ESM self-assessment forms collated in a booklet for each day. Ten times a day on six consecutive days, the watch emitted a signal (beep) at unpredictable moments between 07:30 and 22.30 hours. After each 'beep' subjects were asked to stop their activity and fill out the ESM self-assessment forms previously handed out to them, collecting reports of perceptions, thoughts, mood, current context (activity, persons present, location) and appraisals of the current situation. All self-assessment items were rated on seven-point Likert scales. The ESM procedure was explained to the subjects during an initial briefing session and a practice form was completed to confirm that subjects were able to understand the seven-point Likert scale format. Subjects were asked to complete their reports immediately after the beep, thus minimizing memory distortions and to record the time at which they completed the form. In order to know whether the subjects had completed the form within 15 minutes of the beep, the time at which subjects indicated they completed the report was compared to the actual time of the beep. All reports completed more than 15 minutes after the signal were excluded from the analysis. Previous work has shown that reports completed after this interval are less reliable and consequently less valid (P. A. E. G. Dele- 
spaul, 1995). For the same reason, subjects with less than 20 valid reports were also excluded from the analysis (P. A. E. G. Delespaul, 1995).

\section{Psychotic reactivity to stress}

Psychotic reactivity to stress was previously conceptualized as the psychotic reactions to daily events and disturbances that continually happen in the flow of everyday life (Myin-Germeys, Delespaul et al., 2005; Myin-Germeys, Marcelis et al., 2005). Both the stress measures and the psychosis measure were derived from the experience sampling reports as described below.

\section{Stress assessments}

Stress was conceptualized as the subjectively appraised stressfulness of distinctive events that continually happen in the natural flow of daily life. Subjects were asked to report the most important event that happened between the current and the previous reports. This event was subsequently rated on a seven-point bipolar scale $(-3=$ very unpleasant, $0=$ neutral, $3=$ very pleasant). Responses were recoded to allow high scores to reflect stress $(-3=$ very pleasant, $0=$ neutral, 3 = very unpleasant).

\section{Psychosis assessment}

Psychosis was assessed with 8 pathology items rated on seven-point Likert scales (1-7, indicating "not at all" to "very"). To allow self-reported assessments, these 8 items included aspects of the mental state that subjects are aware of and that are directly associated with psychotic experiences such as delusions and hallucinations. The mean of the items "I feel suspicious", "My thoughts are difficult to express", "I can't get rid of my thoughts", "My thoughts are influenced by other people", "I feel unreal", "I hear voices", "I see things that others cannot see" and "I am afraid to do something uncontrolled" formed the variable psychosis. These items showed high internal consistency (Cronbach's $\alpha=0.86$ over the subject means) showing that they reflect one underlying construct. The use of these items to reflect psychotic psychopathology has been validated previously (MyinGermeys, Marcelis et al., 2005; Myin-Germeys \& van Os, 2007; Thewissen et al., 2008). Hallucinations were defined as the average of the items 'I see things that others cannot see' and 'I hear voices'. Previous studies have shown that patients can distinguish between hearing real voices and verbal hallucinations (P. Delespaul, deVries, \& van Os, 2002; P. A. E. G. Delespaul, 1995; Romme, Honig, Noorthoorn, \& Escher, 1992). Paranoid ideation consisted of the item 'I feel suspicious'. 


\section{Mood assessments}

Mood states were assessed with nine mood adjectives rated on seven-point Likert scales (1-7, indicating "not at all" to "very"). The mood adjectives 'down', 'guilty', 'insecure', 'lonely', and 'anxious' formed the negative affect (NA) scale (Cronbach's $\alpha=0.90$ over the subject mean values). The mood adjectives "happy," "cheerful," "relaxed," and "satisfied" formed the positive affect (PA) scale (Cronbach's $\alpha=0.97$ over the subject mean values).

\section{Statistical analysis}

Initial pairwise group comparisons were performed on the subjects' averages for the dependent and the independent variables using one-way analysis of variance with the Tukey multiple comparison procedure. In addition, multilevel linear random regression models were fitted. Multilevel or hierarchical linear modelling techniques are a variant of the more often used unilevel linear regression analyses and are ideally suited for the analysis of ESM data consisting of multiple observations in one person, i.e. at two levels (ESM beep level and subject level). As - in ESM - observations from the same subject are more similar than observations from different subjects, the residuals are not independent. Conventional regression techniques do not take into account the variance components at 2 different levels. Data were analyzed with the multilevel XTREG module in STATA (Statacorp, 2004). The B is the fixed regression coefficient of the predictor in the multilevel model and can be interpreted identically to the estimate in the conventional unilevel regression analysis.

\section{i) Does the association between stress and psychosis intensity vary with diagnostic} group?

In order to test the hypothesis that diagnostic group modified the association between stress and ESM psychosis intensity, multilevel linear regression models were fitted with the ESM standardized psychosis measure as the dependent variable (standardized psychosis= psychosis/S.D. of psychosis in the whole sample), and stress, group as well as their interactions as independent variables: Psychosis $=\beta 0+\beta 1$ group $+\beta 2$ stress $+\beta 3$ group $x$ stress. Group was defined as a four-level categorical variable with value labels $0=\mathrm{CON}, 1=\mathrm{CPD}, 2=\mathrm{PSY}$ and $3=\mathrm{BPD}$. According to Cohen, 0.8 S.D. can be considered a large effect size, and 0.2 S.D. a small effect size (Cohen, 1988). Estimation of the effect sizes of stress on psychosis for each group was calculated from the model with the interactions by calculating appropriate linear combinations using the STATA LINCOM routine. Main effects and interactions were assessed by Wald test. As it is 
known that BPD patients have high comorbidity of anxiety- and depressive disorders, mean level of NA and PA for each subject - indirect parameters of comorbidity that can also be measured in controls - was added as possible confounder in the analyses along with the variables gender and mean level of ESM daily life stress for each subject.

\section{ii) Is the association between stress and psychosis moderated by BPD dimensionality?}

In order to construct a variable expressing dimensionality of BPD, a sample was identified in which the number of borderline criteria measured with SCID II varied dimensionally. The first was the BPD group (5-9 criteria), the second was the CPD group (zero, one or two criteria) and the third constituted an additional group of 17 subjects with 3 or 4 borderline criteria (subthreshold $\mathrm{BPD})$. This latter group had been collected for this purpose over the course of the recruitment of the BPD sample and assessed in the same fashion as the BPD sample. In order to investigate whether psychotic reactions to stress were modified by greater number of borderline criteria, a model predicting psychosis was fitted with as covariates the number of BPD criteria, stress, as well as their interaction term in the subsample including these three groups.

\section{iii) Is BPD characterized by specific paranoid rather than hallucinatory reactivity?}

In order to test the hypothesis that diagnosis modified the association between stress on the one hand and the ESM psychosis variables hallucinations and paranoid ideation on the other, multilevel linear regression models were fitted with standardized hallucinations / paranoid ideation as the dependent variables, and stress, group as well as their interactions as independent variables.

\section{RESULTS}

Of the 50 control subjects who entered the study, one was excluded because of technical problems with the signaling device (see the Experience Sampling Method section). Of the 113 patients with psychotic disorder, 2 did not return the diary booklets and 30 patients were unable to comply with the research protocol (they had fewer than 20 valid reports and were therefore excluded from the analysis, see the Experience Sampling Method section). Six of 62 patients with BPD and five of the 43 subjects with cluster $\mathrm{C}$ personality disorder were excluded because they had fewer than 20 valid reports. 
The final sample thus consisted of 49 in the CON group, 81 in the PSY, 38 in the CPD group and 56 in the BPD group. 42 of 56 BPD fulfilled the ninth DSM-IV borderline personality disorder criterion, 21 of 38 CPD had one or two borderline personality disorder criteria of which 6 fulfilled the ninth DSMIV borderline personality disorder criterion. Demographic and clinical characteristics of the research sample are summarized in Table 1. The variable gender differed significantly between groups $\left[\chi^{2}(4)=55.22, p=0.00\right]$.

The number of valid reports and the mean scores of the independent and the dependent variables are shown in Table 2. PSY and BPD showed significantly more ESM psychosis than CPD and CON. PSY reported significantly more ESM hallucinatory experiences than the other three groups. PSY and BPD reported significantly more ESM paranoia than CON.

i) Does the association between stress and psychosis intensity vary with diagnostic group? The multilevel random regression analysis showed that - adjusted for sex and mean scores of ESM NA, PA and daily life stress for each subject - stress was significantly associated with ESM psychosis $(\beta=0.05$, (S.E. $=0.00)$, $\mathrm{p}<0.001)$. In addition, significant interaction effects between group and stress were found [unadjusted analysis: $\chi^{2}(4)=51.52, \mathrm{p}<0.001$, adjusted analysis: $\chi^{2}$ $(4)=50.16, p<0.001$, see Table 3], indicating that the impact of small daily stressors on psychosis intensity differed between the diagnostic groups. All three patient groups reacted significantly stronger with psychosis to stress than healthy control subjects. In addition, BPD reacted significantly stronger with psychosis to stress than PSY and CPD, whereas the latter two groups showed no significant differences in psychotic reactivity to daily life stress (Table 3). 
Table 1. Sociodemographic and clinical characteristics of the research sample.

\begin{tabular}{|c|c|c|c|c|}
\hline & $\begin{array}{l}\text { BPD } \\
(\mathrm{n}=56)\end{array}$ & $\begin{array}{l}\text { PSY } \\
(\mathrm{n}=81)\end{array}$ & $\begin{array}{l}\text { CPD } \\
(\mathrm{n}=38)\end{array}$ & $\begin{array}{l}\text { C } \\
(\mathrm{n}=49)\end{array}$ \\
\hline \multicolumn{5}{|c|}{ Sociodemographic and clinical variables } \\
\hline $\begin{array}{l}\text { Mean age (SD) } \\
\text { [range] (years) }\end{array}$ & $\begin{array}{l}36.9(8.8) \\
{[19-55]}\end{array}$ & $\begin{array}{l}35.8(10.7) \\
{[18-63]}\end{array}$ & $\begin{array}{l}39.3(12.0) \\
{[18-59]}\end{array}$ & $\begin{array}{l}35.2(8.8) \\
{[21-50]}\end{array}$ \\
\hline Male-female ratio & $8: 48$ & $63: 18$ & $15: 23$ & $24: 25$ \\
\hline \multicolumn{5}{|l|}{ Education, \% } \\
\hline Elementary school & 4 & 12 & 0 & 4 \\
\hline Secondary school & 76 & 78 & 62 & 67 \\
\hline Higher education & 20 & 10 & 38 & 29 \\
\hline \multicolumn{5}{|l|}{ Marital status, $\%$} \\
\hline Married or living together & 34 & 10 & 53 & 82 \\
\hline Divorced & 21 & 15 & 8 & 2 \\
\hline Never married & 41 & 74 & 37 & 16 \\
\hline Widow & 4 & 1 & 2 & \\
\hline \multicolumn{5}{|l|}{ Work situation, \% } \\
\hline Working & 14 & 3 & 37 & 77 \\
\hline Unemployed & 11 & 12 & 26 & 2 \\
\hline Unable to work & 63 & 75 & 24 & 0 \\
\hline Protected work & 2 & 6 & 0 & 0 \\
\hline School/education & 3 & 3 & 13 & 8 \\
\hline Household & 7 & 0 & 0 & 10 \\
\hline Otherwise & & 1 & & 3 \\
\hline \multicolumn{5}{|l|}{ Medication, \% } \\
\hline Antipsychotics & 34 & 85 & 0 & 0 \\
\hline Antidepressants & 45 & 21 & 34 & 0 \\
\hline Benzodiazepines & 32 & 42 & 8 & 0 \\
\hline Mood stabilizers & 7 & 6 & 0 & 0 \\
\hline
\end{tabular}


Table 2. Mean (S.D.) and F test statistics of the number of valid reports and the independent and dependent variables.

\begin{tabular}{|c|c|c|c|c|c|c|c|c|}
\hline & $\begin{array}{l}\text { BPD } \\
(\mathrm{n}=56)\end{array}$ & $\begin{array}{l}\text { PSY } \\
(\mathrm{n}=81)\end{array}$ & $\begin{array}{l}\text { CPD } \\
(\mathrm{n}=38)\end{array}$ & $\begin{array}{l}\mathrm{CON} \\
(\mathrm{n}=49\end{array}$ & $\begin{array}{l}\text { Total } \\
(\mathrm{n}=224)\end{array}$ & $F_{3,223}$ & p-value & Tukey HSD comparison \\
\hline $\begin{array}{l}\text { Valid } \\
\text { reports }\end{array}$ & $42(8.9)$ & $39(10.3)$ & $44(9.1)$ & $51(5.5)$ & $43(9.9)$ & 18.97 & $<0.001$ & $\begin{array}{l}\mathrm{BPD}, \mathrm{PSY}, \mathrm{CPD}<\mathrm{CON} \\
\mathrm{PSY}<\mathrm{CPD}\end{array}$ \\
\hline Stress & $-0.9(0.8)$ & $-1.3(1.0)$ & $-1.1(0.8)$ & $-1.7(0.7)$ & $-1.2(0.9)$ & 7.29 & $<0.001$ & $\begin{array}{l}\mathrm{CPD}, \mathrm{BPD}>\mathrm{CON} \\
\mathrm{BPD}>\mathrm{PSY}\end{array}$ \\
\hline NA & $2.7(1.2)$ & $2.1(1.0)$ & $2.4(1.0)$ & $1.2(0.3)$ & $2.1(1.1)$ & 24.54 & $<0.001$ & $\begin{array}{l}\text { PSY, CPD, BPD>CON } \\
\text { BPD>PSY }\end{array}$ \\
\hline PA & $3.7(1.1)$ & $4.3(1.1)$ & $4.2(1.1)$ & $5.5(0.8)$ & $4.4(1.2)$ & 27.96 & $<0.001$ & $\begin{array}{l}\mathrm{BPD}, \mathrm{PSY}, \mathrm{CPD}<\mathrm{CON} \\
\mathrm{BPD}<\mathrm{PSY}\end{array}$ \\
\hline Psychosis & $1.9(1.0)$ & $2.1(0.9)$ & $1.5(0.5)$ & $1.1(0.2)$ & $1.7(0.9)$ & 19.14 & $<0.001$ & PSY, BPD>CON, CPD \\
\hline $\begin{array}{l}\text { Halluci- } \\
\text { nations }\end{array}$ & $1.3(1.0)$ & $1.8(1.2)$ & $1.0(0.0)$ & $1.0(0.1)$ & $1.4(0.9)$ & 11.24 & $<0.001$ & $\mathrm{PSY}>\mathrm{BPD}, \mathrm{CPD}, \mathrm{CON}$ \\
\hline $\begin{array}{l}\text { Suspicious- } \\
\text { ness }\end{array}$ & $-1.8(1.1)$ & $2.1(1.4)$ & $1.4(0.7)$ & $1.1(0.1)$ & $1.7(1.1)$ & 11.16 & $<0.001$ & $\begin{array}{l}\mathrm{PSY}, \mathrm{BPD}>\mathrm{CON} \\
\mathrm{PSY}>\mathrm{CPD}\end{array}$ \\
\hline
\end{tabular}

S.D., Standard deviation; HSD, honestly significantly different.

Table 3. The effect of stress on ESM psychosis by group; unadjusted and adjusted for sex and mean score of negative affect, positive affect and daily life stress for each subject.

\begin{tabular}{|c|c|c|c|c|}
\hline \multirow[b]{3}{*}{ Group } & \multicolumn{4}{|l|}{ ESM psychosis } \\
\hline & \multicolumn{2}{|c|}{ ESM stress, unadjusted analysis } & \multicolumn{2}{|c|}{ ESM stress, adjusted analysis } \\
\hline & \multicolumn{2}{|l|}{$\beta^{a}(95 \%$ CI; p) } & \multicolumn{2}{|l|}{$\beta^{a}(95 \% \mathrm{CI} ; \mathrm{p})$} \\
\hline$\overline{\mathrm{CON}}$ & $\beta=0.01(-0.005-0.02)$ & $\mathrm{p}=0.20$ & $\beta=0.01(-0.004-0.02)$; & $\mathrm{p}=0.17$ \\
\hline CPD & $\beta=0.05(0.04-0.07)$ & $\mathrm{p}<0.001$ & $\beta=0.05(0.04-0.07)$ & $\mathrm{p}<0.001$ \\
\hline PSY & $\beta=0.04(0.03-0.06)$; & $\mathrm{p}<0.001$ & $\beta=0.04(0.03-0.06)$ & $\mathrm{p}<0.001$ \\
\hline BPS & $\beta=0.08(0.07-0.09)$; & $\mathrm{p}<0.001$ & $\beta=0.08$ (0.07-0.09); & $\mathrm{p}<0.001$ \\
\hline Interaction & \multicolumn{2}{|c|}{$\chi^{2}(4)=51.52$, Prob $>\chi^{2}=0.000$} & \multicolumn{2}{|c|}{$\chi^{2}(4)=50.16$, Prob $>\chi^{2}=0.000$} \\
\hline
\end{tabular}

CON, healthy control subjects $(\mathrm{n}=49)$; CPD, patients with cluster $\mathrm{C}$ personality disorder $(\mathrm{n}=38)$; PSY, patients with psychotic disorder $(\mathrm{n}=81)$; BPD, patients with borderline personality disorder $(\mathrm{n}=56)$. CI, Confidence interval. 
ii) Is the association between stress and psychosis moderated by BPD dimensionality? Using the subsample of the three groups in which BPD was expressed dimensionally as the continuous number of BPD criteria as described above, a significant interaction between stress and number of BPD criteria was apparent in the unadjusted analysis and in the analysis adjusted for sex, mean score per person of NA, PA, daily life stress, and the ninth DSM-IV borderline personality disorder criterion (unadjusted: $\beta=0.01$, (S.E. 0.00), $p=0.004$, adjusted: $\beta=0.01$, (S.E. 0.00), $\mathrm{p}=0.003$ ). In order to investigate dose-response associations, the sample distribution of number of BPD criteria was divided by its tertiles creating tertile groups (tertile group 1: the 30th percent lowest scores on borderline criteria; tertile group 2: the 30th percent middle scores on borderline criteria; and tertile group 3: the 30th percent highest scores). Using this variable, a doseresponse relationship was apparent that remained unaffected after adjusting for sex, mean score per person of NA, PA, daily life stress, and the ninth DSM-IV borderline personality disorder criterion (unadjusted: $\beta=0.02$, S.E. (0.01), $p=0.007$, adjusted: $\beta=0.02$, S.E. (0.01), $p=0.005)$.

\section{iii) Is BPD characterized by specific paranoid rather than hallucinatory reactivity?}

The multilevel random regression analysis in the combined sample showed that - adjusted for sex and mean scores of ESM NA, PA and daily life stress for each subject - stress was significantly associated with both hallucinations $(\beta=0.01$, $($ S.E. $=0.00), p<0.001)$ and with paranoia $(\beta=0.05$ (S.E $=0.00, p<0.001)$. For hallucinations, significant interaction effects between group and stress were found [unadjusted analysis: $\chi^{2}(4)=13.90, p=0.003$, adjusted analysis: $\chi^{2}$ $(4)=13.78, p=0.003$, see Fig 1$]$. Thus, hallucinatory reactivity to daily life stress was most intense in BPD and significantly higher than in CON and CPD. However, no significant difference with PSY was apparent (Fig 1). Similarly, for paranoia, significant interaction effects were found between group and stress [unadjusted analysis: $\chi^{2}(4)=30.50, p<0.001$, adjusted analysis: $\chi^{2}(4)=28.90$, $\mathrm{p}<0.001]$. Paranoia was significantly more reactive to daily life stress in BPD, PSY and CPD compared to CON (Fig 2). 


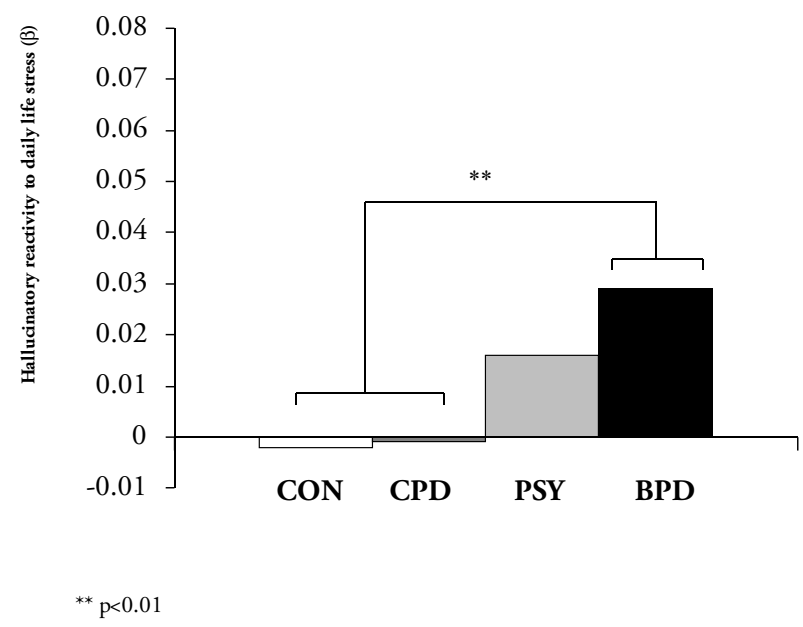

Figure 1: Hallucinatory reactivity to daily life stress, effect size by diagnosis, adjusted for sex and mean score of NA, PA and daily life stress for each subject.

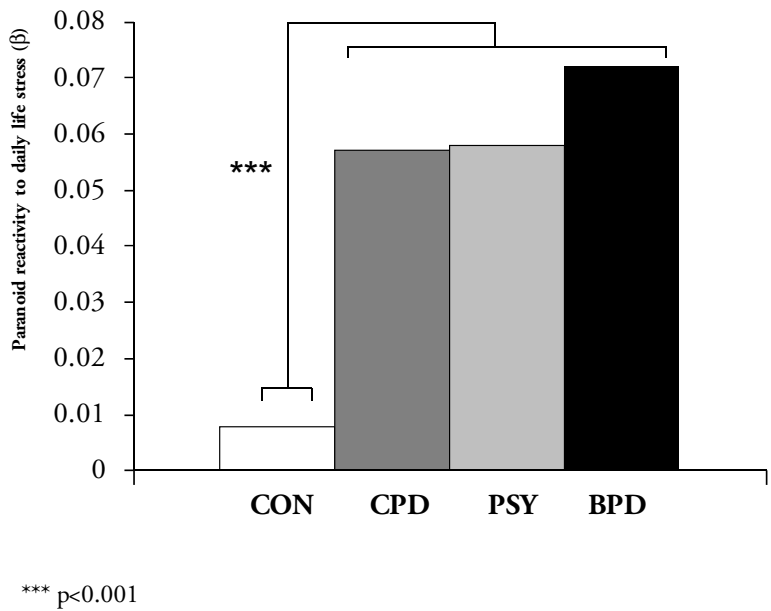

Figure 2: Paranoid reactivity to daily life stress, effect size by diagnosis, adjusted for sex and mean score of NA, PA and daily life stress for each subject. 


\section{DISCUSSION}

The current study showed that BPD is characterized by the strongest psychotic reaction to daily hassles and minor stresses that continually happen in the flow of everyday life. Subjects with BPD not only were significantly more psychotically reactive to daily life stress than healthy controls, they also reacted with a larger increase in psychosis intensity than subjects with cluster $C$ personality disorder and subjects with psychotic disorder, the latter group being defined on the basis of overt and severe psychotic symptomatology. Although the effect sizes were small, they were not negligible, especially as we assessed frequently occurring exposures in daily life, the cumulative effects of which may be considerable.

\section{Transient stress-related psychosis in BPD}

Although several studies have addressed psychosis and stress in BPD (Chopra \& Beatson, 1986; Jonas \& Pope, 1984; Miller et al., 1993; Pope et al., 1985; Zanarini et al., 1990), no study to date has assessed psychotic reactivity do daily life stress using a momentary design. After Stiglmayr et al.'s (Stiglmayr et al., 2008) validation of the stress related dissociation part of the ninth DSM-IV borderline personality disorder criterion, the current study is the first to ecologically validate the stress-related paranoid ideation part of the ninth criterion by investigating psychotic reactivity to daily life stress in a clinical sample of borderline patients using a momentary design. The current study shows that the class of common, daily hassles is a powerful predictor of psychotic experiences in patients with BPD, similar to what was found in psychotic disorder (MyinGermeys \& van Os, 2007). In addition, this study revealed that enhanced psychotic reactivity to daily life stress is most specific for BPD compared with patients with psychotic disorder and patients with cluster $\mathrm{C}$ personality disorder, thus generating scientific support for the incorporation of the criterion stressrelated psychosis for the purpose of BPD classification. This was further supported by the dose-response association between number of borderline criteria and psychotic reactivity (see the Results section).

Symptom specificity: is it paranoia, hallucinations or psychosis in general?

The data showed that patients in the BPD group were most strongly reactive to stress compared with the other groups in all symptoms of psychosis, including paranoia, hallucinations and psychosis in general. The difference between the borderline patients and the psychotic disorder patients, however, only reached 
statistical significance for psychosis in general. Hallucinations were probably not added to the definition of BPD because overall, hallucinations are less reactive to stress compared with paranoia (see difference between Figs. 1 and 2). Interestingly, however, when compared with cluster $\mathrm{C}$ personality disorder, subjects with BPD report more hallucinations in response to stress, whereas no difference was found for paranoid reactivity.

\section{Is psychosis in psychotic disorder different from psychosis in BPD?}

The current study found that patients with BPD reported as much ESM psychosis as patients with PSY, a diagnostic category defined on the basis of overt and severe psychotic symptomatology (Table 2). In addition, the psychotic experiences were most stress reactive in BPD, although patients with psychotic disorder and even cluster $\mathrm{C}$ personality disorder patients also showed some contextual reactivity (Table 3). Previous research has shown that contextual reactivity in psychotic disorder may be the result of a sensitization process (Collip, Myin-Germeys, \& Van Os, 2008), in which cumulative exposure to major life events or traumatic experiences during childhood may increase emotional and psychotic reactivity to daily life stress (Glaser et al., 2006; Lataster et al., 2006; Read, Perry, Moskowitz, \& Connolly, 2001). It is well known that patients with BPD show enhanced exposure to traumatic experiences, both during childhood (Fossati et al., 1999) and later on (Zanarini et al., 1999). Noteworthy in this regard are studies that found childhood adversity to be a risk factor for hallucinatory experiences (Gracie et al., 2007; Hammersley et al., 2003; Offen et al., 2003; Read et al., 2003; Shevlin et al., 2007; Whitfield et al., 2005). One could thus hypothesize that stress-related psychosis in BPD may result from a sensitization process associated with severe early-life exposures (Larkin \& Read, 2008; Read et al., 2001). Given the absence of a clear overlap in genetic vulnerability between BPD and psychotic disorder (Loranger, Oldham, \& Tulis, 1982; Torgersen, 1984), it is attractive to additionally hypothesize that psychotic experiences in BPD may result from a sensitization process in subjects without genetic risk for psychotic disorder.

\section{Confounding}

It has been shown that women are more emotionally reactive to daily life stress than men (Myin-Germeys, Krabbendam, Delespaul, \& van Os, 2004). Although gender differed significantly between groups, controlling for sex did not substantially change the relationship between group and psychotic reactivity to daily life stress (Table 3). 
In line with the literature, the borderline group showed large comorbidity of depressive and anxiety disorders (Fyer, Frances, Sullivan, Hurt, \& Clarkin, 1988; Zanarini et al., 1998a; Zanarini, Frankenburg, Hennen, Reich, \& Silk, 2004). Seventy-one percent ( 40 of 56 subjects) of the BPD and sixty-three percent of the CPD (24 of 38 subjects) expressed a current anxiety or mood disorder. Since anxiety and depressive disorders are highly prevalent in both groups, it is unlikely that the findings of increased psychotic reactivity in BPD are entirely due to the presence of anxiety or depressive disorder in this sample. Furthermore, previous research of our group has shown that subjects with unipolar affective disorder or bipolar affective disorder are less emotionally reactive to daily life stress compared to patients with psychotic disorder (Myin-Germeys et al., 2003). Finally, controlling for the mean of the total scores of NA and PA per person, as an indirect parameter of comorbidity that can also be measured in controls, revealed no alteration in the significance of the relationship between group and psychotic reactivity to daily life stress (see the Results section). Selecting a sample without comorbidity might decrease these problems of confounding. However, since very high axis I comorbidity rates are found in BPD, this would question the validity of the selected sample (Fyer et al., 1988; Zanarini et al., 1998a; Zanarini et al., 2004).

A substantial part of the BPD (34\%) used antipsychotic medication which probably reflects the severity of the BPD group that was mainly recruited from out-patient social psychiatry departments. Referral to out-patient social psychiatry departments mostly occurs when borderline personality disorder patients are resistant to specific psychotherapy approaches or when they are to vulnerable to comply with the psychotherapy regimen. The effects of our study may therefore be less pronounced in borderline personality disorder of less severity and may thus not be generalized to bordeline personality disorder of all severity. It should be noted, however, that in recent years modern antipsychotic drugs may be more easily prescribed due to milder side effect profiles and multiple offlabel indications such as mood stabilisation, sleep or sedation, or antidepressant effects (Kapoor, 2009). A recent study by Reisch et al. (Reisch, Ebner-Priemer, Tschacher, Bohus, \& Linehan, 2008) revealed a antipsychotic medication use of $26 \%$ in their BPD group.

Finally, it could be argued that higher stress reactivity measures in borderline patients results from higher daily life stress appraisals in this group (Table 2). However, after controlling for mean stress levels, the results remained the same. 


\section{Methodological issues}

The following methodological issues should be taken into account. First, the data are based on subjective reports. Although subjective reports are considered less reliable (e.g. do all subjects interpret or answer the questions identically?), they can be valid, whereas the validity of objective approaches cannot be taken for granted (Strauss, 1994). Second, the present study was a cross-sectional study, which makes it impossible to establish causal relationships. Therefore it is impossible to determine whether stress measures influenced psychosis or psychosis influenced the subjective appraisal of stress. However either explanation has clinical relevance. Third, the current study used ESM, a daily life assessment technique in which subjects have to comply with a paper-and-pencil diary protocol without the researcher being present. Recently, some authors have put doubt on the reliability and subject compliance in paper-and-pencil ESM studies, favoring the use of electronic devices (Stone, Shiffman, Schwartz, Broderick, \& Hufford, 2002, 2003). However, in a comparative study, Green et al. concluded that both methods yielded similar results (Green, Rafaeli, Bolger, Shrout, \& Reis, 2006). In addition, a recent study of our group using a signalcontingent random-time sampling procedure with multiple observations per day - such as the protocol used in the current study - also found evidence underscoring the validity of the

paper-and-pencil random-time self-report data in the current study (Jacobs, Nicolson et al., 2005). Fourth, it can be argued that stronger emotional reactivity to daily life stress in subjects with BPD might result directly from the intrusiveness of the ESM. Borderline subjects, however, only reported significantly more distress related to the ESM than healthy controls. Controlling for the ESM item "How much did this beep disturb you?" did not substantially change the results of the current study.

Fifth, one might argue that some of the ESM psychosis items such as "I can't get rid of my thoughts", "I am afraid to do something uncontrolled" or "I feel unreal", may not reflect psychosis but rather pertain to obsessive or dissociative disorders. However, the high internal consistency showed that they reflect one underlying dimension (Myin-Germeys, Delespaul et al., 2005). Furthermore, patients with psychosis scored higher not only on psychosis but also on these individual items compared with borderline patients and excluding these items from the (general) psychosis variable did not substantially change the results of the current study. 


\section{Conclusion}

This study is the first to investigate stress-related paranoid ideation in DSM-IVdefined BPD using momentary assessment technology. Subjects with BPD appeared most psychotically reactive to the effects of daily life stress, compared with healthy control subjects, subjects with psychotic disorder and subjects with cluster C personality disorder. Although DSM-IV specifically refers to transient stress-related paranoid ideation, the current study found psychosis in general and hallucinatory reactivity to be more specific for BPD. With regard to the development of DSM-V, stress-related psychosis may better define the stress-related reality-disturbances in BPD than the current DSM-IV criterion transient stressrelated paranoid ideation. 


\section{REFERENCES}

American Psychiatric Association (2000). Diagnostic and Statistical Manual of Mental disorders, 4th edn, Text Revision (DSM-IV-TR). Washington, DC.

Chopra, H. D., \& Beatson, J. A. (1986). Psychotic symptoms in borderline personality disorder. Am J Psychiatry, 143(12), 1605-1607.

Cohen, J. (1988). Statistical power analysis for the behavioral sciences (2nd edn. ed.). Hillsdale, NY: Lawrence Earlbaum Associates.

Collip, D., Myin-Germeys, I., \& Van Os, J. (2008). Does the concept of "sensitization” provide a plausible mechanism for the putative link between the environment and schizophrenia? Schizophr Bull, 34(2), 220-225.

Delespaul, P., deVries, M., \& van Os, J. (2002). Determinants of occurrence and recovery from hallucinations in daily life. Soc Psychiatry Psychiatr Epidemiol, 37(3), 97-104.

Delespaul, P. A. E. G. (1995). Assessing Schizophrenia in Daily Life. Universitaire Pers Maastricht: Maastricht.

First, M. B., Gibbon, M., Spitzer, R. L., Williams, J. B. W., \& Benjamin, L. S. (1997). User's Guide for the Structured Clinical Interview for DSM-IV Axis II personality disorders (SCID-II). Washington, DC: American Psychiatric Press.

First, M. B., Spitzer, R. L., Gibbon, M., \& Williams, J. B. W. (2002). Structured Clinical Interview for DSM-IV Axis I Disorders-Patient Edition (SCID-I/P), 11-2002 revision. New York: Biometrics Research Department, New York State Psychiatric Institute.

Fossati, A., Madeddu, F., \& Maffei, C. (1999). Borderline Personality Disorder and childhood sexual abuse: a meta-analytic study. J Personal Disord, 13(3), 268-280.

Frosch, J. (1964). The Psychotic Character: Clinical Psychiatric Considerations. Psychiatr Q, 38, 81-96.

Fyer, M. R., Frances, A. J., Sullivan, T., Hurt, S. W., \& Clarkin, J. (1988). Comorbidity of borderline personality disorder. Arch Gen Psychiatry, 45(4), 348-352.

George, A., \& Soloff, P. H. (1986). Schizotypal symptoms in patients with borderline personality disorders. Am J Psychiatry, 143(2), 212-215.

Glaser, J. P., van Os, J., Portegijs, P. J., \& Myin-Germeys, I. (2006). Childhood trauma and emotional reactivity to daily life stress in adult frequent attenders of general practitioners. $J$ Psychosom Res, 61(2), 229-236.

Gracie, A., Freeman, D., Green, S., Garety, P. A., Kuipers, E., Hardy, A., et al. (2007). The association between traumatic experience, paranoia and hallucinations: a test of the predictions of psychological models. Acta Psychiatr Scand, 116(4), 280-289.

Green, A. S., Rafaeli, E., Bolger, N., Shrout, P. E., \& Reis, H. T. (2006). Paper or plastic? Data equivalence in paper and electronic diaries. Psychol Methods, 11(1), 87-105.

Grilo, C. M., Miguel Anez, L., \& McGlashan, T. H. (2002). DSM-IV axis II comorbidity with borderline personality disorder in monolingual Hispanic psychiatric outpatients. $J$ Nerv Ment Dis, 190(5), 324-330.

Groenestijn, M. A. C., Akkerhuis, G. W., Kupka, R. W., Schneider, N., \& Nolen, W. A. (1999). Structured Clinical Interview for DSM IV Axis I Disorders. Lisse, the Netherlands: Swets \& Zeitlinger BV. 
Hammersley, P., Dias, A., Todd, G., Bowen-Jones, K., Reilly, B., \& Bentall, R. P. (2003). Childhood trauma and hallucinations in bipolar affective disorder: preliminary investigation. Br J Psychiatry, 182, 543-547.

Jacobs, N., Myin-Germeys, I., Derom, C., Vlietinck, R., \& van Os, J. (2005). Deconstructing the familiality of the emotive component of psychotic experiences in the general population. Acta Psychiatr Scand, 112(5), 394-401.

Jacobs, N., Nicolson, N. A., Derom, C., Delespaul, P., van Os, J., \& Myin-Germeys, I. (2005). Electronic monitoring of salivary cortisol sampling compliance in daily life. Life Sci, 76(21), 2431-2443.

Janssen, I., Krabbendam, L., Bak, M., Hanssen, M., Vollebergh, W., de Graaf, R., et al. (2004). Childhood abuse as a risk factor for psychotic experiences. Acta Psychiatr Scand, 109(1), 3845.

Jonas, J. M., \& Pope, H. G. (1984). Psychosis in borderline personality disorder. Psychiatr Dev, 2(4), 295-308.

Jovev, M., \& Jackson, H. J. (2006). The relationship of borderline personality disorder, life events and functioning in an Australian psychiatric sample. J Personal Disord, 20(3), 205217.

Kapoor, S. (2009). Management of borderline personality disorder: emerging, new pharmacological and non-pharmacological strategies. Acta Psychiatr Scand, 119(1), 85-86; author reply 86.

Kay, S. R., Fiszbein, A., \& Opler, L. A. (1987). The positive and negative syndrome scale (PANSS) for schizophrenia. Schizophr Bull, 13(2), 261-276.

Larkin, W., \& Read, J. (2008). Childhood trauma and psychosis: Evidence, pathways, and implications. J Postgrad Med, 54(4), 287-293.

Lataster, T., van Os, J., Drukker, M., Henquet, C., Feron, F., Gunther, N., et al. (2006). Childhood victimisation and developmental expression of non-clinical delusional ideation and hallucinatory experiences: victimisation and non-clinical psychotic experiences. Soc Psychiatry Psychiatr Epidemiol, 41(6), 423-428.

Lataster, T., Wichers, M., Jacobs, N., Mengelers, R., Derom, C., Thiery, E., et al. (2009). Does reactivity to stress cosegregate with subclinical psychosis? A general population twin study. Acta Psychiatr Scand, 119(1), 45-53.

Loranger, A. W., Oldham, J. M., \& Tulis, E. H. (1982). Familial transmission of DSM-III borderline personality disorder. Arch Gen Psychiatry, 39(7), 795-799.

Markon, K. E., \& Krueger, R. F. (2005). Categorical and continuous models of liability to externalizing disorders: a direct comparison in NESARC. Arch Gen Psychiatry, 62(12), 13521359 .

McCrae, R. R., \& John, O. P. (1992). An introduction to the five-factor model and its applications. J Pers, 60(2), 175-215.

McGuffin, P., Farmer, A., \& Harvey, I. (1991). A polydiagnostic application of operational criteria in studies of psychotic illness. Development and reliability of the OPCRIT system. Arch Gen Psychiatry, 48(8), 764-770.

Miller, F. T., Abrams, T., Dulit, R., \& Fyer, M. (1993). Psychotic symptoms in patients with borderline personality disorder and concurrent axis I disorder. Hosp Community Psychiatry, 44(1), 59-61. 
Myin-Germeys, I., Delespaul, P., \& van Os, J. (2005). Behavioural sensitization to daily life stress in psychosis. Psychol Med, 35(5), 733-741.

Myin-Germeys, I., Krabbendam, L., Delespaul, P. A., \& van Os, J. (2004). Sex differences in emotional reactivity to daily life stress in psychosis. J Clin Psychiatry, 65(6), 805-809.

Myin-Germeys, I., Marcelis, M., Krabbendam, L., Delespaul, P., \& van Os, J. (2005). Subtle fluctuations in psychotic phenomena as functional states of abnormal dopamine reactivity in individuals at risk. Biol Psychiatry, 58(2), 105-110.

Myin-Germeys, I., Peeters, F., Havermans, R., Nicolson, N. A., DeVries, M. W., Delespaul, P., et al. (2003). Emotional reactivity to daily life stress in psychosis and affective disorder: an experience sampling study. Acta Psychiatr Scand, 107(2), 124-131.

Myin-Germeys, I., \& van Os, J. (2007). Stress-reactivity in psychosis: evidence for an affective pathway to psychosis. Clin Psychol Rev, 27(4), 409-424.

Norman, R. M., \& Malla, A. K. (1991). Subjective stress in schizophrenic patients. Soc Psychiatry Psychiatr Epidemiol, 26(5), 212-216.

Offen, L., Waller, G., \& Thomas, G. (2003). Is reported childhood sexual abuse associated with the psychopathological characteristics of patients who experience auditory hallucinations? Child Abuse Negl, 27(8), 919-927.

Pagano, M. E., Skodol, A. E., Stout, R. L., Shea, M. T., Yen, S., Grilo, C. M., et al. (2004). Stressful life events as predictors of functioning: findings from the collaborative longitudinal personality disorders study. Acta Psychiatr Scand, 110(6), 421-429.

Peeters, F., Nicolson, N. A., Berkhof, J., Delespaul, P., \& deVries, M. (2003). Effects of daily events on mood states in major depressive disorder. J Abnorm Psychol, 112(2), 203-211.

Pope, H. G., Jr., Jonas, J. M., Hudson, J. I., Cohen, B. M., \& Tohen, M. (1985). An empirical study of psychosis in borderline personality disorder. Am J Psychiatry, 142(11), 1285-1290.

Read, J., Agar, K., Argyle, N., \& Aderhold, V. (2003). Sexual and physical abuse during childhood and adulthood as predictors of hallucinations, delusions and thought disorder. Psychol Psychother, 76(Pt 1), 1-22.

Read, J., Perry, B. D., Moskowitz, A., \& Connolly, J. (2001). The contribution of early traumatic events to schizophrenia in some patients: a traumagenic neurodevelopmental model. Psychiatry, 64(4), 319-345.

Read, J., van Os, J., Morrison, A. P., \& Ross, C. A. (2005). Childhood trauma, psychosis and schizophrenia: a literature review with theoretical and clinical implications. Acta Psychiatr Scand, 112(5), 330-350.

Reisch, T., Ebner-Priemer, U. W., Tschacher, W., Bohus, M., \& Linehan, M. M. (2008). Sequences of emotions in patients with borderline personality disorder. Acta Psychiatr Scand, $118(1), 42-48$.

Romme, M. A., Honig, A., Noorthoorn, E. O., \& Escher, A. D. (1992). Coping with hearing voices: an emancipatory approach. Br J Psychiatry, 161, 99-103.

Shevlin, M., Dorahy, M., \& Adamson, G. (2007). Childhood traumas and hallucinations: an analysis of the National Comorbidity Survey. J Psychiatr Res, 41(3-4), 222-228.

Silk, K. R., Westen, D., Lohr, N. E., Benjamin, J., \& Gold, L. (1990). DSM-III and DSM-III-R schizotypal symptoms in borderline personality disorder. Compr Psychiatry, 31(2), 103-110. 
Skodol, A. E., Gunderson, J. G., Pfohl, B., Widiger, T. A., Livesley, W. J., \& Siever, L. J. (2002). The borderline diagnosis I: psychopathology, comorbidity, and personality structure. Biol Psychiatry, 51(12), 936-950.

Statacorp. (2004). Stata Statistical Software: Release 8.0. STATA: College Station; TX.

Stein, K. F. (1996). Affect instability in adults with a borderline personality disorder. Arch Psychiatr Nurs, 10(1), 32-40.

Stiglmayr, C. E., Ebner-Priemer, U. W., Bretz, J., Behm, R., Mohse, M., Lammers, C. H., et al. (2008). Dissociative symptoms are positively related to stress in borderline personality disorder. Acta Psychiatr Scand, 117(2), 139-147.

Stone, A. A., Shiffman, S., Schwartz, J. E., Broderick, J. E., \& Hufford, M. R. (2002). Patient non-compliance with paper diaries. Bmj, 324(7347), 1193-1194.

Stone, A. A., Shiffman, S., Schwartz, J. E., Broderick, J. E., \& Hufford, M. R. (2003). Patient compliance with paper and electronic diaries. Control Clin Trials, 24(2), 182-199.

Strauss, J. S. (1994). The person with schizophrenia as a person. II: Approaches to the subjective and complex. BrJ Psychiatry Suppl(23), 103-107.

Thewissen, V., Bentall, R. P., Lecomte, T., van Os, J., \& Myin-Germeys, I. (2008). Fluctuations in self-esteem and paranoia in the context of daily life. J Abnorm Psychol, 117(1), 143-153.

Tolpin, L. H., Gunthert, K. C., Cohen, L. H., \& O’Neill, S. C. (2004). Borderline personality features and instability of daily negative affect and self-esteem. J Pers, 72(1), 111-137.

Torgersen, S. (1984). Genetic and nosological aspects of schizotypal and borderline personality disorders. A twin study. Arch Gen Psychiatry, 41(6), 546-554.

van Eck, M., Berkhof, H., Nicolson, N., \& Sulon, J. (1996). The effects of perceived stress, traits, mood states, and stressful daily events on salivary cortisol. Psychosom Med, 58(5), 447458.

van Eck, M. M., Nicolson, N. A., Berkhof, H., \& Sulon, J. (1996). Individual differences in cortisol responses to a laboratory speech task and their relationship to responses to stressful daily events. Biol Psychol, 43(1), 69-84.

Ventura, J., Green, M. F., Shaner, A., \& Liberman, R. P. (1993). Training and Quality Assurance with the Brief Psychiatric Rating Scale: 'the Drift Busters'. International Journal of Methods in Psychiatric Research, 3, 221-244.

Weertman, A., Arntz, A., \& Kerkhofs, M. L. M. (2000). Structured Clinical Interview for DSM IV Axis II Personality Disorders. Lisse, the Netherlands: Swets \& Zeitlinger BV.

Whitfield, C. L., Dube, S. R., Felitti, V. J., \& Anda, R. F. (2005). Adverse childhood experiences and hallucinations. Child Abuse Negl, 29(7), 797-810.

Wichers, M., Myin-Germeys, I., Jacobs, N., Peeters, F., Kenis, G., Derom, C., et al. (2007). Genetic risk of depression and stress-induced negative affect in daily life. Br J Psychiatry, 191, 218-223.

Yee, L., Korner, A. J., McSwiggan, S., Meares, R. A., \& Stevenson, J. (2005). Persistent hallucinosis in borderline personality disorder. Compr Psychiatry, 46(2), 147-154.

Zanarini, M. C., Frankenburg, F. R., Dubo, E. D., Sickel, A. E., Trikha, A., Levin, A., et al. (1998a). Axis I comorbidity of borderline personality disorder. Am J Psychiatry, 155(12), 1733-1739. 
Zanarini, M. C., Frankenburg, F. R., Dubo, E. D., Sickel, A. E., Trikha, A., Levin, A., et al. (1998b). Axis II comorbidity of borderline personality disorder. Compr Psychiatry, 39(5), 296-302.

Zanarini, M. C., Frankenburg, F. R., Hennen, J., Reich, D. B., \& Silk, K. R. (2004). Axis I comorbidity in patients with borderline personality disorder: 6-year follow-up and prediction of time to remission. Am J Psychiatry, 161(11), 2108-2114.

Zanarini, M. C., Frankenburg, F. R., Reich, D. B., Marino, M. F., Haynes, M. C., \& Gunderson, J. G. (1999). Violence in the lives of adult borderline patients. J Nerv Ment Dis, 187(2), 65-71.

Zanarini, M. C., Gunderson, J. G., \& Frankenburg, F. R. (1990). Cognitive features of borderline personality disorder. Am J Psychiatry, 147(1), 57-63. 
Part 2

A e tiology 



\section{CHAPTER 4}

\section{Childhood trauma and emotional reactivity to daily life stress in adult frequent attenders of general practitioners}

Jean-Paul Glaser ${ }^{1}$, Jim van Os ${ }^{1,2}$, Piet Portegijs ${ }^{3}$, Inez Myin-Germeys ${ }^{1,4}$

${ }^{1}$ Department of Psychiatry and Neuropsychology, South Limburg Mental Health Research and Teaching Network, EURON, Maastricht University, The Netherlands

${ }^{2}$ Division of Psychological Medicine, Institute of Psychiatry, London, UK

${ }^{3}$ Department of General Practice, Maastricht University, The Netherlands

${ }^{4}$ Mondriaan Zorggroep, Section Social Cognition, Heerlen, the Netherlands.

Journal of Psychosomatic Research (2006); 61(2): 229-236 


\section{ABSTRACT}

Objective: Childhood trauma (CT) has consistently been associated with neuroticism, a personality trait reflecting vulnerability to stress. However, not much is known about the impact of a history of trauma on the moment-to-moment emotions and experiences in the flow of daily life. The relationship between CT and emotional reactivity to daily life stress was investigated.

Method: Ninety frequent attenders of general practitioners, of which 29 fulfilled criteria for CT (sexual and/or physical trauma before the age of 19 years), were studied with the Experience Sampling Method (a structured diary technique assessing current context and mood in daily life) to assess: (1) appraised subjective stress related to daily events and activities, and (2) emotional reactivity conceptualized as changes in negative affect (NA).

Results: Multilevel regression analysis revealed that subjects with a history of CT reported significantly increased emotional reactivity to daily life stress, reflected in an increase in NA. This effect was significantly stronger for the subjects that experienced trauma before the age of 10 years.

Conclusion: These results confirm that CT may have long-lasting and enduring effects on adult psychological functioning, as exposed individuals continually react more strongly to small stressors occurring in the natural flow of everyday life. The finding that emotional stress reactivity is most pronounced for subjects that experienced trauma early in life confirms prior evidence suggesting that the effects of trauma are more detrimental when trauma occurs at a younger age.

Key words: childhood trauma; Experience Sampling Method; momentary assessment; neuroticism; stress response 


\section{INTRODUCTION}

Although prevalence rates of childhood trauma (CT) vary widely, it appears to be common in western society (Bifulco, Brown, \& Harris, 1994; Brown, 2002; Finkelhor, 1994; Freyd et al., 2005; MacMillan et al., 1997). For women in the general population, prevalence rates of childhood sexual trauma have been estimated at between 10\% and 20\% (Brown, 2002; Finkelhor, 1994; Freyd et al., 2005 ), whereas in males much lower prevalence rates have been reported (Briere \& Elliott, 2003; Brown, 2002; Dunne, Purdie, Cook, Boyle, \& Najman, 2003; Freyd et al., 2005; Silverman, Reinherz, \& Giaconia, 1996). Physical abuse assessed in a general population study revealed a prevalence rate of $31.2 \%$ for men and $21.1 \%$ for women, whereas for severe physical abuse prevalence rates of $10.7 \%$ for males and $9.2 \%$ for females were found (MacMillan et al., 1997). Physical and sexual trauma tend to co-occur along with other trauma types such as neglect, emotional abuse and loss (Dong et al., 2004).

Evidence from animal and human research shows that the effects of CT may be severe and enduring, affecting emotion, cognition, and behaviour into adult life (Meaney, 2001; Meaney \& Szyf, 2005; Oitzl, Workel, Fluttert, Frosch, \& De Kloet, 2000; Perry, 2002; van Praag, van Os, \& de Kloet, 2004). Age at traumatization may be an important predictor of the effects of CT in later life. Consequences of childhood trauma appear more detrimental when it occurs at a younger age, a time of vulnerable stages in brain development, with several neurobiological processes ending or attenuating before puberty (De Bellis, 2005; Perry, 2002). Several studies found that CT may have an enduring influence on the development of adult personality characteristics (Bunce, Larsen, \& Peterson, 1995; Herman, Perry, \& van der Kolk, 1989; Kendler, Kuhn, \& Prescott, 2004; Roy, 2002). One personality characteristic that is consistently associated with CT is neuroticism, a personality trait reflecting instability, vulnerability to stress or anxiety proneness (Bunce et al., 1995; Lysaker, Meyer, Evans, Clements, \& Marks, 2001; Roy, 2002). High neuroticism predisposes people to react with more negative emotion (anxiety, depressive mood, anger, irritability) to stressful circumstances (Costa \& McCrae, 1980; Eysenck \& \& Eysenck, 1975; Watson \& Clark, 1984). It is important to further explore the association between CT and neuroticism as neuroticism may be the generic factor explaining the association between CT and a number of mental and somatic disorders (Neeleman, Bijl, \& Ormel, 2004).

Neuroticism is most often assessed with questionnaires reflecting global patterns of experience and behaviour (Bunce et al., 1995; Eysenck \& \& Eysenck, 1975; 
Lysaker et al., 2001; Roy, 2002). However, it is unclear how these global patterns of behaviour translate to the reality of every day life. Thus, not much is known about the impact of a history of trauma on the moment-to-moment emotions and experiences in the flow of daily life. A reliable and valid approach to study experiences in the flow of daily life is the Experience Sampling Method (ESM) (P. A. E. G. Delespaul, 1995). ESM is a structured diary approach assessing thoughts, mood, and context in daily life. ESM is ideally suited to study emotional reactivity to stressful experiences and can thus be considered a more ecologically valid approach to assess neuroticism (Bolger \& Schilling, 1991). Emotional reactivity towards stressors has previously been studied with ESM in different groups of subjects ranging from white collar workers to patients with psychosis and depression (Myin-Germeys et al., 2003; Myin-Germeys, van Os, Schwartz, Stone, \& Delespaul, 2001; Peeters, Nicholson, \& Berkhof, 2003; M. van Eck, Berkhof, Nicolson, \& Sulon, 1996).

In the current study, ESM was used to investigate the effect of sexual and physical trauma during childhood and adolescence on emotional reactivity to daily life stress in adult life. In order to investigate such an association, a sample of frequent general practitioner (GP) attenders with somatic complaints was selected, as it was expected that this sample would have a higher prevalence of childhood trauma than a general population sample, hence increasing the power of the study (Schilte et al., 2001).

\section{Methods}

\section{Subjects}

A sampling frame of frequent GP attenders with a more or less comparable medical history of somatic complaints was selected from the Registration Network of Family Practices (RNH) database at Maastricht University (Metsemakers, Hoppener, Knottnerus, Kocken, \& Limonard, 1992). Participating GPs reported health problems in the RNH if they were permanent, chronic or recurrent. Subjects were selected from the RNH if they had a history of back, neck or abdominal complaints in the absence of an active, serious somatic condition and in the absence of a history of psychiatric disorders other than anxiety or depression. In addition, subjects had to be aged 20-44 years (young adulthood) to minimize the risk of underlying somatic morbidity explaining somatic complaints. The participating GPs, using their medical records, then selected subjects on the basis of frequency of consultation, with a correction for obvious or 
serious somatic problems: at least 15 consultations without any compelling somatic reason for the visit in the previous three years. The GPs excluded a patient if they thought that participation would seriously harm the patient or their relationship with the patient. The GPs invited the selected patients to participate by letter. Patients who agreed were visited by a trained interviewer (P.J.M. Portegijs or a research psychologist) for further information about the study and data collection. The protocol for selection and recruitment has been described in detail elsewhere (Portegijs, Jeuken, van der Horst, Kraan, \& Knottnerus, 1996). The Diagnostic Interview Schedule (DIS) was used to establish DSM III ${ }^{\mathrm{R}}$ psychiatric diagnoses (Robins, Helzer, Croughan, \& Ratcliff, 1981).

\section{Childhood Trauma (CT)}

CT was assessed using a standardized questionnaire following Draijer (Draijer, 1988; Portegijs et al., 1996). Subjects were asked whether they had experienced any kind of sexual or physical trauma before the age of 19 years, a cutoff point in line with sensitive timeframes for brain and personality development (American Psychiatric Association, 2000; De Bellis, 2005; Perry, 2002). If a person reported a traumatic event, specific follow-up questions were asked in order to fully understand the nature of the event. Sexual trauma was subsequently defined as any unwanted sexual experience before age 15 years or indecent assault or rape after that age. Physical trauma was defined as beating that was subjectively threatening or necessitated a visit to the doctor. A dichotomous variable 'CT' was defined ( $1=$ experience of sexual and/or physical trauma; $0=$ no experience of sexual or physical trauma).

In addition, a second CT variable was constructed, taking into account the age at first occurrence of the traumatic experience. This categorical variable CT_age consisted of 3 levels ( $0=$ no trauma; $1=$ first trauma occurring after age 10 years; $2=$ first trauma occurring before age 10 years).

\section{Experience Sampling Method (ESM)}

The ESM is a within-day momentary self-assessment technique. Previous applications of ESM have demonstrated the feasibility, validity and reliability of the method in general population samples and in samples of psychiatric patients (P. Delespaul, deVries, \& van Os, 2002; Jacobs et al., 2005; Myin-Germeys, Nicolson, \& Delespaul, 2001; Myin-Germeys, van Os et al., 2001; Stein, 1996; M. M. van Eck, Nicolson, Berkhof, \& Sulon, 1996). Subjects were studied in their normal daily living environment. They received a digital wristwatch and a 
set of ESM self-assessment forms collated in a booklet for each day. Ten times a day on six consecutive days, the watch emitted a signal (beep) at unpredictable moments between 0730 and $2230 \mathrm{~h}$. After every 'beep', subjects were asked to stop their activity and fill out the ESM self-assessment forms previously handed out to them, collecting reports of thoughts, current context (activity, persons present, location), appraisals of the current situation, and mood. All selfassessment items were rated on seven-point Likert scales. The ESM procedure was explained to the subjects during an initial briefing session and a practice form was completed to confirm that subjects were able to understand the sevenpoint Likert scale format. Subjects were asked to complete their reports immediately after the beep, thus minimizing memory distortions, and to record the time at which they completed the form. In order to know whether the subjects had completed the form within 15 minutes of the beep, the time at which subjects indicated they completed the report was compared to the actual time of the beep. All reports completed more than 15 minutes after the signal were excluded from the analysis. Previous work has shown that reports completed after this interval are less reliable and, consequently, less valid (P. A. E. G. Delespaul, 1995). Subjects with less than 20 valid reports were excluded from the analysis.

\section{Emotional stress reactivity assessment}

In line with previous work, emotional stress reactivity was conceptualized as mood reactivity to daily events and minor disturbances in daily life (MyinGermeys, Nicolson et al., 2001; Myin-Germeys, van Os et al., 2001). Both the mood measures and the stress measures were derived from the Experience Sampling reports as described below.

\section{Assessment of mood.}

Mood states reported after each beep were assessed with different mood adjectives rated on seven-point Likert scales $(1=$ not at all; $7=v e r y)$. The variable negative affectivity (NA) was created by calculating the mean of the scores on the items: "do you feel irritated?", "do you feel lonely?", "do you feel anxious?", and "do you feel down?" (Cronbach's $\alpha=0.61$ ).

\section{Assessment of stress.}

Stress was conceptualized as subjectively appraised stressfulness of distinctive events and of minor disturbances that continually happen in the natural flow of daily life (i.e. event-related or activity-related stress). For event-related stress, 
subjects were asked after each beep to report whether an important event had happened between the current and the previous report. If an event had happened, subjects were asked to report on a seven-point Likert scale how bothersome this was $(1=n o t$ at all; $7=$ very). Response on this item was called eventrelated stress. If no event was reported, a score of "0" was given. For activityrelated stress, subjects judged their current activity after each beep on 3 selfreport items (scored on a seven-point Likert scale: $1=$ not at all; $7=v e r y$ ). The mean of the scales 'I do not like to do this activity', 'I would rather do something else' and 'This activity requires effort' formed the activity-related stress scale (Cronbach's $\alpha=0.54)$.

\section{Statistical analysis}

$\mathrm{T}$ tests and $\chi^{2}$ tests were conducted to assess differences in clinical and demographic characteristics between the CT group and the non-CT group.

In order to investigate the association between CT and stress-reactivity, a multilevel linear random regression model (Goldstein, 1987) was used. Multilevel or hierarchical linear modelling techniques are a variant of the more often used unilevel linear regression analyses and are ideally suited for the analyses of ESM data, consisting of multiple observations within one person (i.e. at two levels: ESM beep level and the subject level) (Schwartz \& Stone, 1998). Since, in ESM -observations from the same subject are more similar than observations from different subjects, the residuals are not independent. Conventional regression techniques do not take into account the variance components at two different levels.

Data were analyzed with the XTREG module in STATA (Statacorp, 2004). B is the fixed regression coefficient of the predictor in the multilevel model and can be interpreted identically to the estimate in the conventional unilevel regression analysis.

To test the hypothesis that CT moderates the emotional reaction to daily life stress, multilevel linear regression analyses were conducted with NA as the dependent variable. CT, the two stress measures, and their interactions were the independent variables: $\mathrm{NA}=\mathrm{B} 0+\mathrm{B} 1$ stress $+\mathrm{B} 2 \mathrm{CT}+\mathrm{B} 3$ stress $\mathrm{x} C \mathrm{C}$. The interaction term (stress $\mathrm{x} C \mathrm{C}$ ) was of great interest in the present study, as the main hypothesis revolved around the question whether a history of CT moderated emotional reactivity to daily life stress. Demographic and clinical characteristics that differed significantly between the CT and the non-CT group were added to the regression model as control variables. 
To compare effect sizes of trauma before and after the age ten years, a second analysis was conducted with CT_age, the two stress measures, and their interactions as independent variables. Estimation of the effect sizes of stress on NA, with CT present before the age of 10 years, with CT present after the age 10 years, or without CT, were calculated from the model with the interactions by calculating appropriate linear combinations using STATA LINCOM routine. The main effects and interactions were assessed by Wald test.

Finally, a post hoc analysis was conducted to investigate whether CT influenced appraised stressfulness rather than the emotional reaction to stress. The multilevel regression model included appraised stress as a dependent variable and CT as an independent variable.

\section{RESULTS}

\section{Subjects and descriptive statistics}

The RNH database contained 1378 patients aged 20-44 years with back, neck, or abdominal problems and without serious somatic or psychiatric problems. Of these, 185 have had at least 15 consultations with a GP in the previous 3 years without a compelling somatic reason. The GPs excluded 19 patients, and a further 55 refused to participate. Of the remaining 111 subjects, 92 provided valid ESM data. The trauma questionnaire was administered in 90 of these 92 subjects, resulting in a final study sample of 90 persons. The prevalence of reported trauma in this sample was $32 \%(n=29)$. The sociodemographic and clinical characteristics of the patients are summarized in Tables 1 and 2, respectively, and the mean scores of the independent and dependent variables are shown in Table 3. With regard to clinical characteristics, the CT group differed significantly from the non-CT group on the number of somatic complaints and on history of depression (Table 2).

\section{Does CT moderate the emotional reaction to daily life stress?}

Multilevel random regression analyses showed a significant main effect of the two ESM daily life stress measures on NA [activity-related stress: $B=0.09$ (S.E. $=0.01$ ), $\mathrm{p}<0.001$; event-related stress: $\mathrm{B}=0.08$ (S.E. $=0.01$ ), $\mathrm{p}<0.001$ ]. A significant increase in NA associated with the daily stress $\mathrm{x} C \mathrm{C}$ interaction term was found for both activity-related and event-related stress [activity-related stress: $\mathrm{B}=0.03$ (S.E. $=0.01$ ), $\mathrm{p}<0.05$; event-related stress: $\mathrm{B}=0.02$ (S.E. $=0.01$ ), $\mathrm{p}<0.05]$, indicative of a moderating synergistic effect of $\mathrm{CT}$ on the emotional 
impact of small daily events in adult life. The association remained similar after adjustment for the clinical variables: the number of somatic complaints and history of depression [activity-related stress: $B=0.03$ (S.E. $=0.01$ ), $p<0.05$; eventrelated stress: $\mathrm{B}=0.02(\mathrm{~S} . \mathrm{E} .=0.01), \mathrm{p}<0.05]$.

The association between stress and NA was modified by the age at first traumatization [interaction term for activity-related stress: $B=0.07 \quad$ (S.E. $=0.01$ ), $\mathrm{p}<0.001$; interaction term for event-related stress: $\mathrm{B}=0.06 \quad$ (S.E. $=0.01$ ), $\mathrm{p}<0.001]$, indicating that the association between stress and NA was stronger when CT occurred before age ten years compared to that when CT occurred after the age of 10 years or when there was no CT (Table 4). The interaction effect remained significant after the adjustment of a priori selected confounders [activity-related stress: $\mathrm{B}=0.07 \quad(\mathrm{~S} . \mathrm{E} .=0.01), \mathrm{p}<0.001$; event-related stress: $\mathrm{B}=0.06$ (S.E. $=0.01), \mathrm{p}<0.001]$.

Post hoc analyses revealed no main effect of $\mathrm{CT}$ on subjective appraisal of stress on activity-related stress $[\mathrm{B}=-0.27$ (S.E. $=0.14$ ), $\mathrm{p}=0.85]$ or event-related stress $[\mathrm{B}=0.25$ (S.E. $=0.15), \mathrm{p}=0.10]$.

Table 1. Sociodemographic characteristics of the research sample

\begin{tabular}{lcll}
\hline & $\begin{array}{l}\text { CT group } \\
(\mathrm{n}=29)\end{array}$ & $\begin{array}{l}\text { Non-CT group } \\
(\mathrm{n}=61)\end{array}$ & $\begin{array}{l}\mathrm{Pr}^{\mathrm{a}} \\
\mathrm{p}^{\mathrm{b}}\end{array}$ \\
\hline Age [mean (S.D.)] & $35.8(5.9)$ & $35.2(6.3)$ & $\mathrm{p}=0.70$ \\
Male-female ratio & $12: 17$ & $23: 38$ & $\operatorname{Pr}=0.74$ \\
Marital status (\%) & & & \\
Never married & $6.9 \%$ & $16.4 \%$ & $\mathrm{Pr}=0.36$ \\
Married or living together & $89.7 \%$ & $77.0 \%$ & \\
Divorced & $3.4 \%$ & $6.6 \%$ & \\
Level of Education & & & $\operatorname{Pr}=0.16$ \\
Elementary school & $0 \%$ & $6.6 \%$ & \\
Secondary school & $96.6 \%$ & $83.6 \%$ & \\
Higher education & $3.4 \%$ & $9.8 \%$ & \\
Work situation & & & \\
Working/household/school & $69.0 \%$ & $83.6 \%$ & \\
Unemployed & $10.3 \%$ & $1.7 \%$ & \\
$>3$ months ill & $13.8 \%$ & $4.9 \%$ & \\
Protected work & $0 \%$ & $4.9 \%$ & \\
Other & $6.9 \%$ & & \\
\hline
\end{tabular}

${ }^{\mathrm{a}}$ Pearsons $\chi^{2}$; ${ }^{\mathrm{b}}$ Two-sample t test with equal variances 
Table 2. Diagnostic characteristics of the research sample according to DIS

\begin{tabular}{|c|c|c|c|}
\hline & $\begin{array}{l}\text { CT Group } \\
(\mathrm{n}=29)\end{array}$ & $\begin{array}{l}\text { Non-CT Group } \\
(\mathrm{n}=61)\end{array}$ & $\begin{array}{l}\operatorname{Pr}^{\mathrm{a}} \\
\mathrm{p}^{\mathrm{b}}\end{array}$ \\
\hline Depressive disorder & $6.9 \%$ & $3.3 \%$ & $\operatorname{Pr}=0.44$ \\
\hline Panic disorder & $20.7 \%$ & $11.5 \%$ & $\operatorname{Pr}=0.25$ \\
\hline Generalized anxiety disorder & $0.0 \%$ & $1.6 \%$ & $\operatorname{Pr}=0.49$ \\
\hline Social phobia & $6.9 \%$ & $6.6 \%$ & $\operatorname{Pr}=0.95$ \\
\hline Dysthymic disorder & $3.5 \%$ & $8.2 \%$ & $\operatorname{Pr}=0.40$ \\
\hline Depressive disorder, history & $44.8 \%$ & $24.6 \%$ & $\operatorname{Pr}=0.05$ \\
\hline $\begin{array}{l}\text { Lifetime number of depressive } \\
\text { episodes }\end{array}$ & $3.3(3.6)$ & $2.9(4.2)$ & $\mathrm{p}=0.72$ \\
\hline $\begin{array}{l}\text { Generalized Anxiety Disorder } \\
\text { (GAD), history }\end{array}$ & $6.9 \%$ & $3.3 \%$ & $\operatorname{Pr}=0.44$ \\
\hline $\begin{array}{l}\text { Somatisation disorder } \\
(>5 \text { DIS somatic complaints) }\end{array}$ & $55.2 \%$ & $47.5 \%$ & $\operatorname{Pr}=0.50$ \\
\hline $\begin{array}{l}\text { Somatisation disorder } \\
\text { (>13 DIS somatic complaints) }\end{array}$ & $10.3 \%$ & $1.6 \%$ & $\operatorname{Pr}=0.06$ \\
\hline $\begin{array}{l}\text { Number of somatic complaints } \\
\text { [mean (S.D.)] }\end{array}$ & $7.3(4.5)$ & $5.2(3.3)$ & $\mathrm{p}=0.01$ \\
\hline Longest depressive episode, in weeks & $59.5(84.0)$ & $52.6(83.6)$ & $\mathrm{p}=0.78$ \\
\hline Age at first somatic complaint & $16.4(8.8)$ & $20.1(13.0)$ & $\mathrm{p}=0.12^{\mathrm{c}}$ \\
\hline Age at first panic attack & $21.5(11.9)$ & $20.3(13.7)$ & $\mathrm{p}=0.82$ \\
\hline Age at onset GAD & $22.3(9.3)$ & $26.3(1.5)$ & $\mathrm{p}=0.45^{\mathrm{c}}$ \\
\hline Age at first depressive episode & $23.1(8.4)$ & $28(8.2)$ & $\mathrm{p}=0.06$ \\
\hline
\end{tabular}

${ }^{a}$ Pearsons $\chi^{2}$; ${ }^{b}$ Two-sample t test with equal variances; ${ }^{c}$ Two-sample t test with unequal variances

Table 3. Ratings of the number of valid reports, and the independent and dependent variables

\begin{tabular}{lcccc}
\hline & $\begin{array}{l}\text { Trauma } \\
{[\text { mean (S.D.) }]}\end{array}$ & $\begin{array}{l}\text { Non-trauma } \\
{[\text { mean (S.D.) }]}\end{array}$ & $\mathrm{t}(88)=$ & $\mathrm{p}$-value \\
\hline Valid reports & $43.9(8.6)$ & $43.1(9.2)$ & 0.4 & 0.72 \\
Independent variables & & & & 0.11 \\
Event-related stress & $1.0(0.7)$ & $0.8(0.7)$ & 1.6 & 0.86 \\
Activity-related stress & $1.9(0.6)$ & $2.0(0.7)$ & 0.2 & 0.98 \\
Dependent variable & & & & \\
NA & $1.3(0.3)$ & $1.3(0.4)$ & 0.0 & \\
\hline
\end{tabular}

S.D., Standard deviation 
Table 4. Interaction between stress and age at first traumatization

\begin{tabular}{|c|c|c|}
\hline \multirow[b]{3}{*}{ Exposure level } & \multicolumn{2}{|l|}{ NA } \\
\hline & Activity-related stress & Event-related stress \\
\hline & $\beta^{\mathrm{a}}(95 \% \mathrm{CI} ; p)$ & $\beta^{\mathrm{a}}(95 \% \mathrm{CI} ; p)$ \\
\hline 1. No Childhood trauma & $\mathrm{B}=0.08(0.06-0.09) ; \mathrm{p}<0.001$ & $\mathrm{~B}=0.07(0.06-0.09) ; \mathrm{p}<0.001$ \\
\hline $\begin{array}{l}\text { 2. Childhood trauma after } \\
\text { age } 10 \text { years }\end{array}$ & $\mathrm{B}=0.06(0.02-0.09) ; \mathrm{p}=0.001$ & $\mathrm{~B}=0.05(0.03-0.07) ; \mathrm{p}<0.001$ \\
\hline $\begin{array}{l}\text { 3. Childhood trauma before } \\
\text { age } 10 \text { years }\end{array}$ & $\mathrm{B}=0.16(0.13-0.19 ; \mathrm{p}<0.001$ & $\mathrm{B}=0.13(0.11-0.15) ; \mathrm{p}<0.001$ \\
\hline Interaction $^{\mathrm{b}}$ & $\chi^{2}=24.81, \mathrm{p}<0.001$ & $\chi^{2}=30.48, p<0.001$ \\
\hline
\end{tabular}

$\overline{{ }^{a} \text { regression coefficient indicates change in NA associated with activity-related stress adjusted for }}$ number of somatic complaints and history of depression; ${ }^{b}$ stress x CT_age interaction adjusted for number of somatic complaints and history of depression

CI, Confidence interval

\section{DISCUSSION}

\section{Findings}

The current study demonstrated - in a sample of frequent GP attenders - that CT is associated with increased emotional reactivity to daily life stress in adult life. The effect sizes were small but not negligible, especially since we assessed frequently occurring exposures in daily life, the cumulative effects of which may be considerable. These results therefore confirm that CT has an enduring and long-lasting impact on adult psychological function, as exposed individuals lastingly and continually react with stronger negative emotions in the face of small stresses in the natural flow of everyday life. Given the fact that ESM negative emotional reactivity arguably is the ecologically valid operationalization of neuroticism (Bolger \& Schilling, 1991), the results of this study are in line with previous studies reporting associations between childhood adversity and neuroticism (Bunce et al., 1995; Lysaker et al., 2001; Roy, 2002). The results also suggest that traumatization at a younger age is particularly harmful, since traumatization before the age of 10 years was significantly associated with increased emotional reactivity to daily stress in adult life, while no such association was found for first traumatization after the age of 10 years. These results are in line with neurobiological stress research findings, suggesting the impact of trauma to be more detrimental when exposure occurs at a younger age (De Bellis, 2005; Perry, 2002). 
Although a clear association was demonstrated between CT and increased stress sensitivity, it should be argued that CT is probably not a sufficient - but rather a component - cause of neuroticism. Evidence from genetic research, for example, suggests that functional polymorphisms of the serotonin transporter gene moderate the impact of stressful environmental influences (e.g. CT). (Caspi et al., 2003; Jacobs et al., 2006).

It could be argued that trauma not so much influences emotional reactivity to stress but rather increases the overall levels of perceived stress per se. A post hoc analysis, however, revealed no main effect of CT on activity-related stress or event-related stress. Thus, a history of CT did not significantly increase the subjective stressfulness of daily activities or events, but increased emotional reactivity towards these stresses.

The stronger emotional stress reactivity in the CT group could possibly be explained by the larger number of somatic complaints and the higher prevalence of history of depression in this group, generating vulnerability due to 'scarring' (Ormel, Oldehinkel, \& Vollebergh, 2004; Zeiss \& Lewinsohn, 1988). However, controlling for number of somatic complaints and history of depression did not change the significant relationship between CT and emotional stress reactivity.

\section{Reverse causality}

It could be argued that neuroticism might lead to over-reporting of traumatic events, rather than CT causing neuroticism (Bolger \& Schilling, 1991; Johnson, Edman, \& Danko, 1995). This reverse causality hypothesis, however, unlikely constitutes the sole explanation of the association between CT and neuroticism in the current sample. First, there is some inconsistency in the literature on whether subjects with neuroticism are more likely to report stressful events. Bolger and colleagues (Bolger \& Schilling, 1991) found no association between neuroticism and over-reporting of stressful events. In addition, trauma data in the current study were collected with an extensive interview, including multiple follow-up questions, allowing the interviewer to get a complete picture of the traumatic event, as such diminishing the likelihood of over-reporting. Finally, strong evidence against reverse causality evolves from experimental animal research findings, showing rodents to express immediate and enduring alterations in neurobiological stress systems such as the hypothalamic-pituitaryadrenal (HPA) axis, after early adversity (van Praag et al., 2004; Weiss, Longhurst, \& Mazure, 1999). Long-lasting alterations in HPA axis functioning after CT have also been reported in human studies (Rinne et al., 2002; van 
Praag et al., 2004; Weiss et al., 1999). Altered functioning of the HPA axis may likely represent a biological correlate of ESM negative emotional stress reactivity found in this study (van Praag et al., 2004).

\section{CT}

The current study defined CT as severe sexual and/or physical abuse. This stringent definition was used to increase specificity (few false positives) rather than sensitivity (few false negatives). As the main goal of this study was to investigate the impact of trauma during childhood on adult stress reactivity, certainty about trauma (e.g. few false positives) was more important than capacity to detect trauma (e.g. few false negatives). Other trauma types such as the experience of loss, emotional neglect and emotional abuse, were not considered in the current study for similar reasons. Their occurrence and severity are more difficult to assess reliably compared to sexual and physical adversity. In addition, there is a large degree of co-occurrence between the different trauma types (Dong et al., 2004).

One could argue that the other kinds of trauma might be over-represented in the non-CT group. This, however, seems unlikely since different trauma types tend to co-occur. If overrepresentation in the non-trauma group occurred, this would only bias the results in a direction other than the null if these other trauma types lowered stress reactivity, which is highly unlikely.

\section{Sample}

As this study aimed to study the effect of childhood trauma on stress reactivity in adult daily life, the sample - frequent attenders of GPs - was chosen to increase the prevalence rate of CT. Given reported general population prevalence rates of serious childhood adversity of 10-20\% (Briere \& Elliott, 2003; Brown, 2002; MacMillan et al., 1997), the prevalence rate of $32 \%(29 / 90)$ in the current sample confirms the enrichment strategy followed. The sampling strategy was also successful in terms of comparability of potential confounders in the trauma and non-trauma group (Table 1 and 2).

The significantly higher negative emotional stress reactivity in the trauma group should be seen in the light of a research design in which the non-CT group also consisted of frequent attenders of GPs. As this non-CT group can be expected to have higher neuroticism levels than a general population sample (Neeleman et al., 2004), the significant results underscore the strength of the effect of CT on negative emotional stress reactivity. A general population study probably 
would have resulted in more differences in potential confounders, making it more difficult to ascribe enhanced stress reactivity to CT.

\section{Methodological issues}

First, CT was assessed by retrospective recollection in adult life, with the inherent risk of underreporting (Fink, Bernstein, Handelsman, Foote, \& Lovejoy, 1995). However, had underreporting occurred, then this would only have biased the results if it had been differential with regard to ESM stress reactivity, with non-reporting of trauma occurring differentially in individuals with abnormally low stress reactivity. This is highly unlikely, as a more likely scenario is that people do not report trauma because of the emotional impact (Briere, 1992; Fink et al., 1995). Thus, if anything, underreporting may have served more to underestimate rather than overestimate reported effects.

Second, the cross-sectional nature of the ESM data makes it impossible to establish the temporal order of relationships between variables. A worse mood might influence the subjective appraisal of the environment, instead of the environment affecting the mood state. The overall effect, however, would still be for the individual to experience distress associated with an environmental event.

Third, the current study used ESM, a daily life assessment technique in which subjects have to comply with the research protocol without the researcher being present. Some recent studies using a light sensor in the dairy booklets to confirm compliance with a fixed time sampling protocol have put doubts on the compliance of subjects in daily life studies (Broderick, Schwartz, Shiffman, Hufford, \& Stone, 2003; Stone, Shiffman, Schwartz, Broderick, \& Hufford, 2002 , 2003). However, a recent study of our group using a signal-contingent random time sampling procedure with multiple observations per day - such as the protocol used in the current study - found evidence supporting the validity of the random time self-report data in the current study (Jacobs et al., 2005).

Fourth, the measurements of daily stress and mood are based on subjective reports. Although subjective reports are considered less reliable (e.g. Do all subjects interpret or answer the questions identically?), they can be valid whereas the validity of objective approaches should not be taken for granted (Strauss, 1994).

Fifth, it was argued that the ESM stress reactivity measure is an ecologically valid assessment of neuroticism. However, no traditional neuroticism scale, such as the Eysenck Personality Questionnaire (Eysenck \& \& Eysenck, 1975) was administered to support this claim. 


\section{Implications}

The current results make it attractive to speculate that increased levels of psychiatric and somatic morbidity associated with childhood trauma may be mediated by increased neuroticism (Neeleman et al., 2004; Talley, Boyce, \& Jones, 1998). This hypothesis is supported by: (a) studies showing an association between CT and psychiatric and somatic morbidity (Goodwin \& Stein, 2004; Herman et al., 1989; Hyun, Friedman, \& Dunner, 2000; Janssen et al., 2004; Kendler et al., 2000; MacMillan et al., 2001; Mullen, Romans-Clarkson, Walton, \& Herbison, 1988; Talley et al., 1998); (b) the finding in the current study of an association between childhood trauma and daily life stress-reactivity; (c) evidence suggesting that negative emotional reactivity to stressful events (NA) or neuroticism is a risk factor for the development of a broad range of psychiatric and somatic morbidity (1992; Myin-Germeys et al., 2003; Neeleman et al., 2004; Ormel \& Wohlfarth, 1991; Van Os \& Jones, 2001) and; (d) evidence suggesting that altered HPA axis functioning - a possible biological correlate of ESM stress-reactivity - is an aetiological factor in the development of (some forms) of depression (van Praag et al., 2004). Absence of support for excess psychopathology due to $\mathrm{CT}$ in current sample most likely results from selection resulting in the (equal) distribution of somatization disorder within the CT and non-CT group. The power to detect differences in psychopathology due to CT will be diminished by somatization disorder, a diagnosis known for its co-morbidity with many psychiatric disorders. Thus, the current finding is not only important in terms general population health parameters, it may also be important in the elucidation of specific mechanisms leading to psychiatric and somatic pathology.

\section{Future research}

The finding that early CT resulted in more stress reactivity deserves further exploration. Furthermore, it seems important to investigate whether different trauma types have similar effects on stress reactivity. The generic role of emotional stress reactivity with regard to psychopathology needs further investigation. Finally, it seems crucially important to investigate whether underlying genotype moderates the effect of trauma on stress reactivity and thus clarify the role of underlying gene-environment interactions. 


\section{REFERENCES}

American Psychiatric Association (2000). Diagnostic and Statistical Manual of Mental disorders, 4th edn, Text Revision (DSM-IV-TR). Washington, DC.

Bifulco, A., Brown, G. W., \& Harris, T. O. (1994). Childhood Experience of Care and Abuse (CECA): a retrospective interview measure. J Child Psychol Psychiatry, 35(8), 1419-1435.

Bolger, N., \& Schilling, E. A. (1991). Personality and the problems of everyday life: the role of neuroticism in exposure and reactivity to daily stressors. J Pers, 59(3), 355-386.

Briere, J. (1992). Methodological issues in the study of sexual abuse effects. J Consult Clin Psychol, 60(2), 196-203.

Briere, J., \& Elliott, D. M. (2003). Prevalence and psychological sequelae of self-reported childhood physical and sexual abuse in a general population sample of men and women. Child Abuse Negl, 27(10), 1205-1222.

Broderick, J. E., Schwartz, J. E., Shiffman, S., Hufford, M. R., \& Stone, A. A. (2003). Signaling does not adequately improve diary compliance. Ann Behav Med, 26(2), 139-148.

Brown, G. W. (2002). Measurement and the epidemiology of childhood trauma. Semin Clin Neuropsychiatry, 7(2), 66-79.

Bunce, S. C., Larsen, R. J., \& Peterson, C. (1995). Life after trauma: personality and daily life experiences of traumatized people. J Pers, 63(2), 165-188.

Caspi, A., Sugden, K., Moffitt, T. E., Taylor, A., Craig, I. W., Harrington, H., et al. (2003). Influence of life stress on depression: moderation by a polymorphism in the 5-HTT gene. Science, 301(5631), 386-389.

Costa, P. T., Jr., \& McCrae, R. R. (1980). Influence of extraversion and neuroticism on subjective well-being: happy and unhappy people. J Pers Soc Psychol, 38(4), 668-678.

De Bellis, M. D. (2005). The psychobiology of neglect. Child Maltreat, 10(2), 150-172.

Delespaul, P., deVries, M., \& van Os, J. (2002). Determinants of occurrence and recovery from hallucinations in daily life. Soc Psychiatry Psychiatr Epidemiol, 37(3), 97-104.

Delespaul, P. A. E. G. (1995). Assessing Schizophrenia in Daily Life. Universitaire Pers Maastricht: Maastricht.

Dong, M., Anda, R. F., Felitti, V. J., Dube, S. R., Williamson, D. F., Thompson, T. J., et al. (2004). The interrelatedness of multiple forms of childhood abuse, neglect, and household dysfunction. Child Abuse Negl, 28(7), 771-784.

Draijer, N. (1988). Seksueel misbruik van meisjes door verwanten [Sexual abuse of Girls by Relatives: a National Survey on Prevalence, Characteristics, Family Background, Emotional meaning, Psychological and Psychosomatic Sequelae). The Hague: Ministry of Social Affairs and Employment.

Dunne, M. P., Purdie, D. M., Cook, M. D., Boyle, F. M., \& Najman, J. M. (2003). Is child sexual abuse declining? Evidence from a population-based survey of men and women in Australia. Child Abuse Negl, 27(2), 141-152.

Eysenck, H. J., \& \& Eysenck, S. B. G. (1975). Manual of the Eysenck Personality Questionnaire. Hodder \& Stoughton: London.

Fink, L. A., Bernstein, D., Handelsman, L., Foote, J., \& Lovejoy, M. (1995). Initial reliability and validity of the childhood trauma interview: a new multidimensional measure of childhood interpersonal trauma. Am J Psychiatry, 152(9), 1329-1335. 
Finkelhor, D. (1994). Current information on the scope and nature of child sexual abuse. Future Child, 4(2), 31-53.

Freyd, J. J., Putnam, F. W., Lyon, T. D., Becker-Blease, K. A., Cheit, R. E., Siegel, N. B., et al. (2005). Psychology. The science of child sexual abuse. Science, 308(5721), 501.

Goldberg, D., \& Huxley, P. (1992). Common Mental Disorders. A Biosocial Model.: Routledge: London.

Goldstein, H. (1987). Multilevel Models in Educational and Social Research. Charles Griffin \& Co.: London.

Goodwin, R. D., \& Stein, M. B. (2004). Association between childhood trauma and physical disorders among adults in the United States. Psychol Med, 34(3), 509-520.

Herman, J. L., Perry, J. C., \& van der Kolk, B. A. (1989). Childhood trauma in borderline personality disorder. Am J Psychiatry, 146(4), 490-495.

Hyun, M., Friedman, S. D., \& Dunner, D. L. (2000). Relationship of childhood physical and sexual abuse to adult bipolar disorder. Bipolar Disord, 2(2), 131-135.

Jacobs, N., Kenis, G., Peeters, F., Derom, C., Vlietinck, R., \& Van Os, J. (2006). Stress-related Negative Affectivity and Genetically Altered Serotonin Transporter Function:

Evidence for Synergism in Shaping Risk for Depression. Arch Gen Psychiatry, 63(9), 989-96.

Jacobs, N., Nicolson, N. A., Derom, C., Delespaul, P., van Os, J., \& Myin-Germeys, I. (2005). Electronic monitoring of salivary cortisol sampling compliance in daily life. Life Sci, 76(21), 2431-2443.

Janssen, I., Krabbendam, L., Bak, M., Hanssen, M., Vollebergh, W., de Graaf, R., et al. (2004). Childhood abuse as a risk factor for psychotic experiences. Acta Psychiatr Scand, 109(1), 3845.

Johnson, R. C., Edman, J. L., \& Danko, G. P. (1995). Self reported negative experiences and dissociation. Pers Individ Dif, 18(6), 793-795.

Kendler, K. S., Bulik, C. M., Silberg, J., Hettema, J. M., Myers, J., \& Prescott, C. A. (2000). Childhood sexual abuse and adult psychiatric and substance use disorders in women: an epidemiological and cotwin control analysis. Arch Gen Psychiatry, 57(10), 953-959.

Kendler, K. S., Kuhn, J. W., \& Prescott, C. A. (2004). Childhood sexual abuse, stressful life events and risk for major depression in women. Psychol Med, 34(8), 1475-1482.

Lysaker, P. H., Meyer, P. S., Evans, J. D., Clements, C. A., \& Marks, K. A. (2001). Childhood sexual trauma and psychosocial functioning in adults with schizophrenia. Psychiatr Serv, 52(11), 1485-1488.

MacMillan, H. L., Fleming, J. E., Streiner, D. L., Lin, E., Boyle, M. H., Jamieson, E., et al. (2001). Childhood abuse and lifetime psychopathology in a community sample. Am J Psychiatry, 158(11), 1878-1883.

MacMillan, H. L., Fleming, J. E., Trocme, N., Boyle, M. H., Wong, M., Racine, Y. A., et al. (1997). Prevalence of child physical and sexual abuse in the community. Results from the Ontario Health Supplement. JAMA, 278(2), 131-135.

Meaney, M. J. (2001). Maternal care, gene expression, and the transmission of individual differences in stress reactivity across generations. Annu Rev Neurosci, 24, 1161-1192.

Meaney, M. J., \& Szyf, M. (2005). Maternal care as a model for experience-dependent chromatin plasticity? Trends Neurosci, 28(9), 456-463. 
Metsemakers, J. F., Hoppener, P., Knottnerus, J. A., Kocken, R. J., \& Limonard, C. B. (1992). Computerized health information in The Netherlands: a registration network of family practices. Br J Gen Pract, 42(356), 102-106.

Mullen, P. E., Romans-Clarkson, S. E., Walton, V. A., \& Herbison, G. P. (1988). Impact of sexual and physical abuse on women's mental health. Lancet, 1(8590), 841-845.

Myin-Germeys, I., Nicolson, N. A., \& Delespaul, P. A. (2001). The context of delusional experiences in the daily life of patients with schizophrenia. Psychol Med, 31(3), 489-498.

Myin-Germeys, I., Peeters, F., Havermans, R., Nicolson, N. A., DeVries, M. W., Delespaul, P., et al. (2003). Emotional reactivity to daily life stress in psychosis and affective disorder: an experience sampling study. Acta Psychiatr Scand, 107(2), 124-131.

Myin-Germeys, I., van Os, J., Schwartz, J. E., Stone, A. A., \& Delespaul, P. A. (2001). Emotional reactivity to daily life stress in psychosis. Arch Gen Psychiatry, 58(12), 1137-1144.

Neeleman, J., Bijl, R., \& Ormel, J. (2004). Neuroticism, a central link between somatic and psychiatric morbidity: path analysis of prospective data. Psychol Med, 34(3), 521-531.

Oitzl, M. S., Workel, J. O., Fluttert, M., Frosch, F., \& De Kloet, E. R. (2000). Maternal deprivation affects behaviour from youth to senescence: amplification of individual differences in spatial learning and memory in senescent Brown Norway rats. Eur J Neurosci, 12(10), 37713780 .

Ormel, J., Oldehinkel, A. J., \& Vollebergh, W. (2004). Vulnerability before, during, and after a major depressive episode: a 3-wave population-based study. Arch Gen Psychiatry, 61(10), 990-996.

Ormel, J., \& Wohlfarth, T. (1991). How neuroticism, long-term difficulties, and life situation change influence psychological distress: a longitudinal model. J Pers Soc Psychol, 60(5), 744755 .

Peeters, F., Nicholson, N. A., \& Berkhof, J. (2003). Cortisol responses to daily events in major depressive disorder. Psychosom Med, 65(5), 836-841.

Perry, B. D. (2002). Childhood experience and the expression of genetic potential: what childhood neglect tells us about nature and nurture. Brain and Mind, 3(1), 79-100.

Portegijs, P. J., Jeuken, F. M., van der Horst, F. G., Kraan, H. F., \& Knottnerus, J. A. (1996). A troubled youth: relations with somatization, depression and anxiety in adulthood. Fam Pract, 13(1), 1-11.

Rinne, T., de Kloet, E. R., Wouters, L., Goekoop, J. G., DeRijk, R. H., \& van den Brink, W. (2002). Hyperresponsiveness of hypothalamic-pituitary-adrenal axis to combined dexamethasone/corticotropin-releasing hormone challenge in female borderline personality disorder subjects with a history of sustained childhood abuse. Biol Psychiatry, 52(11), 11021112.

Robins, L. N., Helzer, J. E., Croughan, J., \& Ratcliff, K. S. (1981). National Institute of Mental Health Diagnostic Interview Schedule. Its history, characteristics, and validity. Arch Gen Psychiatry, 38(4), 381-389.

Roy, A. (2002). Childhood trauma and neuroticism as an adult: possible implication for the development of the common psychiatric disorders and suicidal behaviour. Psychol Med, 32(8), 1471-1474. 
Schilte, A. F., Portegijs, P. J., Blankenstein, A. H., Latour, M. B., van Eijk, J. T., \& Knottnerus, J. A. (2001). Indicators of childhood adversity in somatisation in general practice. Scand J Prim Health Care, 19(4), 232-236.

Schwartz, J. E., \& Stone, A. A. (1998). Strategies for analyzing ecological momentary assessment data. Health Psychol, 17(1), 6-16.

Silverman, A. B., Reinherz, H. Z., \& Giaconia, R. M. (1996). The long-term sequelae of child and adolescent abuse: a longitudinal community study. Child Abuse Negl, 20(8), 709-723.

Statacorp. (2004). Stata Statistical Software: Release 8.0. STATA: College Station; TX.

Stein, K. F. (1996). Affect instability in adults with a borderline personality disorder. Arch Psychiatr Nurs, 10(1), 32-40.

Stone, A. A., Shiffman, S., Schwartz, J. E., Broderick, J. E., \& Hufford, M. R. (2002). Patient non-compliance with paper diaries. Bmj, 324(7347), 1193-1194.

Stone, A. A., Shiffman, S., Schwartz, J. E., Broderick, J. E., \& Hufford, M. R. (2003). Patient compliance with paper and electronic diaries. Control Clin Trials, 24(2), 182-199.

Strauss, J. S. (1994). The person with schizophrenia as a person. II: Approaches to the subjective and complex. Br J Psychiatry Suppl(23), 103-107.

Talley, N. J., Boyce, P. M., \& Jones, M. (1998). Is the association between irritable bowel syndrome and abuse explained by neuroticism? A population based study. Gut, 42(1), 47-53.

van Eck, M., Berkhof, H., Nicolson, N., \& Sulon, J. (1996). The effects of perceived stress, traits, mood states, and stressful daily events on salivary cortisol. Psychosom Med, 58(5), 447458.

van Eck, M. M., Nicolson, N. A., Berkhof, H., \& Sulon, J. (1996). Individual differences in cortisol responses to a laboratory speech task and their relationship to responses to stressful daily events. Biol Psychol, 43(1), 69-84.

Van Os, J., \& Jones, P. B. (2001). Neuroticism as a risk factor for schizophrenia. Psychol Med, 31(6), 1129-1134.

van Praag, H. M., van Os, J., \& de Kloet, E. R. (2004). Stress, the Brain and Depression: Cambridge University Press.

Watson, D., \& Clark, L. A. (1984). Negative affectivity: the disposition to experience aversive emotional states. Psychol Bull, 96(3), 465-490.

Weiss, E. L., Longhurst, J. G., \& Mazure, C. M. (1999). Childhood sexual abuse as a risk factor for depression in women: psychosocial and neurobiological correlates. Am J Psychiatry, 156(6), 816-828.

Zeiss, A. M., \& Lewinsohn, P. M. (1988). Enduring deficits after remissions of depression: a test of the scar hypothesis. Behav Res Ther, 26(2), 151-158. 

CHAPTER 5

Discussion 
A momentary assessment study of the reputed emotional phenotype associated with borderline personality disorder

This study investigated emotional reactivity to daily life stress in borderline personality disorder, psychotic disorder and healthy controls. We found that subjects with borderline personality disorder reported the strongest emotional reactivity to daily life stress, significantly exceeding emotional reactivity level of subjects with psychotic disorder, a diagnostic group that thus far reported the strongest emotional stress reactivity, significantly stronger than subjects with bipolar disorder, unipolar depressive disorder and healthy controls (MyinGermeys et al., 2003). The findings of our study are the first to ecologically validate the DSM-IV criterion affective instability due to a marked reactivity of mood in a sample of subjects with clinical borderline personality disorder. The one study that also investigated emotional reactivity to (interpersonal) stress using a daily process design did so in a sample of subjects with non-clinical borderline personality disorder (Tolpin, Gunthert, Cohen, \& O’Neill, 2004). Contrary to the results of our study they did not find subjects with borderline symptoms to be more emotionally reactive to stress. This contradiction was most likely due to: i) their use of a non-clinical sample, ii) the sampling procedure with only one sampling moment at the end of each day with the inherent risk of recall bias, and iii) their assessment of interpersonal stressors which may have lacked sensitivity due to their focus on a specific range of daily events (questionnaire) without determining the frequency of a particular stressor during the day.

Interestingly, the findings of our study show enhanced emotional reactivity to common daily stresses, while life events and major interpersonal stresses thus far have been postulated as main causes of emotional reactivity in borderline personality disorder (American Psychiatric Association, 2000; Gunderson, 2007; Jovev \& Jackson, 2006; Pagano et al., 2004; Russell, Moskowitz, Zuroff, Sookman, \& Paris, 2007; Tolpin et al., 2004). A study by Jovev et al. (Jovev \& Jackson, 2006) investigating the effect of live events on functioning in borderline personality disorder, other personality disorders and in subjects with an axis I disorder without a personality disorder, however, found that subjects with borderline personality disorder experienced more hassles, greater intensity of hassles and less uplifts, while the frequency of life events was closely associated with a non-borderline diagnosis in predicting diminished psychosocial functioning. Strongly enhanced emotional reactivity to daily life stress in borderline personality disorder - as found in our study - may thus induce a ceiling effect that explains why borderline patients may be distressed by common daily has- 
sles regardless of life events while non-borderline subjects become distressed because of life events (Jovev \& Jackson, 2006). The results of our study indeed clearly reveal that emotional reactivity in borderline personality disorder is no longer solely a matter of live events and stresses in the reputed interpersonal domain, which is in line with previous evidence showing that the class of frequently occurring common daily events, rather than low-prevalent life events, probably represent more important predictors of psychopathology in general (Kanner, Coyne, Schaefer, \& Lazarus, 1981; Monroe, 1983), and of subjective distress in particular (Norman \& Malla, 1991).

\section{Psychotic reactivity in borderline personality disorder}

This study investigated psychotic reactivity to daily life stress in subjects with borderline personality disorder, subjects with psychotic disorder, subjects with cluster $\mathrm{C}$ personality disorder and healthy controls. It was the first to ecologically validate the stress-related paranoid reactivity part of the ninth DSM-IV borderline personality disorder criterion by investigating paranoid specificity and psychotic reactivity to daily life stress in borderline personality disorder using a momentary assessment design. We found that subjects with borderline personality disorder express the strongest psychotic reactivity to daily life stress. Paranoid reactivity to stress, specifically incorporated in the ninth criterion of DSM-IV borderline personality disorder classification, showed no significant differences between the patient groups that all were significantly more paranoid reactive to daily life stress than healthy controls. Subjects with borderline personality disorder, however, reported significantly more hallucinations in reaction to daily life stress than subjects with cluster $\mathrm{C}$ personality disorder and healthy controls, though effect sizes were substantially less than the effect sizes of general psychotic reactivity and paranoid reactivity. General psychotic reactivity to daily life stress was found to be most specific for borderline personality disorder.

Psychotic reactivity in borderline personality disorder, thus, may not to be limited to paranoid ideation as is suggested by DSM-IV. Looking forward to DSM-V our findings would plea for the implementation of psychotic reactivity rather than paranoid reactivity in borderline personality disorder classification.

\section{Do borderline patients express true psychotic symptoms?}

A central discussion is whether psychotic symptoms, as measured in the ESM diaries reflect true psychotic symptoms. This is particularly relevant in borderline research since it has been argued that the psychotic symptoms of patients 
suffering from borderline personality reflect broadly defined or quasi-psychotic symptoms rather than true psychotic symptoms (Chopra \& Beatson, 1986; Frosch, 1964; Jonas \& Pope, 1984; Links, Steiner, \& Mitton, 1989; Pope, Jonas, Hudson, Cohen, \& Tohen, 1985; Zanarini, Gunderson, \& Frankenburg, 1990). However, what does it mean to have true psychotic symptoms? When referring to true (e.g. narrowly defined) psychotic symptoms, one thinks of patients with severe psychotic disorder (e.g. schizophrenia). Severe psychotic disorder by definition is characterized by a long duration of psychotic symptoms while level of reality testing is severely disturbed (American Psychiatric Association, 2000; Jonas \& Pope, 1984; Zanarini et al., 1990). Aspects of severe psychotic disorder other than duration and level of reality testing, however, may also give rise to the non-true connotation of psychotic symptoms in borderline personality disorder. Psychotic symptoms in severe psychotic disorder are often accompanied by negative symptoms such as affective flattening, alogia, avolition and by cognitive disturbances (Murray et al., 2004). Since both negative and cognitive symptom dimensions may strongly 'colour' the phenomenological expression of psychotic symptoms in severe psychotic disorder, we argue that severe psychosis of long duration embedded in a context of negative and cognitive symptoms may have been the basis for a true psychosis definition thus far. When eliminating the 'colouring' influences of negative and cognitive symptom dimension on psychosis phenomenology, the distinction between narrowly, broadly and psychotic-like symptoms in borderline personality disorder most likely relies on severity parameters such as level of reality testing, impact on functioning and duration. A representation on the basis of severity level, very well fits within a continuum model of psychosis (van Os, Linscott, Myin-Germeys, Delespaul, \& Krabbendam, 2009), ranging from 'no reality disturbance at all to extremely psychotic with full-blown enduring reality disturbances' (van Os et al., 2009). It has been shown that more subtle, broadly defined psychotic-like experiences are on a symptomatic and an etiological continuity with more severe psychotic symptoms (van Os et al., 2009) which means that risk factors for severe psychotic symptoms (e.g. narrowly defined psychotic symptoms, delusions and hallucinations according to DSM-IV) such as genetic risk factors, childhood trauma, cannabis use also predict less severe, broadly defined, psychotic symptoms (Myin-Germeys et al., 2004). According to an etiologic and symptomatic continuum model of psychosis, cumulation of risk factors, or greater severity of risk factors will likely result in more severe psychotic symptoms (Cougnard et al., 2007) 


\section{Dissociation or psychosis?}

Since the general psychosis variable used in our study contained the classic dissociation item 'I feel unreal' one might argue that we measured dissociation instead of psychosis. Excluding the item 'I feel unreal' from the general psychosis variable in our study, however, did not substantially change the results of our study, which is in line with the studies reporting strong correlations between dissociation and psychosis (Moskowitz, Barker-Collo, \& Ellson, 2005).

DSM-IV defines dissociation as a disruption in the usually integrated functions of consciousness, memory, identity, or perception, while none of the DSM-IV dissociative disorders is explicitly characterized by delusions or hallucinations. It is remarkable, however, that - in clinical practice - despite this clear definitional delineation between psychosis and dissociation, delusions and hallucinations in subjects with borderline personality disorder are not seldom referred to as dissociative or 'not psychotic'. Psychotic symptoms in (traumatized) subjects with borderline personality disorder may be characterized by clinicians as (dissociative) re-experiences. It could be argued that classifying broadly defined psychotic symptoms that do not arise in a context of negative and cognitive symptoms, as a different psychiatric category (e.g. dissociation), or diagnosing them as 'not psychotic', factitious or malingering (Links et al., 1989; Pope et al., 1985), may be due to non-familiarity with a psychosis continuum (e.g. different levels of reality testing).

Childhood trauma and emotional reactivity to daily life stress in adult frequent attenders of general practitioners

Emotional reactivity to daily life stress was investigated in a non-clinical sample of frequent attenders of general practitioners with and without a history of childhood trauma. It was found that subjects with a history of childhood trauma were significantly more reactive to daily life stress compared to those without childhood trauma. This effect was apparent although the control group also consisted of (stress reactive) frequent attenders of general practitioners. Within the group that experienced childhood trauma, emotional reactivity to daily life stress was significantly stronger in subjects who experienced childhood trauma before the age of ten years. This finding is in line with neurobiological evidence showing that the effects of traumatic events are more detrimental when happening at a younger age (De Bellis, 2005; Perry, 2002). Interestingly, borderline personality disorder also has been shown to be characterized by enhanced emotional reactivity to daily life stress (Glaser, Os, Mengelers, \& MyinGermeys, 2007), while prevalence rates of (severe) childhood trauma have been 
reported to be substantial (Paris, 2005). It is thus attractive to hypothesize that for a subgroup of subjects with borderline personality disorder enhanced emotional reactivity to stress is caused by childhood trauma. A study by Rinne et al. (Rinne et al., 2002) may support this hypothesis on a biological level by showing that subjects with borderline personality disorder and a history of childhood trauma express hyper-responsiveness op the HPA axis (a major biological stress system) while subjects with borderline personality disorder without a history of trauma did not reveal this hyper-responsiveness, an effect that was independent of the presence of a comorbid depressive or post traumatic stress disorder (Rinne et al., 2002). Although childhood trauma is neither a necessary nor a sufficient cause for borderline personality disorder, its impact may be considerable since a quarter of the subjects with BPD report sexual abuse by a caretaker and about a third report severe forms of abuse (Paris, 2005).

The findings of our study also underscore that childhood trauma not only impacts negatively on functioning in case of clinical pathology, it may even have a more widespread impact on functioning in the general population where 'healthy' individuals that experienced childhood trauma - which is not uncommon (Bifulco, Brown, \& Harris, 1994; Brown, 2002; Finkelhor, 1994; Freyd et al., 2005; MacMillan et al., 1997) - may be enduringly burdened by common daily life stresses that continually happen in the flow of daily life, the cumulative impact of which may be considerable on quality of life, disease risk and incapability to work (Gillham et al., 1998).

\section{Mechanisms underlying stress reactivity in borderline personality disorder}

We presented evidence that borderline personality disorder is characterized by a strong emotional en psychotic reactivity to daily life stress. We also showed that childhood trauma is associated with emotional over-reactivity to daily life stress. However, what would be the underlying mechanism that reconciles these different findings? It has been shown that early trauma may cause genetic, biologi$\mathrm{cal}$ and psychological alterations that result in progressively lower thresholds to stress, a mechanism called sensitization (Collip, Myin-Germeys, \& Van Os, 2008; Wichers et al., 2008). Childhood trauma may induce gene transcription factors that are likely to result in long-term structural changes in the expression of neurotransmitters, receptors and neuropeptides (Wichers et al., 2008). These changes may lead to sensitization, or progressively lower thresholds to stress, so that with each further exposure less stress is required for similar behavioral (and biological) responses (Wichers et al., 2008). Eventually psychopathological symptoms may become triggered by minor events and common stresses that 
continually happen in the flow of everyday life (Wichers et al., 2008). This sensitization mechanism may be particularly relevant for borderline personality disorder because stress strongly determines its phenomenology and childhood trauma prevalence rates are substantial. Borderline personality disorder in particular may consist of multiple stress sensitized symptom dimensions such as reactivity of mood, psychotic reactivity, impulsivity and fear of abandonment, the latter being very much in line with a psychoanalytical developmental model of borderline personality disorder (Goldstein, 1995).

\section{Shared vulnerability}

The results of this thesis show that enhanced emotional and psychotic reactivity to daily life stress applies to borderline personality disorder but also - though to a lesser extent - to psychotic disorder and cluster $\mathrm{C}$ personality disorder. A previous study also found increased emotional reactivity to stress in patients with major depression and bipolar disorder (Myin-Germeys et al., 2003). Both emotional and psychotic reactivity may thus represent an area of shared vulnerability across a broader range of severe mental illnesses that according to categorical diagnostics (e.g. DSM-IV) are clearly delineated from each other. Since childhood trauma predicts enhanced emotional reactivity to daily life stress in adult life, childhood trauma may also represent a shared risk factor, which has been supported by the literature (Fossati, Madeddu, \& Maffei, 1999; Read, van Os, Morrison, \& Ross, 2005). This suggests that the boundaries between these different psychiatric classifications may not be so clear-cut (van Os et al., 2009). There is clear overlap in symptoms (e.g. psychotic reactivity), in risk factors (e.g. trauma) and in underlying vulnerability. These findings also challenge the distinction between axis I and axis II diagnoses, since it is difficult to differentiate them in terms of symptoms and aetiology. This has also been acknowledged in the development process of DSM-V since there is debate whether axis II should still be included in DSM-V (Skodol \& Bender, 2009; Widiger, 2003; Widiger, Simonsen, Krueger, Livesley, \& Verheul, 2005).

On the other hand, the general clinical impression of psychotic disorder and borderline personality disorder clearly reveals differences. In order to capture these differences as well as the similarities more clearly, it might be helpful to move from a categorical to a dimensional approach. Symptom dimensions may constitute more homogeneous entities with similar symptom patterns, etiology, prognosis and possibly treatment. Borderline patients may thus score on the positive symptom dimension, whereas the cognitive en negative symptom domains of psychotic disorder may be lacking. 


\section{Clinical implications}

With regard to clinical implications, the findings of our studies underscore the importance of stress reduction or stress management targets in the treatment of subjects with borderline personality disorder since it clearly impacts negatively on mood and psychosis intensity which both have been shown to be predictors of negative course and prognosis (Dowson, Sussams, Grounds, \& Taylor, 2000; Hull, Yeomans, Clarkin, Li, \& Goodman, 1996; Paris, 2005; Skodol et al., 2002). Psychodynamic and cognitive behavior therapy have been reported to be effective treatments for borderline personality disorder (Giesen-Bloo et al., 2006; American Psychiatric Association, 2001). These treatments focus on insight and personality change by investigating problematic life situations in relation to perception and behavior (American Psychiatric Association," 2001). Stress reduction theoretically follows - during the course of these usually longterm therapies - from alterations in insight, (cognitive) schemes about the self, attributions and believes about the environment, and behavior (American Psychiatric Association, 2001). Cognitive behavior and psychodynamic therapy, however, mainly focus on emotionally charged (inter)personal dynamics and not so much on common daily life stresses. Since the studies in this thesis have shown that subjects with borderline personality disorder are emotionally and psychotically reactive to common daily life stresses that continually happen during the day and thus not exclusively to interpersonal crises or (perceived) abandonment (Skodol et al., 2002), we plea for therapeutic interventions that buffer the cumulative effects of daily life stress. Reactivity to daily life stress could be implemented as an additional focus in cognitive behavior therapy such as the systems training for emotional predictability and problem solving (Blum, Pfohl, John, Monahan, \& Black, 2002; Van Wel et al., 2006). For more vulnerable patients cognitive behavior therapy could be embedded in additional stress reducing interventions such as case management, relaxation therapy and family therapy (American Psychiatric Association, 2001). The most (psychotically) vulnerable borderline patients may benefit best from stress reducing interventions in combination with a cognitive behavior therapy aimed at psychotic experiences (Krabbendam \& Aleman, 2003).

Since it has been shown that psychotic vulnerability in borderline personality disorder predicts suicide risk and need for hospitalization (Dowson et al., 2000; Hull et al., 1996; Skodol et al., 2002) underdiagnosing psychosis in borderline personality disorder may underestimate the need for care and the severity of the disorder with the inherent risk of serious negative consequences. The results of our study may add to the clinical awareness that psychotic phenomena in bor- 
derline personality do exist and should therefore not be underestimated or ignored.

Also of clinical relevance is our finding that patients with borderline personality disorder are not only burdened by life events and significant interpersonal stresses, but possibly even more by daily routine with frequently occurring common stresses. It is these common daily life stresses that generate negative affect and psychotic symptoms that have been shown to predict a negative course and prognosis (Skodol et al., 2002). This knowledge is of importance for treatment plans making sure the patient is not overestimated in his/her rehabilitation capacity with excessive stress induction as a result.

Though several classes of psychiatric medication have been shown to be effective in reducing borderline personality disorder symptoms (American Psychiatric Association, 2001), new psychopharmacologic agents that specifically target neurobiological stress systems such as the hypothalamic-pituitary-adrenal axis may hold promises for the future (van Praag, van Os, \& de Kloet, 2004).

In case of frequent illness, burnout or sickness absence company doctors should be alert for the possibility of childhood trauma in case of which referral to a psychologist may be indicated. In case of psychotic disorder clinicians also should routinely inform about childhood trauma since it has been shown to predict psychotic disorder (Read, Perry, Moskowitz, \& Connolly, 2001; Read et al., 2005). In case of a positive childhood trauma anamnesis, a trauma focused psychotherapy may be installed to treat psychotic or stress-related symptoms (Read et al., 2001; Read et al., 2005).

Because of the enduring and detrimental impact of childhood trauma, primary prevention should have ongoing priority on the societal agendas.

\section{Future research}

Following from the discussion above the following issues need to be addressed to further elucidate the aetiology and pathogenesis of psychosis and affective instability in borderline personality disorder.

Do differences in trauma prevalence and trauma severity between diagnostic groups result in differences in emotional and psychotic reactivity to stress?

Do different trauma types (physical abuse, sexual abuse, emotional neglect, separations) differently predict symptom dimensions such as affective instability and psychotic reactivity to daily life stress when measured by momentary assessment? 
The cognitive and negative symptom domains of psychotic disorder should be studied in borderline personality disorder to elucidate differences between borderline personality disorder and psychotic disorder.

The search for shared and non-shared vulnerability factors between borderline personality disorder and psychotic disorder should be (further) extended with genetic research and imaging studies of the brain.

With regard to psychotherapy, interventions designed to buffer common daily life stresses, such as the systems training for emotional predictability and problem solving should be investigated with a long-term follow-up by means of randomized controlled designs using momentary assessment methodology in daily life. It should be investigated whether booster session are necessary in case of an effective first intervention.

A new momentary assessment technology of our group (the Met-D device), a digital interactive version of the Experience Sampling Method enables prospective assessment of person-context interactions for extended periods of time while it automatically stores data in its memory. The Med-D device contains an active resource-mobilising psychotherapeutic training module (RMT) that give patients tools by providing feedback based on daily behavior, to reshape their interaction with the daily life context in the direction of diminishing reasoning bias (paranoid ideation, black-and-white thinking), increasing experience of positive emotions and generating insight in the relationship between negative mood, psychosis and contextual factors such as stress. The more active involvement of patients and reinforcing feedback on early signs of improvement in daily life experience is expected to increase patient compliance. The efficacy of stress reducing feedback programs for borderline patients implemented in the Med-D device should be investigated with randomized controlled designs.

\section{CONCLUSION}

In this thesis, the Experience Sampling Method appeared to be an excellent tool to study - in a natural daily life context - the phenomenology of borderline personality disorder and the long-term consequences of risk factors such as childhood trauma. 
Investigating the reputed reactivity of the emotional and psychosis phenotype associated with borderline personality disorder in a momentary fashion made it possible to study the relationship between mood, psychosis and daily life stress very directly, excluding recall bias related to retrospective questioning, which may be of particular importance in borderline personality disorder (EbnerPriemer et al., 2006).

Although it has been acknowledged for a long time that borderline personality disorder symptomatology is strongly reactive in nature, this thesis is the first to ecologically validate reactivity of mood and psychosis in subjects with clinical borderline personality disorder.

Studying emotional and psychotic reactivity to daily life stress in different disorders (borderline personality disorder, psychotic disorder, cluster $\mathrm{C}$ personality disorder) yielded results that underscore the presence of shared symptomatology and the relevance of shared vulnerability, which is in support of a dimensional representation of psychopathology. The plea - made in this thesis - for dimensional diagnostics is in line with the recent debate regarding the next version of the Diagnostic and Statistical Manual of Mental Disorders (DSM-V) considering the implementation of dimensional models of psychopathology. 


\section{REFERENCES}

American Psychiatric Association (2000). Diagnostic and Statistical Manual of Mental disorders, 4th edn, Text Revision (DSM-IV-TR). Washington, DC.

American Psychiatric Association (2001). Practice guideline for the treatment of patients with borderline personality disorder. Am J Psychiatry, 158(10 Suppl), 1-52.

Bifulco, A., Brown, G. W., \& Harris, T. O. (1994). Childhood Experience of Care and Abuse (CECA): a retrospective interview measure. J Child Psychol Psychiatry, 35(8), 1419-1435.

Blum, N., Pfohl, B., John, D. S., Monahan, P., \& Black, D. W. (2002). STEPPS: a cognitivebehavioral systems-based group treatment for outpatients with borderline personality disorder--a preliminary report. Compr Psychiatry, 43(4), 301-310.

Brown, G. W. (2002). Measurement and the epidemiology of childhood trauma. Semin Clin Neuropsychiatry, 7(2), 66-79.

Chopra, H. D., \& Beatson, J. A. (1986). Psychotic symptoms in borderline personality disorder. Am J Psychiatry, 143(12), 1605-1607.

Collip, D., Myin-Germeys, I., \& Van Os, J. (2008). Does the Concept of “Sensitization” Provide a Plausible Mechanism for the Putative Link Between the Environment and Schizophrenia? Schizophr Bull.

Cougnard, A., Marcelis, M., Myin-Germeys, I., De Graaf, R., Vollebergh, W., Krabbendam, L., et al. (2007). Does normal developmental expression of psychosis combine with environmental risk to cause persistence of psychosis? A psychosis proneness-persistence model. Psychol Med, 37(4), 513-527.

De Bellis, M. D. (2005). The psychobiology of neglect. Child Maltreat, 10(2), 150-172.

Dowson, J. H., Sussams, P., Grounds, A. T., \& Taylor, J. (2000). Associations of self-reported past "psychotic" phenomena with features of personality disorders. Compr Psychiatry, 41(1), $42-48$.

Ebner-Priemer, U. W., Kuo, J., Welch, S. S., Thielgen, T., Witte, S., Bohus, M., et al. (2006). A valence-dependent group-specific recall bias of retrospective self-reports: a study of borderline personality disorder in everyday life. J Nerv Ment Dis, 194(10), 774-779.

Finkelhor, D. (1994). Current information on the scope and nature of child sexual abuse. Future Child, 4(2), 31-53.

Fossati, A., Madeddu, F., \& Maffei, C. (1999). Borderline Personality Disorder and childhood sexual abuse: a meta-analytic study. J Personal Disord, 13(3), 268-280.

Freyd, J. J., Putnam, F. W., Lyon, T. D., Becker-Blease, K. A., Cheit, R. E., Siegel, N. B., et al. (2005). Psychology. The science of child sexual abuse. Science, 308(5721), 501.

Frosch, J. (1964). The Psychotic Character: Clinical Psychiatric Considerations. Psychiatr Q, 38, 81-96.

Giesen-Bloo, J., van Dyck, R., Spinhoven, P., van Tilburg, W., Dirksen, C., van Asselt, T., et al. (2006). Outpatient psychotherapy for borderline personality disorder: randomized trial of schema-focused therapy vs transference-focused psychotherapy. Arch Gen Psychiatry, 63(6), 649-658.

Gillham, B., Tanner, G., Cheyne, B., Freeman, I., Rooney, M., \& Lambie, A. (1998). Unemployment rates, single parent density, and indices of child poverty: their relationship to different categories of child abuse and neglect. Child Abuse Negl, 22(2), 79-90. 
Glaser, J. P., Os, J. V., Mengelers, R., \& Myin-Germeys, I. (2007). A momentary assessment study of the reputed emotional phenotype associated with borderline personality disorder. Psychol Med, 1-9.

Goldstein, W. N. (1995). The borderline patient: update on the diagnosis, theory, and treatment from a psychodynamic perspective. Am J Psychother, 49(3), 317-337.

Gunderson, J. G. (2007). Disturbed relationships as a phenotype for borderline personality disorder. Am J Psychiatry, 164(11), 1637-1640.

Hull, J. W., Yeomans, F., Clarkin, J., Li, C., \& Goodman, G. (1996). Factors associated with multiple hospitalizations of patients with borderline personality disorder. Psychiatr Serv, 47(6), 638-641.

Jonas, J. M., \& Pope, H. G. (1984). Psychosis in borderline personality disorder. Psychiatr Dev, 2(4), 295-308.

Jovev, M., \& Jackson, H. J. (2006). The relationship of borderline personality disorder, life events and functioning in an Australian psychiatric sample. J Personal Disord, 20(3), 205217.

Kanner, A. D., Coyne, J. C., Schaefer, C., \& Lazarus, R. S. (1981). Comparison of two modes of stress measurement: daily hassles and uplifts versus major life events. J Behav Med, 4(1), 139.

Krabbendam, L., \& Aleman, A. (2003). Cognitive rehabilitation in schizophrenia: a quantitative analysis of controlled studies. Psychopharmacology (Berl), 169(3-4), 376-382.

Links, P. S., Steiner, M., \& Mitton, J. (1989). Characteristics of psychosis in borderline personality disorder. Psychopathology, 22(4), 188-193.

MacMillan, H. L., Fleming, J. E., Trocme, N., Boyle, M. H., Wong, M., Racine, Y. A., et al. (1997). Prevalence of child physical and sexual abuse in the community. Results from the Ontario Health Supplement. Jama, 278(2), 131-135.

Monroe, S. M. (1983). Major and minor life events as predictors of psychological distress: further issues and findings. J Behav Med, 6(2), 189-205.

Moskowitz, A. K., Barker-Collo, S., \& Ellson, L. (2005). Replication of dissociation-psychosis link in New Zealand students and inmates. J Nerv Ment Dis, 193(11), 722-727.

Murray, R. M., Sham, P., Van Os, J., Zanelli, J., Cannon, M., \& McDonald, C. (2004). A developmental model for similarities and dissimilarities between schizophrenia and bipolar disorder. Schizophr Res, 71(2-3), 405-416.

Myin-Germeys, I., Peeters, F., Havermans, R., Nicolson, N. A., DeVries, M. W., Delespaul, P., et al. (2003). Emotional reactivity to daily life stress in psychosis and affective disorder: an experience sampling study. Acta Psychiatr Scand, 107(2), 124-131.

Myin-Germeys, I., Spauwen, J., Jacobs, N., Lieb, R., Wittchen, H. U., \& Van Os, J. (2004). (2003). The aetiological continuum of psychosis In W. F. Gattaz \& H. Hafner (Eds.), Search for the Causes of Schizophrenia (Vol 5) (Vol. 5). Darmstadt: Steinkopff Verlag.

Norman, R. M., \& Malla, A. K. (1991). Subjective stress in schizophrenic patients. Soc Psychiatry Psychiatr Epidemiol, 26(5), 212-216.

Pagano, M. E., Skodol, A. E., Stout, R. L., Shea, M. T., Yen, S., Grilo, C. M., et al. (2004). Stressful life events as predictors of functioning: findings from the collaborative longitudinal personality disorders study. Acta Psychiatr Scand, 110(6), 421-429.

Paris, J. (2005). Borderline personality disorder. Cmaj, 172(12), 1579-1583. 
Perry, B. D. (2002). Childhood experience and the expression of genetic potential: what childhood neglect tells us about nature and nurture. Brain and Mind, 3(1), 79-100.

Pope, H. G., Jr., Jonas, J. M., Hudson, J. I., Cohen, B. M., \& Tohen, M. (1985). An empirical study of psychosis in borderline personality disorder. Am J Psychiatry, 142(11), 1285-1290.

Read, J., Perry, B. D., Moskowitz, A., \& Connolly, J. (2001). The contribution of early traumatic events to schizophrenia in some patients: a traumagenic neurodevelopmental model. Psychiatry, 64(4), 319-345.

Read, J., van Os, J., Morrison, A. P., \& Ross, C. A. (2005). Childhood trauma, psychosis and schizophrenia: a literature review with theoretical and clinical implications. Acta Psychiatr Scand, 112(5), 330-350.

Rinne, T., de Kloet, E. R., Wouters, L., Goekoop, J. G., DeRijk, R. H., \& van den Brink, W. (2002). Hyperresponsiveness of hypothalamic-pituitary-adrenal axis to combined dexamethasone/corticotropin-releasing hormone challenge in female borderline personality disorder subjects with a history of sustained childhood abuse. Biol Psychiatry, 52(11), 11021112.

Russell, J. J., Moskowitz, D. S., Zuroff, D. C., Sookman, D., \& Paris, J. (2007). Stability and variability of affective experience and interpersonal behavior in borderline personality disorder. J Abnorm Psychol, 116(3), 578-588.

Skodol, A. E., \& Bender, D. S. (2009). The future of personality disorders in DSM-V? Am J Psychiatry, 166(4), 388-391.

Skodol, A. E., Siever, L. J., Livesley, W. J., Gunderson, J. G., Pfohl, B., \& Widiger, T. A. (2002). The borderline diagnosis II: biology, genetics, and clinical course. Biol Psychiatry, 51(12), 951-963.

Tolpin, L. H., Gunthert, K. C., Cohen, L. H., \& O’Neill, S. C. (2004). Borderline personality features and instability of daily negative affect and self-esteem. J Pers, 72(1), 111-137.

van Os, J., Linscott, R. J., Myin-Germeys, I., Delespaul, P., \& Krabbendam, L. (2009). A systematic review and meta-analysis of the psychosis continuum: evidence for a psychosis proneness-persistence-impairment model of psychotic disorder. Psychol Med, 39(2), 179195.

van Praag, H. M., van Os, J., \& de Kloet, E. R. (2004). Stress, the Brain and Depression: Cambridge University Press.

Van Wel, B., Kockmann, I., Blum, N., Pfohl, B., Black, D. W., \& Heesterman, W. (2006). STEPPS group treatment for borderline personality disorder in The Netherlands. Ann Clin Psychiatry, 18(1), 63-67.

Wichers, M., Schrijvers, D., Geschwind, N., Jacobs, N., Myin-Germeys, I., Thiery, E., et al. (2008). Mechanisms of gene-environment interactions in depression: evidence that genes potentiate multiple sources of adversity. Psychol Med, 1-10.

Widiger, T. A. (2003). Personality disorder and Axis I psychopathology: the problematic boundary of Axis I and Axis II. J Pers Disord, 17(2), 90-108.

Widiger, T. A., Simonsen, E., Krueger, R., Livesley, W. J., \& Verheul, R. (2005). Personality disorder research agenda for the DSM-V. J Personal Disord, 19(3), 315-338.

Zanarini, M. C., Gunderson, J. G., \& Frankenburg, F. R. (1990). Cognitive features of borderline personality disorder. Am J Psychiatry, 147(1), 57-63. 


\section{S U M M A R Y}

This thesis entitled Stress reactivity in borderline personality disorder, investigates the phenomenology and aetiology of borderline personality disorder by means of the Experience Sampling Method, a momentary assessment technique preeminently appropriate to study psychological phenomena in the context of a daily life. Emotional and psychotic reactivity to stress have been considered core features of borderline personality disorder, but there is still much unknown about the exact nature of these phenomena, in particular the stress relatedness of these symptoms. In this thesis emotional and psychotic reactivity to daily life stress are studied in different patient groups and it is investigated whether the 'reputed' borderline personality disorder risk factor childhood trauma also predicts emotional stress reactivity, a core feature of borderline personality disorder, at the lower end of the psychopathology continuum.

Chapter 1 of this thesis provides general background information about the borderline personality disorder, describes the definition and explains the advantages and disadvantages of categorical and dimensional representations of personality pathology. Unclarity about the phenomenology of borderline personality disorder is illustrated and the evidence underlying the criteria emotional instability due to a marked reactivity of mood and transient stress-related paranoid ideation is presented. The mainstay research instrument of this thesis, the Experience Sampling Method is introduced as a tool pre-eminently appropriate to study the phenomenology of borderline personality disorder. The relevance of a continuum model of psychosis is explained as is the importance of non-clinical studies. The impact of childhood trauma, relative to other risk factors, is discussed within a gene-environment framework of borderline personality development and sensitization is introduced as a possible mechanism explaining the relationship between childhood trauma and enhanced emotional reactivity to stress. Finally, the aims and outline of the thesis are described. 
Chapter 2 of this thesis describes an experience sampling study investigating emotional reactivity to daily life stress in a sample of subjects with borderline personality disorder, subjects with psychotic disorder and healthy controls. The study revealed that subjects with borderline personality disorder are most emotionally reactive to the effects of daily life stress, significantly more than healthy controls, but also significantly more than subjects with psychotic disorder a group known for strong emotional reactivity to daily life stress. It is concluded that this study is the first to ecologically validate the DSM-IV criterion affective instability due to a marked reactivity of mood in a sample of subjects with clinical borderline personality disorder.

Chapter 3 of this thesis describes an experience sampling study investigating psychotic reactivity to daily life stress in a sample of subjects with borderline personality disorder, subjects with cluster $\mathrm{C}$ personality disorder, subjects with psychotic disorder and healthy controls. The results showed that subjects with borderline personality disorder are most psychotically reactive to the effects of daily life stress. Psychotic reactivity, however, was not limited to expression of paranoia, but involved a broader range of psychotic experiences including hallucinations. It is concluded that the results of the study are the first to ecologically validate stress-related psychosis in borderline personality disorder.

Chapter 4 describes an experience sampling study investigating the effects of childhood trauma on emotional reactivity to daily life stress in a sample of adult frequent attenders of general practitioners. The results of the study showed that frequent attenders of general practitioners with a history of childhood trauma reported significantly more (negative) emotional reactivity to daily life stress than frequent attenders who did not experience childhood trauma. This effect was significantly stronger for subjects who experienced trauma before the age of 10 years. It is concluded that the results of the study confirm that childhood trauma may have long-lasting and enduring effects on adult psychological functioning, as exposed individuals continually react more strongly to small stressors occurring in the natural flow of everyday life. The finding that emotional stress reactivity is most pronounced for subjects who experienced trauma early in life is stated to confirm prior evidence suggesting that the effects of trauma are more detrimental when trauma occurs at a younger age.

In Chapter 5 the results of his thesis are discussed against the background of existing evidence and placed within the perspective of a dimensional-continuum 
hypothesis of psychopathology. Sensitization is discussed as a possible mechanism explaining the relationship between childhood trauma and enhanced stress reactivity in borderline personality disorder. The possibility of shared vulnerability is introduced on the basis of the finding of enhanced emotional and psychotic reactivity in different patient groups and discussed in relation to categorical and dimensional models of psychopathology. A plea for the diagnostic implementation of dimensional models of psychopathology is made on the basis of the evidence for shared symptomatology, shared vulnerability and shared risk factors (e.g. childhood trauma). Finally, clinical implementations of the findings in this thesis are provided and directions for future research. 



\section{S A M E N VA T T I N G}

Dit proefschrift Stress reactivity in borderline personality disorder onderzoekt de fenomenologie en etiologie van de borderline persoonlijkheidsstoornis door middel van de Experience Sampling Methode, een onderzoeksmethodiek welke bij uitstek geschikt is om psychische fenomenen te bestuderen in de context van het dagelijks leven. Hoewel emotionele en psychotische reactiviteit worden beschouwd als kernsymptomen van de borderline persoonlijkheidsstoornis, is er nog veel onbekend over de precieze aard van deze fenomenen en in het bijzonder van de relatie met stress. In dit proefschrift worden emotionele en psychotische reactiviteit onderzocht in relatie tot alledaagse stress in verschillende patientengroepen. Er wordt tevens onderzocht of de voor de borderline persoonlijkheidsstoornis 'gereputeerde' risicofactor trauma in de kindertijd ook voorspellend is voor emotionele stressreactiviteit - een kernsymptoom van de borderline persoonlijkheidsstoornis - in het lagere gedeelte van het psychopathologiecontinuüm.

Hoofdstuk 1 van dit proefschrift voorziet in algemene achtergrondinformatie over de borderline persoonlijkheidsstoornis. Het beschrijft de definitie van de borderline persoonlijkheidsstoornis en de voor- en nadelen van categoriale en dimensionale representaties van persoonlijkheidspathologie. Onduidelijkheden over de fenomenologie van de borderline persoonlijkheidsstoornis worden geïllustreerd en de evidentie betreffende de criteria emotionele instabiliteit als gevolg van een duidelijke reactiviteit van de stemming en voorbijgaande, aan stress gebonden paranoïde ideeёn wordt gepresenteerd. Het centrale onderzoeksinstrument van dit proefschrift, de Experience Sampling Methode, wordt geïntroduceerd als een methodiek welke bij uitstek geschikt is om de fenomenologie van de borderline persoonlijkheidsstoornis te bestuderen. De relevantie van een continuümmodel van psychose wordt uitgelegd, evenals het belang van non-klinische studies. De impact van trauma in de kindertijd wordt bediscussieerd in relatie 
tot andere risicofactoren, in het kader van een gen-omgevingsraamwerk voor borderline persoonlijkheidsstoornisontwikkeling. Sensitisatie wordt geïntroduceerd als een mogelijk mechanisme, dat de relatie tussen trauma in de kindertijd en emotionele stressreactiviteit verklaart. Het hoofdstuk eindigt met de doelstellingen en uiteenzetting van het proefschrift.

Hoofdstuk 2 van dit proefschrift beschrijft een experience sampling studie welke emotionele reactiviteit met betrekking tot alledaagse stress onderzoekt in een steekproef van personen met een borderline persoonlijkheidsstoornis, personen met een psychotische stoornis en gezonde controlepersonen. De studie laat zien dat personen met een borderline persoonlijkheidsstoornis het meest emotioneel reactief zijn met betrekking tot alledaagse stress, significant meer dan gezonde controlepersonen, maar ook significant meer dan personen met een psychotische stoornis, een groep bekend met een sterke emotionele reactiviteit ten opzichte van alledaagse stress. Er wordt geconcludeerd dat deze studie de eerste is die het DSM-IV criterium 'affectieve instabiliteit als gevolg van een duidelijke reactiviteit van de stemming' ecologisch heeft gevalideerd in een steekproef van personen met een klinische borderline persoonlijkheidsstoornis.

Hoofdstuk 3 van dit proefschrift beschrijft een experience sampling studie welke psychotische reactiviteit met betrekking tot alledaagse stress onderzoekt in een steekproef van personen met een borderline persoonlijkheidsstoornis, personen met een cluster $\mathrm{C}$ persoonlijkheidsstoornis, personen met een psychotische stoornis en gezonde controlepersonen. De resultaten laten zien dat personen met een borderline persoonlijkheidsstoornis het meest psychotisch reactief zijn ten opzichte van alledaagse stress. Psychotisch reactiviteit, was echter niet beperkt tot de expressie van paranoia, maar betrof een bredere range van psychotische ervaringen waaronder hallucinaties. Geconcludeerd wordt dat de resultaten van de studie de eerste zijn die stressgerelateerde psychose bij de borderline persoonlijkheidsstoornis ecologisch valideren.

Hoofdstuk 4 beschrijft een experience sampling studie welke in een steekproef van volwassen frequente bezoekers van de huisarts de effecten onderzoekt van trauma in de kindertijd op emotionele reactiviteit ten opzichte van alledaagse stress. De resultaten van de studie laten zien dat frequente bezoekers van de huisarts met een geschiedenis van trauma in de kindertijd een sterkere (negatieve) emotionele reactiviteit ten opzichte van alledaagse stress rapporteerden dan frequente huisartsbezoekers die geen trauma in de kindertijd meemaakten. Dit 
effect was significant sterker voor personen die trauma hadden meegemaakt vóór de leeftijd van 10 jaar. Er wordt geconcludeerd dat de resultaten van de studie bevestigen dat trauma in de kindertijd langdurige effecten lijkt te hebben op het psychologisch functioneren op volwassen leeftijd, daar personen die getraumatiseerd zijn in de kindertijd continu sterker reageren op de stressoren die optreden in het natuurlijk beloop het leven van alledag. De bevinding dat emotionele stressreactiviteit het meest uitgesproken is bij personen die trauma meemaakten in de vroege kindertijd, wordt gezien als ondersteuning van eerdere evidentie welke suggereerde dat de effecten van trauma schadelijker zijn naarmate het voorkomt op jongere leeftijd.

In hoofdstuk $\mathbf{5}$ worden de resultaten van dit proefschrift bediscussieerd tegen de achtergrond van de voorhanden zijnde evidentie en geplaatst in het perspectief van een dimensie-continuümhypothese van psychopathologie. Sensitisatie wordt bediscussieerd als en mogelijk mechanisme dat de relatie tussen trauma in de kindertijd en verhoogde stressreactiviteit bij bordeline persoonlijkheidsstoornissen verklaart. De mogelijkheid van gedeelde kwetsbaarheid wordt geïntroduceerd op basis van de bevindingen van verhoogde emotionele en psychotische reactiviteit in verschillende patiëntengroepen en bediscussieerd in relatie tot categoriale en dimensionale modellen van psychopathologie. Op basis van de evidentie voor gedeelde symptomatologie, gedeelde kwetsbaarheid en gedeelde risicofactoren (bv. trauma in de kindertijd) wordt een pleidooi geformuleerd voor de diagnostische implementatie van dimensionale modellen van psychopathologie. Tot slot worden de klinische implementaties van de bevindingen van dit proefschrift geformuleerd, alsmede de anbevelingen voor toekomstig onderzoek. 



\section{A N K W O O R D}

Hoewel het vak geschiedenis op de middelbare school niet mijn bijzondere aandacht had, is het in de loop van mijn leven een steeds belangrijkere rol gaan spelen. Steeds vaker vraag ik me af, hoe mijn leven zou zijn verlopen wanneer ik bijvoorbeeld in 1800 geboren zou zijn. Terugblikkend op mijn carrière, blijft ik het fascinerend vinden dat individuele gebeurtenissen en ontmoetingen - niet zelden berustend op toeval - zo bepalend kunnen zijn voor je levensloop. Om deze reden wil ik mijn dankwoord chronologisch opbouwen beginnend met psychiater en psychoanalyticus Prof. dr. Mark Richartz die in het derde jaar van mijn studie geneeskunde in Maastricht - een tijdperk waarin ik nog internist wilde worden - mijn fascinatie aanwakkerde voor de specialisatie psychiatrie. Hij maakte mij attent op pendelbewegingen in de geschiedenis van de psychiatrie, een topic welke mij ook heden ten dage nog regelmatig bezighoudt. Beste Mark, hartelijk dank voor je inspirerende uiteenzettingen.

Periode P.C. Welterhof (December 1995-2001)

Vervolgens was er psychiater / zenuwarts Albert Groot die 1995 ervoor zorgde dat ik werd aangenomen binnen de divisie ouderenpsychiatrie van het toenmalige P.C. Welterhof in Heerlen (thans Mondriaan). Hoewel ik nog geen ervaring had, gaf hij duidelijk blijk open te staan voor het opleiden van "een broekie" waarop ik werd angesteld. Zijn inspirerende en kundige begeleiding en supervisie heeft mij vakinhoudelijk en als persoon veel geleerd. Beste Albert, hartelijk dank voor de fijne samenwerking en het vertrouwen in mij.

$\mathrm{Na}$ de ouderenpsychiatrie vervolgde ik mijn weg (vanaf 1998 in opleiding tot psychiater) binnen de volwassenenpsychiatrie van P.C. Welterhof waar ik twee mensen ontmoette die grote betekenis hebben gehad voor mijn verdere ontwikkeling als psychiater en wetenschapper. 
Allereerst Yves Dekeyser, psychiater, manager en groot mensenkenner. In de aanwezigheid van Yves werd mij duidelijk dat er een kwaliteit bestaat die wijsheid wordt genoemd. Als - altijd bereikbare - charmante, gezaghebbende generalist met superieure kwaliteiten op het gebied van de diagnostiek en behandeling van mensen met persoonlijkheidsstoornissen, had ik het geluk mij een tijd te kunnen spiegelen aan zijn uitzonderlijke combinatie van kwaliteiten. Tot op de dag van vandaag ben ik ervan onder de indruk; the professional reference! Beste Yves, bedankt voor alles.

Dan dr. Joost à Campo, opleider, clinicus en schizofrenie-expert. Beste Joost, ik ben ervan overtuigd dat door jouw buitengewone capaciteiten op het vlak van de (vroeg)diagnostiek van schizofrenie menig patiënt tijdig een veilige 'behandelhaven' heeft gevonden. Gedurende de opleiding heb je mij laten zien welke ernstige consequenties het voor patiënten kan hebben wanneer gedrag in het kader van psychiatrische ziekbeelden zoals psychose wordt gediagnosticeerd als persoonlijkheidsproblematiek. Je relativerende beschouwingen en humor maken het tot een plezier om met je samen te werken. Thanks for everything!

Het 'gouden duo' Stan en Eva Vorel. Tezamen namen zij de Millenniumdienst van P.C. Welterhof voor hun rekening. Met een zenuwarts en een internist van dit niveau kon Welterhof niet op betere en veiligere wijze het nieuwe Millennium inrollen. Van beiden heb ik geleerd dat somatiek onlosmakelijk verbonden is met de psychiatrie. Hartelijk dank voor de fijne samenwerking en jullie vertrouwen in mij!

Thom van Lierop, hartelijk dank voor je professionele en kundige begeleiding. Je kennis over de psychoanalyse en begrip van psychodynamische concepten is indrukwekkend. Freud en Kuiper live on!

Rens Evers die met mij de opleiding tot psychiater volgde in P.C. Welterhof wil ik bedanken voor zijn collegialiteit en geweldige reiscompagnonschap (congressen) gedurende vele jaren.

De behandelaren die vanuit Mondriaan, Heerlen hebben bijgedragen aan de werving van patiënten voor mijn onderzoek wil ik harte bedanken voor hun inspanningen en interesse. 
Tot slot wil ik eenieder bedanken die de periode P.C. Welterhof (de opstap naar mijn promotietraject) tot zo'n fijne tijd heeft gemaakt zoals de Raad van Bestuur (Jan Breij, Dick Ravelli), het management, de collega arts-assistenten (thans collega psychiaters) (Ingrid Decker, Joris Minis, Taco Eisenga, René de Bruijn, Leon Beckers, Paul Koevoets, Arnoud Senden, Koemar Gokoel), de psychiaters (Huug Mans, Rob van Loo, Peter van Harten, Marina Vercauteren, Chris de Schinkel, Karin Hohmann, Wim Kardaun), het gerontopsychiatrieteam (Wil Langenhuijsen, Thijs Peeters, Jan Meinster), de psychologen (Paul Jung, Luc de Vooght), de maatschappelijk werkenden, de verpleegkundige teams, de medische dienst (Rob Helming), de secretariaten (Frieda Muller) en eenieder die ik vergeten ben te noemen.

\section{Periode Riagg Midden-Limburg te Roermond (2001-2002)}

Bij de Riagg Midden-Limburg te Roermond rondde ik niet alleen mijn psychiatrieopleiding af, maar legde ik tevens de basis voor mijn promotieonderzoek. De medewerking die ik hier heb gekregen om patiënten te vinden voor mijn onderzoek was immens! $\mathrm{Na}$ één referaat tijdens welke ik mijn onderzoek aankondigde, kreeg ik van de afdeling sociale psychiatrie zoveel aanmeldingen dat er gelijk een wachtlijst ontstond. Zeer veel dank wil ik dan ook uitspreken naar de medewerkers van de afdeling sociale psychiatrie en in het bijzonder naar Hanneke Keiren die bereid was mijn onderzoek over meerdere jaren onder de aandacht te houden binnen het team. Speciale dank gaat tevens uit naar Tina Dolmans en Betty Butz voor hun intensieve wervingsinspanningen. Mijn dank gaat verder uit naar directeur Max Beekers, Cees van Rees, Leo Vanmolkot, Angela Guzzardi en wijlen Steffi Tiggelovend voor de prettige samenwerking. Vele positieve herinneringen heeft de RIAGG Roermond bij mij nagelaten.

\section{Periode Universiteit Maastricht / P.M.S. Vijverdal (Mondriaan): 2002-heden}

In 2001/2002 ontmoette ik in Maastricht mijn promotor, prof. dr. Jim van Os. Hij bood mij de mogelijkheid om bij zijn onderzoeksgroep (Capaciteitsgroep Psychiatrie en Neuropsychologie, Universiteit Maastricht) te kunnen promoveren waarvoor ik hem zeer dankbaar ben. Zijn continue bereikbaarheid (reactie per e-mail altijd binnen een dag, doorgaans binnen enkele uren, 24/7) en weergaloos wetenschappelijk talent makten dat problemen altijd snel en effectief werden opgelost en nimmer hebben geleid tot 'stroperige' fasen tijdens het promotieproces. Zijn persoon en toegankelijkheid creëren een dermate positieve en productieve sfeer binnen de onderzoeksgroep dat werk wel tot hobby moet evolueren. Beste Jim, bedankt voor alles. 
In 2002 ontmoette ik ook mijn copromotor dr. Inez Myin-Germeys. Tot op de dag van vandaag ben ik onder de indruk van haar uitzonderlijke vermogen om in een oogopslag te kunnen invoegen in de wetenschappelijke probleemstellingen van haar promovendi. De samenwerking met Inez had doorgaans niet meer dan 'twee woorden' nodig om verder te kunnen met mijn onderzoek, hetgeen een geweldige ervaring is! Haar wetenschappelijk talent, maar ook haar managementkwaliteiten hebben grote indruk op mij gemaakt. Beste Inez, hartelijk dank voor de prettige samenwerking en je kundige begeleiding.

Philippe Delespaul wil ik bedanken voor zijn hulp bij de samenstelling van de ESM-boekjes en de organisatie van de databestanden. Daarnaast wil ik hem bedanken voor zijn diepgaande en inspirerende wetenschappelijke uiteenzettingen.

Karola Huistra was gedurende meerdere jaren als onderzoeksassistent verbonden aan mijn onderzoek (“de BOPS-studie”). Beste Karola, de samenwerking met jou was een stimulans voor het wetenschappelijke proces. Je inzet en zorgvuldigheid hebben geleid tot een zeer gedegen en succesvolle dataverzameling. Hartelijk dank voor alles. Fijn dat we je na de 'Zwitserlandjaren' weer in ons midden hebben!

Truda Driesen en Frieda van Goethem, wil ik bedanken voor de prettige samenwerking en ondersteuning van de BOPS-studie. Jullie expertise en zorgvuldigheid hebben ertoe geleid dat ik altijd gerust heb kunnen zijn over het fundament van mijn onderzoek (dataverzameling en data-invoer).

De co-autheurs Piet Portegijs en Viviane Thewissen wil ik bedanken voor de prettige samenwerking.

Jelleke Consten, Jelle Harts en Johan Lataster wil ik bedanken voor hun assistentie bij de dataverzameling.

Ron Mengelers wil ik bedanken voor zijn toegankelijkheid en altijd vriendelijke ondersteuning wanneer computerproblemen het wetenschappelijke proces dreigden te verstoren.

Tineke Lataster wil ik bedanken voor haar vriendelijke, heldere uitleg over diverse organisatorische 'promotieweetjes'. 
Trees Soute wil ik bedanken voor de secretariële ondersteuning tijdens mijn promotietraject.

\section{P.M.S. Vijverdal (thans Mondriaan)}

In Vijverdal werk ik sinds april 2002 als psychiater. Ondanks de drukte welke drie jobs (wetenschapper, universitair docent, psychiater) met zich meebrengen, hebben de afwisseling en de interactie tussen de drie functies een bijzondere meerwaarde gegeven aan mijn professionele bestaan. Als behandelend psychiater deed ik inspiratie op voor mijn promotieonderzoek en vice versa. Door mijn inbedding in de kliniek meldden via diverse collega-behandelaren patiënten zich aan voor mijn onderzoek. De mensen waarmee ik heb samengewerkt in P.M.S. Vijverdal wil ik daarom bedanken voor de prettige en inspirerende samenwerking tijdens bedrijfseconomisch moeilijke jaren.

Speciale dank gaat uit naar Rob Beurskens waarmee ik de afgelopen jaren zeer prettig en productief heb samengewerkt inzake somatiek bij mensen met severe mental illness. Beste Rob, je toegankelijkheid, aanhoudende drive om somatisch-psychiatrische problemen diepgaand te willen exploreren, evidence-based handelen en groot ethisch besef hebben een diepe indruk op mij gemaakt. De samenwerking met jou motiveert, stimuleert en inspireert. Hartelijk dank voor alles.

De collega psychiaters Carla Vermeulen, Marcel Hilwig, Frank van Dael, Koen Schruers, Inge Knuts, Machteld Marcelis, Fons Bos, Kristien Scheepers, Peter Vervoort, Patrick Domen, Maarten Bak, Rob Havermans, Arthur de Bie, Henk Milius en Rob Rotteveel wil ik bedanken voor de prettige samenwerking.

Detlef Petry wil ik bedanken voor de prettige samenwerking en het uitdragen van zijn rehabilitatievisie. Wat een achievement, de documentaire 'Uitbehandeld maar niet opgegeven'! Beste Detlef, het was een eer dat ik als naaste collega met je heb mogen samenwerken. Hartelijk dank voor alles.

Chris Vleugels wil ik bedanken voor zijn bereidheid om in 2001 - voorafgaande aan mijn promotietraject - het artikel "Wel of niet autorijden: een moeilijke kwestie voor de behandelend psychiater" met mij te willen schrijven. Tevens wil ik hem bedanken voor zijn wijsheid en expertise als Geneesheer-Directeur van Mondriaan. Beste Chris, altijd weer lukt het jou de meest complexe problema- 
tiek terug te brengen tot de essentie. Je beschouwingen geven blijk van een groot hart voor de patiëntenzorg! Bedankt voor alles.

Marianne van de Boogerd wil ik bedanken voor de prettige samenwerking en haar collegialiteit.

De arts-assistenten waarmee ik heb samengewerkt wil ik bedanken voor hun inspirerende vragen, voordrachten en uiteenzettingen. You keep evidence-based medicine alive!

Mijn dank gaat verder uit naar de verpleegkundige teams van afdelingen KD01, KDE 1.1, KE01/02 en locatie Proosdijweg, waarmee ik verschillende jaren intensief heb samengewerkt. Mijn dank gaat tevens uit naar mijn collega's in team IV (mijn huidige werkplek) en de verpleegkundige teams van de volwassenenen ouderenpsychiatrie (KD02, KC01/02, SRO, KC1.1) waarmee ik door de jaren eveneens heb samengewerkt.

De verschillende secretariaten binnen Vijverdal wil ik bedanken voor hun ondersteuning en de prettige samenwerking.

De Raad van Bestuur (Richard Janssen, Peter Peters) en het management wil ik bedanken voor het faciliteren van academiseringsinitiatieven zoals mijn promotieonderzoek.

\section{De proefpersonen}

De patiënten en controlepersonen die hebben deelgenomen aan mijn onderzoek wil ik van harte bedanken voor hun initiatief, bereidheid en doorzettingsvermogen. Zonder hun participatie zou mijn promotieonderzoek niet mogelijk zijn geweest.

\section{Mijn ouders}

Mijn ouders wil ik van harte bedanken voor hun continue steun over de jaren. De mogelijkheid om na je klinisch werk te kunnen aanschuiven bij het middagmaal met de expliciete voorwaarde van een afwasverbod maakt dat je inderdaad 's avonds nog tijd en zin overhoudt om met je onderzoek verder te gaan. Hetzelfde geldt voor regelmatig optredende fenomenen waarbij ik constateerde dat mijn huis plots opgeruimd was, de hemden netjes gestreken in de kast hingen en het gras gemaaid was? Some guys have all the luck! 


\section{De paranimfen}

Anita Boreas ('mijn speeltuinvriendin'), vanaf de lagere school hebben onze studietrajecten sterke parallellen gekend: zelfde lagere school, zelfde middelbare school, samen Geneeskunde in Maastricht, jij neurologie, ik psychiatrie, beiden gaan promoveren, ik paranimf bij jouw promotie (2001) en jij nu bij de mijne. Beste Anita, hartelijk dank voor je vriendschap die nu zo'n drie decennia bestaat en je bereidheid om ondanks de grote afstand en je drukke gezinsleven paranimf te willen zijn bij mijn promotie.

Paola Geijselaers leerde ik kennen in 2004 als verpleegkundige op afdeling O6 van Vijverdal waar we intensief samenwerkten. Het viel mij op dat de samenwerking met haar automatisch resulteerde in een interactie die blijk gaf van een hoge mate van verdieping, zorgvuldigheid en verantwoordelijkheidsgevoel. Met groot vertrouwen kon ik de verpleegkundige uitvoering van patiëntenbeleid aan haar overlaten. Haar naam kwam dan ook onmiddellijk bij mij op toen ik de paranimfen voor mijn promotie moest gaan kiezen. Beste Paola, bedankt voor de fijne samenwerking en je bereidheid om paranimf te willen zijn bij mijn promotie.

\section{Familie / vrienden}

Mijn oma van 85 wil ik bedanken voor haar steunende interesse welke voortduurt tot op de dag van vandaag! Mijn familie, en vrienden (René van den Heuvel, Lars Tjaarda, Luc Lentjes, Enrico Boels) wil ik bedanken voor hun altijd weer vertrouwde aanwezigheid, onafhankelijk van afstand en contactfrequentie.

Tot slot wil ik Frans Douven van harte bedanken voor de bereidheid zijn kennis op het gebied van de bètavakken met mij te willen delen. 



\section{URR I C U L U M V I T A E}

Jean-Paul Glaser werd op 25 februari 1969 geboren in Heerlen. Na afronding van het vwo aan het St.- Janscollege te Hoensbroek begon hij in 1988 met de studie Gezondheidswetenschappen aan de Universiteit Maastricht. Na een jaar werd hij (alsnog) ingeloot voor de studie Geneeskunde aan dezelfde universiteit. Hij 'stapte over' en slaagde met het predicaat "met genoegen" voor het doctoraal- (1993) en basisartsexamen (1995). Eind 1995 begon hij te werken als AGNIO in Psychiatrisch Centrum Welterhof te Heerlen (thans Mondriaan). $\mathrm{Na}$ ruim een jaar te hebben gewerkt binnen de gerontopsychiatrie en ongeveer een jaar op diverse plaatsen binnen de volwassenenpsychiatrie (polikliniek, deeltijdbehandeling, opnameafdeling BC), kwam hij in april 1998 in opleiding tot psychiater. In april 2002 rondde hij de opleiding tot psychiater af en werd hij aangesteld bij de Capaciteitsgroep Psychiatrie en Neuropsychologie van de Universiteit Maastricht. Zijn aanstelling omvatte drie taken. Naast zijn promotieonderzoek (promotor prof. dr. Jim van Os) hield hij zich als universitair docent bezig met onderwijs aan geneeskundestudenten. Voor het grootste gedeelte van zijn wekelijkse aanstellingstijd was hij gedetacheerd naar Psychomedisch Streekcentrum Vijverdal (thans Mondriaan) waar hij zich als behandelend psychiater bezig hield met patiënten met severe mental illness. Vanaf april 2002 was hij als psychiater verbonden aan verschillende afdelingen in Vijverdal zoals een gesloten acute opname afdeling (april 2002-oktober 2003), de polikliniek (april 2002-oktober 2003), verschillende langdurige behandelafdelingen (gesloten en open) (oktober 2003-heden) en tijdelijk (2007/2008) aan twee gerontopsychiatrische afdelingen. Op dit moment is hij - wat betreft het klinische gedeelte van zijn universitaire aanstelling - in Mondriaan (locatie Vijverdal) als psychiater verbonden aan een transmuraal werkend integrale zorg team voor mensen met severe mental illness (team IV). 


\section{P U B L I C A T I O N S}

\section{International journals}

Glaser, J. P., van Os, J., Portegijs, P. J., \& Myin-Germeys, I. (2006). Childhood trauma and emotional reactivity to daily life stress in adult frequent attenders of general practitioners. J Psychosom Res, 61(2), 229-236.

Glaser, J. P., van Os, J., Mengelers, R., \& Myin-Germeys, I. (2008). A momentary assessment study of the reputed emotional phenotype associated with borderline personality disorder. Psychol Med, 38(9), 1231-1239.

Glaser, J. P., van Os, J., Thewissen, V., \& Myin-Germeys, I. (2009). Psychotic reactivity in borderline personality disorder. Acta Psychiatr Scand, published online, June 25.

\section{National journals}

Glaser, J. P., \& Vleugels, C.M. (2002). Wel of niet autorijden: Een moeilijke kwestie voor de behandelend psychiater. Medisch Contact, 57 (17), 659.

Glaser, J.P., \& van Harten, P.N. (1998) Incidentie van en risicofactoren voor ernstige tardieve dyskinesie bij ouderen die antipsychotica gebruiken. Ned Tijdschr Geneeskd, 142(14), 810. [Referaat] 